\title{
Chick embryo as a model in fetal physiology
}

Citation for published version (APA):

van Golde, J. M. C. G. (1999). Chick embryo as a model in fetal physiology. [Doctoral Thesis, Maastricht University]. Universiteit Maastricht. https://doi.org/10.26481/dis.19990128jg

Document status and date:

Published: 01/01/1999

DOI:

10.26481/dis.19990128jg

Document Version:

Publisher's PDF, also known as Version of record

\section{Please check the document version of this publication:}

- A submitted manuscript is the version of the article upon submission and before peer-review. There can be important differences between the submitted version and the official published version of record.

People interested in the research are advised to contact the author for the final version of the publication, or visit the DOI to the publisher's website.

- The final author version and the galley proof are versions of the publication after peer review.

- The final published version features the final layout of the paper including the volume, issue and page numbers.

Link to publication

\footnotetext{
General rights rights.

- You may freely distribute the URL identifying the publication in the public portal. please follow below link for the End User Agreement:

www.umlib.nl/taverne-license

Take down policy

If you believe that this document breaches copyright please contact us at:

repository@maastrichtuniversity.nl

providing details and we will investigate your claim.
}

Copyright and moral rights for the publications made accessible in the public portal are retained by the authors and/or other copyright owners and it is a condition of accessing publications that users recognise and abide by the legal requirements associated with these

- Users may download and print one copy of any publication from the public portal for the purpose of private study or research.

- You may not further distribute the material or use it for any profit-making activity or commercial gain

If the publication is distributed under the terms of Article $25 \mathrm{fa}$ of the Dutch Copyright Act, indicated by the "Taverne" license above, 


\title{
CHICK EMBRYO AS A MODEL
}

\author{
IN FETAL PHYSIOLOGY
}


(C) J. van Golde, Maastricht, 1999

ISBN: $90-5681-051-0$

Druk: Unigraphic

Illustratie omslag: Timo Ekhart, naar W. Harvey 'omne vivum ex ovo' (alle leven komt uit een ei) 


\title{
CHICK EMBRYO AS A MODEL
}

\author{
IN FETAL PHYSIOLOGY
}

\section{PROEFSCHRIFT}

ter verkrijging van de graad van doctor

aan de Universiteit Maastricht,

op gezag van de Rector Magnificus, Prof. dr. A.C. Nieuwenhuijzen Kruseman, volgens het besluit van het College van Decanen,

in het openbaar te verdedigen

op donderdag 28 januari 1999 om 16.00 uur

door

Jolanda Maria Clara Guiliaume van Golde 


\section{Promotor}

Prof. dr. C.E. Blanco

\section{Co-promotor}

Dr. W.J. Maertzdorf

\section{Beoordelingscommissie}

Prof. dr. F. Van Bel (Universiteit Utrecht)

Prof. dr. R.A.M.G. Donckerwolcke (voorzitter)

Prof. dr. J. de Haan

Prof. dr. R.S. Reneman

Prof. dr. H.A.J. Struijker Boudier

This study was financially supported by the Department of Pediatrics, AZM. 
Aan mijn ouders 



\section{Contents}

Abbreviations

Chapter I Introduction and review of the literature

Chapter II Intervention models and analyzing techniques

Chapter III The chorioallantoic artery blood flow of the chick embryo from stage 34 to 43 .

Pediatric Research 40 (6): 867-871, 1996

Chapter IV Cardiac output distribution in the chick embryo from stage 33 to 45 .

Cardiovascular Research 34: 525-528, 1997

Chapter $\mathrm{V}$ Changes in mean chorioallantoic artery blood flow and heart rate produced by hypoxia in the developing chick embryo.

Pediatric Research 42 (2): 293-298, 1997

Chapter VI Cardiac output distribution in response to hypoxia in the chick embryo in the second half of the incubation. Journal of Physiology 508 (part 1): 281-287, 1998

Chapter VII Cardiac output distribution in response to hyperoxia in the chick embryo in the second half of the incubation. Journal of Physiology, in press

Chapter VIII Induction of antioxidant enzyme activity by hyperoxia $\left(60 \% \mathrm{O}_{2}\right)$ in the developing chick embryo.

Journal of Physiology 509 (part 1): 293-296, 1998 
Chapter IX Histological changes in the intestine of the developing chick embryo after exposure to repetitive hypoxia or asphyxia under normoxic and hyperoxic conditions.

Chapter X Summary and conclusions.

Samenvatting en conclusies.

Curriculum Vitae

List of Publications

Dankwoord 


\section{Abbreviations}

$\begin{array}{ll}\text { AOE } & \text { antioxidant enzymes } \\ \text { CABF } & \text { chorioallantoic blood flow } \\ \text { CBF } & \text { cerebral blood flow } \\ \text { GPX } & \text { glutathione peroxidase } \\ \text { LT } & \text { leukotrienes } \\ \mathrm{O}^{*} & \text { superoxide anion } \\ \text { ONOO }^{*} & \text { peroxinitrite } \\ \text { PG } & \text { prostaglandin } \\ \text { SOD } & \text { superoxide dismutase } \\ \text { ROS } & \text { reactive oxygen species } \\ \text { SD } & \text { standard deviation }\end{array}$




\section{CHAPTER I}

\section{Introduction and review of the literature}

1.1 General introduction

1.2 The chick embryo

1.2.1 Oxygen exchange and circulatory system

1.2.2 Development of umbilical blood flow and heart rate

1.2.3 Hemodynamic control

1.2.3.1 The autonomic nerve system

1.2.3.2 Catecholamines

1.2.3.3 Receptors

1.3 Cardiovascular responses to blood gas changes

1.3.1 Reduced fetal oxygenation

1.3.2 Mediation of response to reduced oxygenation

1.3.3 Increased fetal oxygenation

1.3.4 Mediation of response to increased oxygenation

1.4 Production of free radicals, scavengers and oxidative damage

1.4.1 Reactive oxygen species

1.4.2 Antioxidant enzyme system

1.4.3 Oxidative stress

1.5 Aims of the study 


\section{CHAPTER I}

\section{Introduction and review of the literature}

\subsection{General introduction}

Deviations of intra-uterine development and maladaptations at birth are a subject of interest for obstetricians, physiologists and pediatricians. These problems are of special importance during the newborn period but also the sequelae determining the future quality of life, are important. The most common insults are either asphyxia, hypoxia or hyperoxia. These insults put the preterm or full term newborn infant to an increased risk for developing complications such as: neurodevelopmental abnormalities, broncho-pulmonary dysplasia, necrotizing enterocolitis and retinopathy of prematurity.

Uterine contractions, umbilical cord compression or maternal placental insufficiency reduce the oxygenation of the fetus. During periods of reduced oxygenation, blood flow supply, $\mathrm{O}_{2}$ extraction and metabolic rates to different organs are regulated in order to limit tissue damage. Cardiac output is redistributed in favour of vital organs, such as the brain, heart and adrenals at expense of peripheral organs (Guissani 1994; Hanson 1988; Peeters 1979; Rudolph 1984; Thornburg 1991). More research is needed to gather information on the development of these cardiovascular responses to hypoxia during gestation.

After a period of reduced fetal oxygenation, a reperfusion period occurs. During this period the oxygen supply to the different tissues and cardiovascular function re-establish, leading to an increase in metabolic rate and release of reactive oxygen species (ROS). This increased release of ROS also occurs at the time of birth when the fetus is exposed to a relative hyperoxic environment. Protection against oxidative stress is provided by an antioxidant enzyme (AOE) defense system (Frank 1985; Saugstad 1990; Varsila 1994). However, when the developing fetus is exposed to an increased oxidative stress at a time that the AOE system is immature, the not detoxified ROS may interact with components of the cell (proteins, lipids or DNA) causing cellular damage or even cell death (Frank 1985; Yu 1994).

The study of responses, adaptations and strategies to unfavorable situations in utero or at birth in men is limited due to invasive methodology. Mainly large 
animals, such as fetall sheep, are frequentlly used as an animal model to gather more insight in the fetal cardiovascular functioning and responses to changes in oxygenation. However, these models are invasive, expensive and time-consuming because of relative long gestational duration. Moreover, in mammalian animal models there is always the interference between the fetus and mother. The chick embryo shows some advantages compared to the mammalian models. The chick embryo has a short incubation period ( 21 days), exposure to hypoxia is noninvasive, because of the characteristics of gas exchange through the pores of the egg shell, the supply of nutrients from the yolk sac is separated from the gas exchange area and the embryo develops independently of the mother (no maternal factors). Therefore, the chick embryo might be an attractive model to design studies on the development of adaptive responses to changes in fetal oxygenation and oxidative stress.

\subsection{The chick embryo}

The total incubation period of the chick embryo is 21 days. After the egg has been led, development ceases unless the temperature is kept up to the temperature of the mother. The development of the chick embryo can be classified into 46 stages, based on characteristics of embryonic maturation, including somite number, limbs size, visceral arches, feather-germs, eyelids, beak and third toes length and extra embryonic membranes (Hamburger 1951).

The unique characteristics of the chick embryo makes it an attractive animal model for studying the cardiovascular system (Broekhuizen 1993; Hu 1989; Nakazawa 1988), the development of the central nervous system (Pappano 1974), angiogenesis (Le Noble 1993), the physiology of gas diffusion and gas exchange (Freeman 1970; Piiper 1980; Rahn 1987; Tazawa 1983a-b; Visschedijk 1968a-c), etiology of intestinal malformations (Tibboel 1979), development of free radical biology (Stock 1990; Wilson 1992) and the effects of altered oxygen availability on prenatal growth (Asson-Batres 1989; Stock 1987).

\subsubsection{Oxygen exchange and circulatory system}

Fetal circulation serves two basic requirements 1) provision of nutrients for energy production through maintenance of oxidative metabolism, and 2) provision of building materials for tissue growth. In the chick embryo, $\mathrm{O}_{2}$ is provided by the chorioallantoic vein and nutrients through the vitellini circulation from yolk sac to embryo (Metcalfe 1993; White 1974). The avian embryo exchanges gases through the rich vascularized membrane, the chorioallantoic membrane (CAM), situated 
beneath the surface of the eggshell (Metcalfe 1993; Rahn 1985; Romanoff 1960). The CAM, the chorioallantoic artery and vein are equivalent to respectively, the placenta and the umbilical circulation in mammalians (Metcalfe 1993; Rahn 1985; Romanoff 1960).

In the developing chick embryo, resistance to gas diffusion is determined by the egg shell, the CAM (including capillary endothelium) and the hemoglobin concentration (Bissonnette 1978). The egg shell resistance is constant, whereas resistance of CAM and hemoglobin decrease during development. Until day 14 , the fall in resistance appears to be due to growth of the CAM, its progressive approximation to the inner shell membrane and its increasing vascularity. In the last several days of incubation the continuing fall in resistance is due to an increase in hemoglobin concentration which reflects a parallel increase in total red cell surface area in the chorioallantoic capillary bed. The blood volume increases up to the time of hatching, the maximum blood volume of the chick embryo on incubation day 21 is $4 \mathrm{ml}$ (Barnes 1959; Windle 1938; Yosphe-Parer 1953). Oxygen demand increases exponentially during development and it exceeds the capacity of the diffusion process for adequate delivery of oxygen by the end of the incubation period (Rahn 1974). With increasing metabolic rate during development (Prinzinger 1995; Rahn 1974; Vleck 1980), a progressive decrease in $\mathrm{O}_{2}$ tension and an increase in $\mathrm{CO}_{2}$ in the chorioallantoic artery and in the air cell occur on days 14-17 (Freeman 1970; Rahn 1974; Visschedijk 1968a-c). The increased $\mathrm{CO}_{2}$ levels inside the egg initiate reflex respiratory movements and stimulate internal pipping, the beak of the chick embryo penetrates the air cell at the blunt side of the egg (around day 20) and initiates the gradual transition from diffusive gas exchange in the CAM to convective gas exchange in the lung (Rahn 1974; Rahn 1985; Windle 1938). This marks the end of the prenatal period and the start of the paranatal period (Rahn 1974 and 1985). After internal pipping, the relative blood flow to the CAM and yolk sac decline rapidly, whereas bload flow to the lungs increases and finally hatching is initiated (Rahn 1985; Visschedijk 1968a-c).

In avian as well as in mammalian fetal species, oxygenated blood transported from the gas exchange organ mixes with venous blood in the cardiovascular shunts (the allantoic shunt, the interartrial foramina and the extracardiac shunt) (Olszowka 1988; Piiper 1980; Tazawa 1985). Not all blood passing the chorioallantoic circulation is oxygenated at the capillary plexus, but a portion of the blood is conjectured to pass through a physiological shunt to the allantoic vein (referred to as the allantoic shunt). The admixture of deoxygenated blood in the allantoic 
artery with the oxygenated blood has been estimated to be 10 to $15 \%$ (Piiper 1980). In the chick embryo a portion of the deoxygenated blood flows from the right atrium to the left side through perforations of the interatrial septum and recirculate to the aortic arch (the intracardiac shunting). The $\mathrm{PO}_{2}$ of arterial and venous blood falls progressively until breathing is established. During hatching the $\mathrm{PO}_{2}$ of arterial blood increases from $\pm 20 \mathrm{mmHg}$ to $\pm 110 \mathrm{mmHg}$ (Freeman 1970). This sudden rise in $\mathrm{Po}_{2}$, presumably leads to closure of the two ductus arteriosi. Furthermore, the perforated interatrial septum closes because of increase in left atrial pressure (Romanoff 1960). These events appear to be similar in avian and mammalian fetus (Rudolph 1970), where a single foramen ovale functionally replaces the perforated interatrial septum. In addition, other similarities between the chick embryo and sheep fetus are observed late in gestation such as cardiac output, blood flow distribution and oxygen delivery. In both species, the total cardiac output is about $500 \mathrm{ml} \cdot \mathrm{kg}^{-1} \cdot \mathrm{min}^{-1}$ (Rahn 1985; Rudolph 1967), and the ratio of cardiac output distribution to the gas exchange organ in the fetus is 50:50\% (Jensen 1991; Rahn 1985). The function of the CAM differs from that of the placenta by the fact that it is anatomically separated from the vitellini circulation, which transports nutrients from the yolk to the embryo (Metcalfe 1993).

\subsubsection{Development of umbilical blood flow and heart rate}

The dynamics of respiratory gas exchange in the CAM in the chick embryo, as in the placenta, depend upon the rate of blood flow that passes the exchange membrane (Olszowka 1988). However, it remains to be studied how the chorioallantoic artery blood flow (CABF) (similar to the umbilical blood flow) develops during incubation. A steady increase in the umbilical blood flow has been observed in fetal lambs as well as in human fetus during gestation (Dawes 1962; Gerson 1987), although the proportion of the cardiac output distribution to the placenta decreases during gestation. Before the third trimester placental circulation requires $50 \%$ of the total cardiac output and $40 \%$ of total cardiac output in the last part of pregnancy (Rudolph 1970).

In the chick embryo, heart rate increases rapidly in the first two days of incubation, and a gradual increase is observed until a maximum is reached on days 16-17 (Romanoff 1960; Tazawa 1991). The heart rate variability increases with advancing incubation time (Tazawa 1991), probably reflecting an increase in autonomic nervous system control (developing vagal control) (Bogdanov 1961; Legrande 1966). This phenomena has also been demonstrated to occur in the exchange through the eggshell towards the end of the incubation period, resulting 
in a relative embryonic hypoxia, might explain the heart rate decrease late in development (Tazawa 1983a). After internal pipping, the embryo starts with pulmonary ventilation, and the heart rate increases again (Tazawa 1991)

\subsubsection{Hemodynamic control}

Adequate control of embryonic circulation is a requisite for normal development and growth. In the first two days of development the circulation in the noninnervated chick embryo probably is controlled by mechanical factors, related to the Frank-Starling mechanism (Clark 1984). Control by the sino-arterial node is established by the end of the second day (Romanoff 1960). Responses to acute hypoxia are mediated by neurohormonal mechanisms. In the non-innervated chick embryo circulating amines or peptides (endocrine factors) play an important role in cardiovascular control during hypoxia. Late in the incubation period, days 16-17, the autonomic nerve system is functional.

\subsubsection{The autonomic nerve system}

Complete anatomic parasympathetic neuron expression in the heart is observed between days 13 and 15 (Rickenbacher 1979). The parasympathetic system is functional from day 15 onwards (Kirby 1986; Pappano 1974; Rickenbacher 1979). Sympathetic innervation of the heart develops between days 7 and 10 (Lelolier 1975; Kirby 1986; Pappano 1974). Although, adrenergic nerve fubers can synthesize and store catecholamines (Higgens 1979), they are incapable of neuroeffector transmission until day 16 of incubation age (Higgens 1981; Kirby 1986; Pappano 1974). The time difference between anatomic sympathetic neurons expression and release of sufficient transmitter by adrenergic axons is determined by the release of sufficient neurotransmitter, the level of receptor sensitivity, and the level of invasion of adrenergic axons in target organs (closer to their effector cells) (Frieswick 1979; Higgens 1979 and 1981; Pappano 1974).

\subsubsection{Catecholamines}

Optimal functioning of the nervous system develops late in incubation, catecholamines or other endocrine factors probably play an important role in the regulation of the cardiovascular control early in development (Bogdanov 1961; Tazawa 1992). Dopamine, noradrenaline and adrenaline, are all present in chick embryos from day 3 (Ingnaro 1968). Catecholamines are released from the adrenal gland, both due to activation by the sympatheticus or by direct effect of hypoxia on the gland. Because cortical and medular cells of adrenal glands are still in development, secretion of catecholamines is minimal early in development (Fujita 1976). The adrenal medulla of the chick embryo and its innervation are functional 
at about day 10 (Fujita 1976). Secretion of catecholamines increases during the first 12 days of incubation (Callingham 1966; Ignarro 1968). After day 12, catecholamines levels are measurable in plasma, but also in amnion- and allantoicfluid (Epple 1992). Marked increase in adrenaline content in the adrenals is observed from day 15 (Wassermann 1970). As in mammalians, this sharp increase is related to corticoid production by the cortex (Margolis 1966; Wassermann 1970). Less is known about other humoral factors which may play a role in the regulation of the peripheral vascular resistance, such as arginine vasopressin, plasma renin and angiotensin II or neuropeptide $Y$.

\subsubsection{Receptors}

Adrenergic and cholinergic receptors can be activated in innervated and noninnervated chick embryos (Clark 1985; Frieswick 1979; Girard 1973; Higgens 1980; Tazawa 1992). McCarty et al. (1960) showed that myocardial receptors in the developing chick embryo respond to (nor)epinephrine and acetylcholine from the $4^{\text {th }}$ incubation day onwards. Positive inotropic effects of nerve stimulation are mediated by B-adrenergic receptors, triggered by isoproterenol (Clark 1985; Frieswick 1979; Higgens 1981). However, it must be noticed that B-receptors density increases towards the end of the incubation (Girard 1973). Vascular $\alpha$ receptors are clearly predominant (Girard 1973). In conclusion, the chick embryo does not have the same adrenergic responses as the adult chick, but it has some adrenergic sensitivity early in the incubation.

\subsection{Cardiovascular responses to blood gas changes}

\subsubsection{Reduced fetal oxygenation}

In contrast to mammalians, little is known about cardiovascular responses to acute hypoxia in the developing chick embryo. In the chick embryo physiological hypoxic conditions develop at the end of incubation, due to the limited gas exchange capacity of the egg shell and an increased metabolic rate. $\mathrm{PO}_{2}$ level is minimal just before internal pipping (Rahn 1974; Tazawa 1983a; Visschendijk 1968b). At the same time an increase in catecholamine occurs (Wittmann 1990). This increase in catecholamines release is also observed when 18 days old chick embryo were exposed to $10 \% \mathrm{O}_{2}$. Furthermore, this elevation in catecholamines produced an increase in blood flow to the CAM, improving gas exchange (Wittmann 1990). In the sheep fetus an increase in catecholamines produces similar effects on the placental flow (Palmer 1984). 


\subsubsection{Mediation of response to reduced oxygenation}

Both species, mammalian and avian, develop vegetative and adrenergic structures and endocrine mediators to respond to a stress situation such as hypoxia. Information about neurohormonal mediation of this response is gathered from fetal mammalian studies. In order to minimize deleterious effects of tissue hypoxia, there is a fetal response to acute hypoxia which consists of: 1) direct effects of hypoxia on tissue metabolites; 2) activation of the autonomic nervous system; 3) release of catecholamines or 4) local autoregulation (possible mediators: NO, prostaglandins, arginine vasopressin, plasma renin, angiotensin II). (Reviews: Giussani 1994; Hanson 1988; Rudolph 1984; Thomburg 1991). In fetal lambs, it has been shown that acute hypoxia late in gestation ( $>110$ days) elicits a chemoreflex by activation of peripheral chemoreceptors, particularly carotid chemoreceptors (Dalton 1977; Parer 1980). This response is characterized by bradycardia and an increased heart rate variability, occurring within 2-3 minutes after onset of hypoxia, caused by efferent effects of the vagus nerve on the heart (chemoreflex). However, hypoxia might also have a direct effect on the heart (Cohn 1974). Furthermore, arterial blood pressure increases, which is mediated by an increased release of catecholamines or other endocrine factors. Increase of catecholamines is caused by activation of sympathetic nerve system or by a direct effect of hypoxia on the adrenal medulla (Cohn 1974). This increased blood pressure stimulates the baroreceptors which in turn causes a delayed bradycardia (baroreflex) (Cohn 1974; Eliott 1985; Itskovitz 1982a-b; Itzkovitz 1983a; Iwamoto 1979; Rurak 1978). In addition, cardiac output is redistributed favouring the brain, heart and adrenals at expense of the peripheral circulation (Cohn 1974; Peeters 1979; Rudolph 1985). This response is also mediated by the above described neuro-hormonal responses together with liberation of regional vasodilators substances such as NO (van Bel 1995) and adenosine (Kurth 1992).

The autonomic nervous system does not appear to be completely functional early in the developing fetus, since ganglionic blockade, administration of adrenergic and cholinergic blocking drugs, and denervation of the sinus and aortic nerves hardly influence basal heart rate or blood pressure (Thomburg, 1991 and 1994). However, carotid chemoreceptors, as well as carotid and aortic baroreceptor discharges can be detected in the last third of gestation in sheep fetus (Blanco 1983, 1984). Spontaneous activity of aortic chemoreceptor is present in sheep fetus from day 90 onwards (Blanco 1984). Administration of $\alpha$ - and $\beta$-adrenergic agonists elicit a clear cardiovascular response resulting in a higher blood pressure and heart rate. Catecholamine release increases many-fold during hypoxic conditions in fetal sheep, mainly due to a direct effect of hypoxia on adrenal 
glands and partly due to sympathetic stimulation. Direct release of catecholamines by the adrenal glands protects the developing fetus with an immature autonomic nervous system against hypoxia (Langercrantz 1986). After removal of adrenal glands or blocking catecholamines release, the exposure to hypoxia will cause death (Langercrantz 1986).

This interplay of neural, hormonal and local organ vascular responses to hypoxia, and changes affecting fetal metabolism or $\mathrm{O}_{2}$ transport, result in a conservation of oxygen and a preferential supply to vital organs to limit the deleterious effects of hypoxia. The severity and duration of impairment of gas exchange as well as the maturity of developing fetus determine the level of adequate fetal compensation (Mann 1970).

\subsubsection{Increased fetal oxygenation}

Hyperoxia is a situation which is not physiological present in nature. The fetus is protected against hyperoxia by fetal shunts and the mammalian fetus has a placenta which limits the maximal $\mathrm{Po}_{2}$. The only situation when the fetus is exposed to hyperoxia is when it is born prematurely. Nowadays, human premature infants can survive when born at $70 \%$ of the total gestation. This situation exposes the fetus/premature infant to higher oxygen environment earlier than expected. The resulting relative hyperoxia might cause excess $\mathrm{O}_{2}$ delivery to organs when vasoconstriction is poor, and contribute to the development of neurological abnormalities, bronchopulmonary dysplasia, necrotizing enterocolitis and retinopathy of prematurity (Larrazabal 1990; Saugstad 1990; Menke 1993). Late in gestation and in term newborn, hyperoxia causes reduced perfusion due to vasoconstriction in the brain, heart, and adrenals (Bendeck 1992; Blanco 1988; Gleason 1988; Jackson 1987; Iwamoto 1987; Peeters 1979). However, the time during development that vasoconstriction as a response to hyperoxia exposure occurs, remains to be established.

The effects of hyperoxia on cerebral (Gleason 1988; Menke 1993) and retinal and choroidal blood flow in (pre)-term newborns have been described extensively. When autoregulation of cerebral blood flow (Almström 1996; Menke 1993), retinal and choroidal blood flow (Hardy 1994, 1996) are immature or absent leading to tissue damage is caused due to increased $\mathrm{O}_{2}$ supply secondary to poor vasoconstrictive response. Routine use of oxygen shortly after birth $\left(80-100 \% \mathrm{O}_{2}\right.$ during initial stabilization) may lead to extremely prolonged vasoconstriction (Lundstrøm 1998), perhaps due to prolonged inhibition of prostacyclin (6-keto $\mathrm{PGl}_{\alpha}$, a vasodilator) production (Stuart 1984). This reduced vasodilatory capacity 
of the cerebral vessels after hyperoxia exposure might place the newborn at risk for tissue damage (Stuart 1984).

\subsubsection{Mediation of response to increased oxygenation}

Development of the response to hypoxia is better described than to hyperoxia. Multitude of factors regulate the contractile tone under various conditions, but the magnitude of contribution of individual factors is unclear. Vasoconstriction during hyperoxia exposure has been attributed to direct effect of oxygen on the vessel wall (Sparks 1980; Lewis 1968) or by release of vasoconstriction factors, such as: leukotrienes, prostaglandin $F_{2 \alpha}$, and thromboxane $A_{2}$ (Gurtner 1985; Stuart 1984; Wagerle 1988). Furthermore, increased release of reactive oxygen species (ROS) during hyperoxia, generated by cyclooxygenase-1 in endothelial cells, might produce vasoconstriction by inhibiting the synthesis or the action of vasodilator components such as prostacyclin $\left(\mathrm{PGI}_{2}\right)$ or nitric oxide (Stuart 1984). In contrast, ROS reduce vascular reactivity, by inhibition of calcium transport and reduction of the vasoconstrictor response to thromboxane (dependent upon $\mathrm{Ca}^{2+}$ influx) (Gurtner 1985; Hardy 1994). Differences in vasoconstrictive response after changes in oxygen tension at different stages of development and in different organs might be explained by different ion channel densities in vascular smooth muscle cells (Weir 1997). Further studies are needed to determine the exact mechanism underlying the vascular response to hyperoxia.

\subsection{Production of free radicals, scavengers and oxidative damage}

\subsubsection{Reactive oxygen species}

Although oxygen is required for aerobic organisms, its more reactive metabolites, ROS, are implicated in a number of diseases ( $Y u$ 1994). A free radical is, in electron orbital terms, a molecule or an atom with an unpaired electron in its outer orbit. The magnitude of free radical reactivity can be judged from the short halflives, which are less than one second. Free radicals react with a wide range of biological molecules ( $\mathrm{Yu}$ 1994). The partial reduction of $\mathrm{O}_{2}$ by sequential single electron steps produces three intermediates, superoxide anion $\left(\mathrm{O}_{2}{ }^{\circ}\right)$, hydrogen peroxide $\left(\mathrm{H}_{2} \mathrm{O}_{2}\right)$ and hydroxyl radical (HO) (most potent oxidant, shortest halflife), each more reactive than $\mathrm{O}_{\vec{z}}$ itself. These products are formed during aerobic metabolic processes in the cell (Saugstad 1990; Varsila 1994; Yu 1994). Aerobic life depends on the energy released in the conversion of $\mathrm{O}_{2}$ to $\mathrm{H}_{2} \mathrm{O}$, achieved in mitochondria by cytochrome oxidase in the respiratory chain. However, 1 per cent of the $\mathrm{O}_{2}$ consumed is released as $\mathrm{O}_{2} *$. Oxidation of xanthine oxidase with the concomitant reduction of $\mathrm{O}_{2}$ to $\mathrm{O}_{2} \cdot$ and $\mathrm{H}_{2} \mathrm{O}_{2}$ is another significant source of free 
radicals. Reperfusion after a period of hypoxia or asphyxia results in the breakdown of adenosine nucleotides to hypoxanthine. After reintroduction of $\mathrm{O}_{2}$, there is sudden burst production of superoxide and $\mathrm{H}_{2} \mathrm{O}_{2}$, produced by the hypoxanthine-xanthine oxidase system, a process which can be blocked by allopurinol (McCord 1985; Thomas 1978; Saugstad 1988). Other sources of ROS are heme-bound $\mathrm{O}_{2}$ released as superoxide, chemical auto-oxidation, granulocytes and mononuclear phagocytes (which produce large amounts of ROS to kill microorganisms) (Thomas 1978; Saugstad 1988). The reaction of $\mathrm{O}_{2}^{--}$with NO (nitric oxide), result in 'ONOO' (peroxinitrite), which is even a more reactive oxygen molecule (Beckman 1991). This reaction is more than 3 times faster than the enzymatic dismutation of superoxide radicals catalyzed by superoxide dismutase (SOD) $\left(\mathrm{k}_{\mathrm{SOD}}=2 \times 10^{9} \mathrm{~m}^{-1} \cdot \mathrm{s}^{-1}\right)$ (Radi 1991). This sudden increase in ROS production occurs also at the time of birth when the newborn is exposed to relative hyperoxic conditions and metabolic rate increases (Frank 1985).

\subsubsection{Antioxidant enzyme system}

Antioxidant enzymatic systems are present for removal of superoxide and hydrogen peroxide. Superoxide dismutase (SOD), catalyzes the breakdown of superoxide to $\mathrm{O}_{2}$ and $\mathrm{H}_{2} \mathrm{O}_{2}$. SOD is present in all mammalian cells, both as copper/zinc SOD in cytoplasma and as manganese SOD in mitochondria. Peroxinitrite (ONOO), has been described to inactivate SOD-activity (MacMillanCrow 1996). Catalase converts hydrogen peroxide to $\mathrm{H}_{2} \mathrm{O}$ and $\mathrm{O}_{2}$. Glutathione peroxidase (GPx) removes both hydrogen peroxide and lipid hydroperoxides (LOOH) by catalyzing their reaction with reduced glutathione (Saugstad 1990; Varsila 1994; Yu 1994) (figure 1). SOD, catalase and GPx are not only distributed in cytosol but are also localized in mitochondria, where most of intracellular free radicals are produced (Yu 1994).

$\mathrm{O}_{2} \stackrel{\mathrm{e}}{\rightarrow} \mathrm{O}_{2} \stackrel{\mathrm{e} / 2 \mathrm{H}^{+}}{\rightarrow} \mathrm{H}_{2} \mathrm{O}_{2} \stackrel{\mathrm{e} / \mathrm{H}^{+}}{\rightarrow} \mathrm{OH}^{*}+\mathrm{H}_{2} \mathrm{O} \stackrel{\mathrm{e} / \mathrm{H}^{+}}{\rightarrow} \mathrm{H}_{2} \mathrm{O}$

$2 \mathrm{O}_{2}^{*}+2 \mathrm{H}^{*} \rightarrow \mathrm{H}_{2} \mathrm{O}_{2}+\mathrm{O}_{2}$

(superoxide dismutase)

$2 \mathrm{H}_{2} \mathrm{O}_{2} \rightarrow 2 \mathrm{H}_{2} \mathrm{O}+\mathrm{O}_{2}$

(catalase)

$\mathrm{H}_{2} \mathrm{O}_{2}$ (or $\left.\mathrm{LOOH}\right)+2 \mathrm{GSH} \rightarrow 2 \mathrm{H}_{2} \mathrm{O}$ (or $\mathrm{LOH}+\mathrm{H}_{2} \mathrm{O}$ )

+ GSSG

(glutathione peroxidase)

Figure 1: Scheme showing the removal of superoxide and hydrogen peroxide by antioxidant enzymatic systems 


\subsubsection{Oxidative stress}

If ROS are not detoxified efficiently, interactions with cell components such as lipids, protein or DNA may occur, causing cellular damage or even cell death (Frank 1985; Janssen 1993; Yu 1994). Cell membrane structure and permeability are mainly affected by lipid peroxidation, and peroxidation products may damage DNA and proteins to some extent (Del Maestro 1980). Free radicals and oxidative stress have been implicated, with many pathological conditions. It has been hypothesized that the level prenatal development of antioxidant defenses is related to (1) spontaneous changes in the supply of $\mathrm{O}_{2} ;(2)$ maturational state of the tissue and (3) concentrations of metalloenzyme cofactors (these factors may differ in different organs and species) (Wilson 1987; Munim 1992). It has been suggested that newborns, when compared to adults, adapt better to hyperoxic conditions by increasing concentrations of antioxidant enzymes (Stock 1990; Rosenfeld 1986). This adaptive mechanism seems to be present only during a short period post partum of full term newborn. However, it is not known how early in fetal development this AOE system can be induced.

\subsection{Aims of the study}

Present techniques in obstetric and perinatal medicine make it possible to recognize perinatal asphyxia. However, more studies are needed to understand the underlying mechanisms of reduced fetal oxygenation and premature exposure to relative hyperoxic conditions in relation to increased risk for development of neuronal damage, intraventricular bleeding or necrotizing enterocolitis. The objectives of the present thesis were (a) to show the feasibility to use the chick embryo as a perinatal model for the mammalian fetus, (b) to study the fetal cardiovascular development and responses, (c) to determine the inducibility of the antioxidant enzyme system during development and (d) to study the effects of repetitive hypoxia and the recovery under normoxic or hyperoxic conditions on the gastrointestinal tract.

The methodological aspects of the preparations and the possibilities for cardiovascular research in the developing chick embryo, are described in chapter 2. The normal development of the $\mathrm{CABF}$, heart rate and cardiac output distribution was observed during the second half of the incubation period (Chapter 3 and 4). Furthermore, the effect of exposure to acute hypoxia or hyperoxia on these cardiovascular functions were investigated (Chapter 5, 6 and 7). 
At birth, premature infants are suddenly exposed to hyperoxic conditions compared to intra-uterine conditions, which results in an increased production of reactive oxygen species (ROS). The AOE system is not expected to be fully developed at early gestational age. In this thesis we describe a model in which we imitate the sudden exposure to rellative hyperoxic conditions at the time of premature birth. Changes in $A O E$ system ( $S O D$, catalase and $G P x$ ) were measured in the developing chick embryo exposed to $60 \% \mathrm{O}_{2}$ at three different time points in the incubation period (Chapter 8).

In periods of reduced oxygenation the cardiac output is redistributed to preserve flow to the brain, heart and kidneys at expense of the peripheral organs. This response predisposes the intestine to develop tissue hypoxia, an important factor in the development of necrotizing enterocolitis. The extension of damage to the intestine is also determined by release of ROS during the reperfusion phase. The release of ROS might be augmented during reoxygenation with pure oxygen after a hypoxic insult. Chapter 9 describes the histological changes in the intestine of the developing chick embryo after exposure to repetitive hypoxia and recovery with pure oxygen or room air are shown. 


\section{References}

Almström H, Sonesson SE (1996) Doppler echocardiographic assessment of fetal blood flow redistribution during matemal hyperoxygenation. Utrasound Obstet Gynecoll 8 (4), 256-261.

Asson-Batres MA, Stock MK, Hare JF, Metcalfe J (1989) $\mathrm{O}_{2}$ effect on composition of chick embryonic heart and brain. Resp Physiol 77, 101-110.

Bames AE, Jensen WN (1959) Blood volume and red cell concentration in the normal chick embryo. Am J Physiol 197, 403-405.

Beckman JS (1991) The double-edged role of nitric oxide in brain function and superoxide-mediated injury. I Devel Physiol 15, 53-59.

Bendenk MP, Langille BL (1992) Changes in blood flow distribution during the perinatal period in fetal sheep and lambs. Can J Physiol Pharm 70, 1576-1582.

Bissonnette JM, Metcalfe J (1978) Gas exchange of the fertile hen's egg: components of resistance. Resp Physiol, 34, 209-218.

Blanco CE Dawes GS, Walker DW (1983) Effect of hypoxia on polysynaptic hindlimb reflexes of unanaesthetized fetal and newbom lambs. J Physiol, 339, 453-466.

Blanco CE, Dawes GS, Hanson MA, McCook HB (1984) The response to hypoxiaof arterial chemoreceptors in fetal sheep and new-bom lambs. J Physiol, 315, 25-37.

Blanco CE, Martin CB, Rankin J, Landauer, Phernetton T (1988) Changes in fetal organ flow during intrauterine mechanical ventilation with or without oxygen. J Dev Physiol 10,53-62.

Bogdanov OV (1961) The effect of damage to different parts of the CNS on the cardiac activity of the chick embryo. Bull Exp Biol Med 50, 889-891.

Broekhuizen MLA, Mast F, Struijk PC, van der Bie W, Mulder PGH, Gittenberger de Groot C, Wladimiroff JW (1993) Hemodynamic parameters of stage 20 to stage 35 chick embryo. Paediatr Resi $34,44-46$.

Callingham BA, Cass R (1966) Catecholamines in the chick. In: Horton-Smith C, Ameiurus EC (eds.) Physiology of Domestic Fowl. Edinburgh, Oliver \& Boyd, pp 279-285.

Clark EB (1984) Hemodynamic control of the embryonic cardiovascular system. In: Nora I, Takao A (eds.) Congenital Heart Disease: Causes and Processes. New York Futura, MT Kisco, pp 377385.

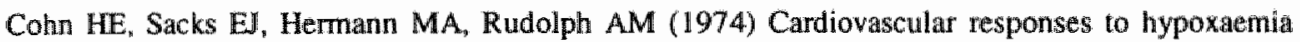
acidemia in fetal lambs. Am J Obstet Gynecol 120,814-824.

Clark EB, Hu N, Dooley JB (1985) The effect of isoproterenol on cardiovascular function in the stage 24 chick embryo. Teratology 31, 41-47.

Dalton KJ, Dawes GS, Patrick JE (1977) Diumal, respiratory and other rhythms of fetal lambs. Am J Obstet Gymecol $127,414-424$.

Dawes GS (1962) The foetus, the placenta and umbilical blood flow. I Physiol, 163, 43P.

Dawes C. Simikiss K (1969) The acid base status of the blood of the developing chick embryo. J Exp Biol 50,79-86.

Del Maestro RF, Thaw HH, Björk J, Planker M, Arfors KE (1980) Free radicals as mediators of tissue injury. Acta Physiol Scand (Suppl) 492, 43-57.

Elliott JM, West MJ, Chalmers $J$ (1985) Effects of vasopressin on heart rate in conscious rabbits. J Cardiowasc Pharm 7, 6-11.

Epple A, Tejindra SG, Nibbio B (1992) The avian allantois: A depot for stress-released catecholamines. Gen Comp Endocr 85, 462-476.

Frank L (1985) Effect of oxygen on the newborn. Federation Proc 44, 2328-2334.

Freeman BM, Misson $\mathrm{BH}(1970) \mathrm{PH}, \mathrm{pO}_{2}$ and $\mathrm{pCO}_{2}$ of blood from the foetus and neonate of Gallus Domesticus. Comp Biochem Physiol 33, 763-772. 
Frieswick GM, Danielson $T$, Shideman FE (1979) Adrenergic inotropic responsiveness of embryonic chick and rat hearts. Dev Neurosci $2,276-285$.

Fujita $H$, Tanizawa $Y$, Hura M (1976) Ontogenesis of granula formation in adrenal chromaffin cells of the chick In : Coupland RE. Fujita $T$ (eds.) Chromaffin, enterochromaffin and related cells. Elsevier Amsterdam, pp 191-208.

Gerson AG, Wallace DM, Stiller RJ, Paul D, Weiner S, Bolognese RJ (1987) Doppler evaluation of umbilical venous and arterial blood flow in the second and third trimester of normal pregnancy. Obstet Gynecol 70, 622-626.

Girard H (1973) Adrenergic sensitivity of circulation in the chick embryo. Am J Physiol 224 (2), 461 469.

Giussani DA, Spencer JAD, Hanson MA (1994) Fetal cardiovascular reflex responses to hypoxaemia. Fetal and Matemal Medicine Review 6, 17-37.

Gleason CA, Jones MD, Traystman RJ, Notter RH (1988) Fetal cerebral responses to ventilation and oxygenation in utero. Am J Physiol 255, R1049-R 1054.

Granger HJ, Nyhof RA (1982) Dynamics of intestinal oxygenation: interaction between oxygen supply and uptake. Am I Physiol 243, G91-96.

Gruntner GH, Michael JR, Farrukh IS, Sciuto AM, Adkinson NF (1985) Mechanism of hyperoxia induced pulmonary vascular paralysis: effect of antioxidant pretreatment. I Appl Physiol 59 (3), 953-958.

Hamburger $V$, Hamilton HL (1951) A series of normal stages in the development of the chick embryo. Morphol 88, 49-98.

Hanson MA (1988) The importance of baro- and chemoreflexes in the control of the fetal cardiovascular system. J Dev Physiol 10, 491-5॥1.

Hardy P. Abran D, Li D, Femandez H, Varma DR, Chemtob S (1994) Free radicals in retinal and choroidal blood flow autoregulation in the piglet: Interaction with prostaglandins. Invest Ophth Vis Sci 35, 580-591.

Hardy P. Peri KG, Lahaie I, Varma DR, Chemtob S (1996) Increased nitric oxide syntheses and action preclude choroidal vasoconstriction to hyperoxia in newborn pigs. Circ Res 79, 504-511.

Higgens D, Pappano AJ (1979) A histochemical study of the ontogeny of catecholamine-containing axons in the chick embryo heart. J Mol Cell Cardiol $11,661-668$.

Higgens D, Pappano AJ (1981) Development of transmitter secretory mechanisms by adrenergic neurons in the embryonic chick heart ventricle. Devel Biol 87, 148-162.

Hu N, Clark EB (1989) Hemodynamics of the stage 12 to stage 29 chick embryo. Circ Res 65,1665 1670.

Ignarro LJ, Shideman FE (1968) Norepinephrine and epinephrine in the embryonic heart of the chick: uptake and subcellular distribution. J Pharmacol Exp Ther $159_{m} 49-58$.

Itskovitz J, Goetzman BW. Rudolph AM (1982) The mechanism of late decelerations of the heart rate and its relationship to oxygenation in nomoxic and chronically hypoxemic fetal lambs. Am J Obstet Gynecol 142,66-73.

Itskovitz I, Rudolpth AM (1982) Denervation of arterial chemoreceptors and baroreceptors in fetal lambs in wtero. Am J Physiol 242, H916-H920."

Itskovitz J, LaGamma EF, Rudolph AM (1983a) Baroreflex control of the circulation in chronically instrumented fetal lambs. Circ Res 52 (5) 589-596.

Iwamoto HS, Rudolph AM, Keil LC, Hermann MA (1979) Hemodynamic responses of the sheep fetus to vasopressin infusion. Circ Res 44, 430- 436. Iwamoto HS, Teitel D, Rudolph AM (1987) Effect of birth-related events on blood flow distribution.
Pediatr Res 22, 634-640. 
Iwamoto HS, Kaufman T, Keil LC, Rudolph AM (1989) Responses to acute hypoxemia in fetal sheep at 0.6-0.7 gestation. Am I Physiol 256, H613-620.

Jackson BT, Piasecki GI, Novy MJ (1987) Fetall responses to altered maternal oxygenation in thesus monkey. Am J Physiol 252, R94-101.

Janssen YMW, Borm PJA, Van Houten B, Mossman BT (1993) Cell and tissue responses to oxidative damage. Lab Invest 3, $261-274$.

Kirby ML, Stewart DE (1986) Development of the ANS innervation of the avian heart. In: Gootman, PM (eds.) Developmental neurobiology of the autonomic nervous system. Humana Press, Clifton, New Jersey, pp 135-158.

Kurth CD, Wagerle LC (1992) Cerebrovascular reactivity to adenosine analogues on 0.6-0.7 gestation and near term fetal sheep. Am J Physiol 262, H1338-1342.

Langercrantz $H$ (1984) Classical and 'new' transmitters during development - some examples from control of respiration. J Devel Physiol 6, 195-205.

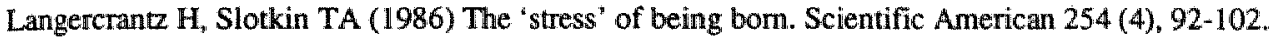

Larrazabal LI, Penn JS (1990) Fluorescence angiography of the new born rat. Implications in oxygen-induced retinopathy. Invest Ophthalmol Vis Sci $31,810-818$.

Legrande MC, Paff GH, Boucek RJ (1966) Initiation of vagal control of heart rate in the embryonic chick. Anat Rec 155, 163-166.

Lelorier J, Minejima N, Shideman FE (1975) Effect of ouabain on the innervated and noninnervated embryonic chick heart. J Parmacol 53 (6), 1005-1006.

Le Noble FAC, Scheurs NHIS, van Straaten HWM, Slaaf DW, Smits JFM, Rogg H, Struyker Boudier HAJ (1993) Evidence for a novel angiotensin II receptor involved in agiogenesis in chick embryo chorioallantoic membrane. Am J Physiol 264, R460-R465.

Lewis BV (1968) The response of isolated sheep and human umbilical arteries tooxygen and drugs. Brit J Obstet Gynaecol 75, 87-91.

Lewis $A B$, Donovan M, Platzker ACG (1980) Cardiovascular responses to autonomic blockade in hypoxaemic fetal lambs. Bioll Neonate 37, 233-242.

Lundstrom $K E_{\text {, Pryds }}$, Greisen $G$ (1995) Oxygen at birth and prolonged cerebral vasoconstriction in preterm infants. Arch Dis Child 73, F81-86.

Mann L (1970) Effects of hypoxia on umbilical circulation and fetal metabolism. Am J Physiol 218 : 1453-1458.

McCarty LP, Lee WC, Shideman FE (1960) Measurement of inotropic effects of drugs on the innervated and noninnervated embryonic chick heart. J Pharmacol Exp Ther $129,315-321$.

McCord JM (1985) Oxygen-derived free radicals in postischemic tissue injury. New Engl J Med 312,159-163.

MacMillan-Crow LA, Crow JP, Kerby JD, Beckman JS, Thompson JA (1996) Nitration and inactivation of manganese superoxide dismutase in chronic rejection of human renal allografts. Proc Natl Acad Sci USA 93(21), 11853-11858.

Menke J, Rabe MH, Bresser W, Grohs R, Schmitt RM, Jorch G (1993) Simultaneous influence of blood pressure $\mathrm{PCO}_{2}$ and $\mathrm{PO}_{2}$ on cerebral blood flow velocity in preterm infants of less than 33 weeks" gestation. Pediatr Res 34, 173-177.

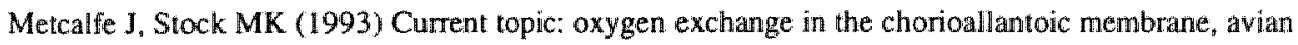
homoloque of the mammalian placenta. Placenta 14, 605-613.

Munim A, Asayama K, Dobashi K, Suzuki K, Kawaoi A, Kato K (1992) Immunohistochemical localization of superoxide dismutase in fetal and neonatal rat tissues. J Histochem Cytochem $40,1705-1713$. 
Nakazawa M, Miyagawa S, Ohno T, Miura S, Takao A (1988) Developmental hemodynamic changes in rat embryos at 11 to 15 days of gestation: normal data of blood pressure and the effect of caffeine compared to data from the chick embryo. Pediatr Res $23,200-205$.

Olszowka AJ, Tazawa $H$ and Rahn $H$ (1988) A blood-gas nomogram of the chick fetus: blood flow distribution between the chorioallantois and fetus. Resp Physiol 71, 315-330.

Palmer SM, Oakes GK, Champion MA. Fisher DA, Hobel CK (1984) Catecholamine physiology in the ovine fetus. III. Matemal and fetal response to acute maternal exercise. Am J Obstet Gynecol 149: 246-434.

Papano $A J$, Loffelholz $K$ (1974) Ontogenesis of adrenergic and cholinergic neuroeffector transmission in chick embryo heart. I Pharmacol Exp Ther 191, 468-478.

Parer JT, Dijkstra HR, Vredebregt PPM, Harris JL, Krueger TR, Reuss ML (1980) Increased fetal heart rate variability with acute hypoxia in chronically instrumented sheep. Eur J Obstet Gyn $R$ 10, 393-399.

Peeters LLH, Sheldon RE, Douglas MD, Jones MD, Makowski EL, Meschia G (1979). Blood flow to fetal organs as a function of arterial oxygen content. Am J Obstet Gynecoll 135, 637-646.

Piper J, Tazawa H, Ar A, Rahn H (1980) Analysis of chorioallantoic gas exchange in the chick embryo. Resp Physiol 39, 273-284.

Prinzinger RM, Smit M, Diet. V (1995) Embryogeny of oxygen consumption in 13 altricial and precocial birds. Resp Physiol 39, 273-284.

Radi R, Beckman JS, Bush KM, Freeman BA (1991) Peroxynitrite induced membrane lipid peroxidation: the cytotoxic potential of superoxide and nitric oxide. Arch Biochem Biophys 2, $481-487$.

Rahn $\mathrm{H}_{*}$ Paganelli CV, Ar A (1974) The avian egg: air-cell gas tension, metabolism and incubation time. Resp Physiol 22, 297-309.

Rahn H, Matalon S, Sotherland PR (1985) Circulatory changes and oxygen delivery in the chick embryo prior to hatching. In: Johanses K, Burggren W (eds.) Cardiovascular Shunts, Phylogenetic, Ontogenetic and Clinical Aspects. Copenhagen: Munksgaard, pp 119-221.

Rahn H. Paganelli CV, Ar A (1987) Pores and gas exchange of avian eggs: areview. J Exp Zool $1,165-172$.

Rickenbacher J, Muller E (1979) The development of cholinergic ganglia in the chick embryo heart. Anat Embryol 155, 253-258.

Romanoff AL (1960) Handbook: The avian embryo; structural and functional development. New York: The Macmillan Company.

Rosenfeld W, Conception L (1980) Endogenous antioxidant defenses in neonate. Free Radical Bio Med 2. 296-298.

Rudolph AM and Hermann MA (1970) Circulatory changes during growth in the fetal lamb. Circ Res 26, 289-299.

Rudolph AM (1984) The fetal circulation and its response to stress. J Devel Physiol 6, 11-19.

Rudolph AM (1985) Distribution and regulation of blood flow in the fetal and neonatal lamb. Circ Res $57,811-821$.

Rudolph AM, Hermann MA (1967) The circulation of the fetus in utero. Methods for studying distribution of blood flow, cardiac output and organ blood flow. Circ Res 21, 163-185.

Rudolph AM, Hermann MA (1985) Methods for studying the circulation in utero. In: Nathanielz PW (eds.) Animal models in fetal medicine (I). Ithaca, NY: Perinatology Press, pp 1-57.

Rurak DW (1978) Plasma vasopressin levels during hypoxaemia and the cardiovascular effect of exogenous vasopressin in foetal and adult sheep. J Physiol 277, pp 341-357.

Saugstad OD (1988) Hypoxanthine as an indicator of hypoxia: its role in health and disease through free radical production. Pediatr Res 23, 143-150. 
Saugstad OD (1990) Oxygen toxicity in the neonatal period. Acta Paediatr Scand 79, 881-892. Sparks HV (1980) Effect of local metabolic factors on vascular smooth muscle. In: Bohr DF, Somylo AP, Sparks HV (edls.) Handbook of Physiology, the Cardiovascular System, Vol II. American Physiology Society, Bethesda, MD, Pp 475-513.

Stock MK, Silvernail KK, Metcalfe J (1990) Prenatal oxidative stress: I. malondialdehyde in hypoxic and hyperoxic chick embryos. Free Radical Bio Med 8, 313-318.

Stuart MJ, Setty BNY, Wallenga RW, Graeber JE, Ganley C (1984) Effects of hyperoxia and hypoxia on vascular prostacyclin formation in vitro. Pediatrics $74,548-553$.

Tazawa H, Visschedijk AHJ, Wittmann J and Piiper J (1983a). Gas exchange, blood gases and acidbase status in the chick embryo before, during and after hatching. Resp Physiol 54,137-144.

Tazawa H, Visschedijk AHJ, Piiper J (1983b) Blood gases and acid-base status in chicken embryos with naturally varying egg shell conductance. Resp Physiol 54, 137-144.

Tazawa $H$ and Takenaka $H$ (1985) Cardiovascular shunt and model analysis in the chick embryo. In: Johanses K Burggren WW (eds.) Cardiovascular Shunts, Alfred Benzon Symposium 21. Munskgaard, pp 179-198.

Tazawa H, Hiraguchi T, Kuroda O, Tullett SG, Deeming DC (1991) Embryonic heart rate during development of domesticated birds. Physiol Zool 64 (4), 1002-1022

Tazawa H, Hashimoto Y, Doi K (1992) Blood pressure and heart rate of the chick embryo (Gallus domesticus) within the egg: responses to autonomic drugs. In: Hill RB, Kuwasawa K, Mcmahon BR, Kuramoto T (eds.) Phylogenetic Models in Functional Coupling of the CNS and the Cardiovascular System. Comp Physiol, Karger, vol 11, pp 86-96.

Thomas MJ, Mehl KS, Pryor WA (1978) The role of the superoxide anion in the xanthine oxidase induced autooxidation of linoleic acid. Biochem Bioph Res Co 83, 927-932.

Thomburg KL (1991) Fetal response to intrauterine stress. In: The children environment and adult disease. Wiley, Chichester (Ciba Foundation Symposium 156), pp 17-37.

Thomburg KL, Morton MJ (1994) Development of the cardiovascular system. In: Thomburg GD and Harding R (eds.) Textbook of Fetal Physiology. Oxford University Press, pp 95-130.

Tibboel D, Molennaar JC, Van Nie CJ (1979) New perspectives in fetal surgery: the chicken embryo. J Pediatr Surg 14, 438-440.

Varsila $E_{v}$ Hallman $M$, Andersson S (1994) Free-radical-induced lipid peroxidation during the early neonatal period. Acta Paediatr 83, 692-695.

van Bel F, Sola A, Roman C, Rudolph AM (1995) Role of nitric oxide in the regulation of the cerebral circulation in the lamb fetus during nomoxaemia and hypoxaemia. Biol Neonate 68; 200-210.

Visschedijk AHJ (1968a) The air space and the embryonic respiration. I The pattern of gaseous exchange in the fertile egg during the closing stages of incubation. Br Poult Sci 9, 173-184.

Visschedijk AHJ (1968b) The air space and the embryonic respiration. 2 The times of pipping and hatching as influenced by an artificial changed permeability of the shell over the air space. $\mathrm{Br}$ Poull Sci 9,185-196.

Visschedijk AHJ (1968c) The air space and the embryonic respiration. 3 The balance between oxygen and carbon dioxide in the air space on the incubating chick egg and its role in stimulating pipping. Br Poult Sci 9,197-210.

Wagerle LC, Mishra OP (1988) Mechanism of $\mathrm{CO}_{2}$ response in cerebral arteries of the newbom pig: role of phospholipase, cyclooxygenase and lipoxygenase. Circ Res 62, 1019-1026.

Wakatsuki A, Murata Y, Ninomiya Y, Masaoka N, Tyner JG, Krishna KK (1992) Autonomic nervous system regulation of baseline heart rate in fetal lamb. Am J Obstet Gynecol 167, 519-523.

Wassermann GF, Bernard EA (1970) Adrenaline content of the chick embryo adrenal gland during development. Acta Physiol Latinoameric 20, 171-173. 
Wheeler T, Murrills A (1978) Pattern of fetal heart rate during nomal pregnancy. Brit I Ostet Gyneaecol 84, 965-974.

Weir EK, Reeve HL, Cornfield DN, Tristani-Firouzi M, Peterson DA, Archer SL (1997) Diversity of response in vascular smooth muscle cells to change in oxygen tension. Kidney Int 51, 462-466.

White PT (1974) Experimental studies on the circulatory system of the late chick embryo. I Exp Biol $61,571-592$.

Willson JX, Lui EMK, Del Maestro RFD (1992) Developmental profiles of antioxidant enzymes and trace metals in chick embryo. Mech Ageing Devel 65,51-64.

Windle W.F., Barcroft J. (1938) Some factors governing initiation of respiration in the chick. Am J Physiol 121, 684-691.

Wittman J, Prechtl $J$ (1991) Respiratory function catecholamines during the late period of avian dewelopment. Resp Physiol 83, 375-386.

Yosphe-Parer YJ, Friedrich J, Davies AM (1953) Estimation of blood wolumes of embryonated hen eggs at different agges. Am J Physiol 35, 1-7.

Yu BP (1994) Cellular defenses against damage from reactive oxygen species. Physiological Reviews $74.139-162$. 


\section{Chapter II}

\section{Intervention models and analyzing techniques}

2.1 Animals

2.2 Gas exchange in the chick embryo

2.2.1 Diffusion capacity, blood gas changes, and metabolic rate

2.2.2 Effect of opening of the air cell on normal gas exchange

2.2.3 Technique used for induction of blood gas changes

2.3 Preparation for the measurement of CABF, heart rate and cardiac output distribution

2.3.1 Transonic flow probe

2.3.2 Fluorescent microspheres

2.4 Measurement of protein content and $\mathrm{AOE}$ activity

2.5 Tissue preparation to measure histological changes in the intestine

2.6 Statistics 


\section{Chapter II}

\section{Intervention models and analyzing techniques}

\subsection{Animals}

Fertilized White Leghom eggs were incubated at $38{ }^{\circ} \mathrm{C}$ and $60 \%$ humidity. During incubation, eggs were turned hourly along their long axis to prevent adhesions between the embryo and its membranes (Tazawa 1981) and to avoid abnormal development (Pearson 1996; Tazawa 1981). All interventions and measurements were made inside a clinical infant incubator in which the temperature was kept at $38{ }^{\circ} \mathrm{C}$ and humidity at $60 \%$. Because the heart rate of the avian embryo is a direct function of environmental temperature (Romanoff 1960; Tazawa 1986), it is important to control the temperature during all interventions and measurements. In this thesis we used chick embryos ranging between days 9 to 20 of the incubation period (total incubation time is 21 days), corresponding to stage 34 to 46 , according to Hamburger and Hamilton (1951).

\subsection{Gas exchange in the chick embryo}

\subsubsection{Diffusion capacity, blood gas changes and metabolic rate}

The chick embryo is surrounded by the amniotic fluid and several membranes. Figure 1 shows a schematic presentation of the pores egg shell, the outer and inner shell membranes, the air cell and the chorioallantoic circulation. Although not clear from the figure, the CAM is distributed evenly over the whole inner eggs surface. The gas exchange in the chick embryo takes place through the micropores in the egg shell. In figure 1 a schematic presentation of the gas exchange structure is given. there are about 10.000 pores distributed over the egg shell. Beside the egg shell there are two other resistance layers for the gas diffusion, the shell membranes and the blood barrier (Bissonnette 1978). Directly under the shell is the structure of the external membrane which has a thickness of about $50 \mu \mathrm{m}$. The inner shell membrane $(15 \mu \mathrm{m})$ separates the air cell from the endothelium of the capillaries. In the capillaries of the chorioallantoic membrane, the oxygenated blood is transported by the chorioallantoic vein to the fetus, and the vitellini veins transports the digested yolk material to the liver. 


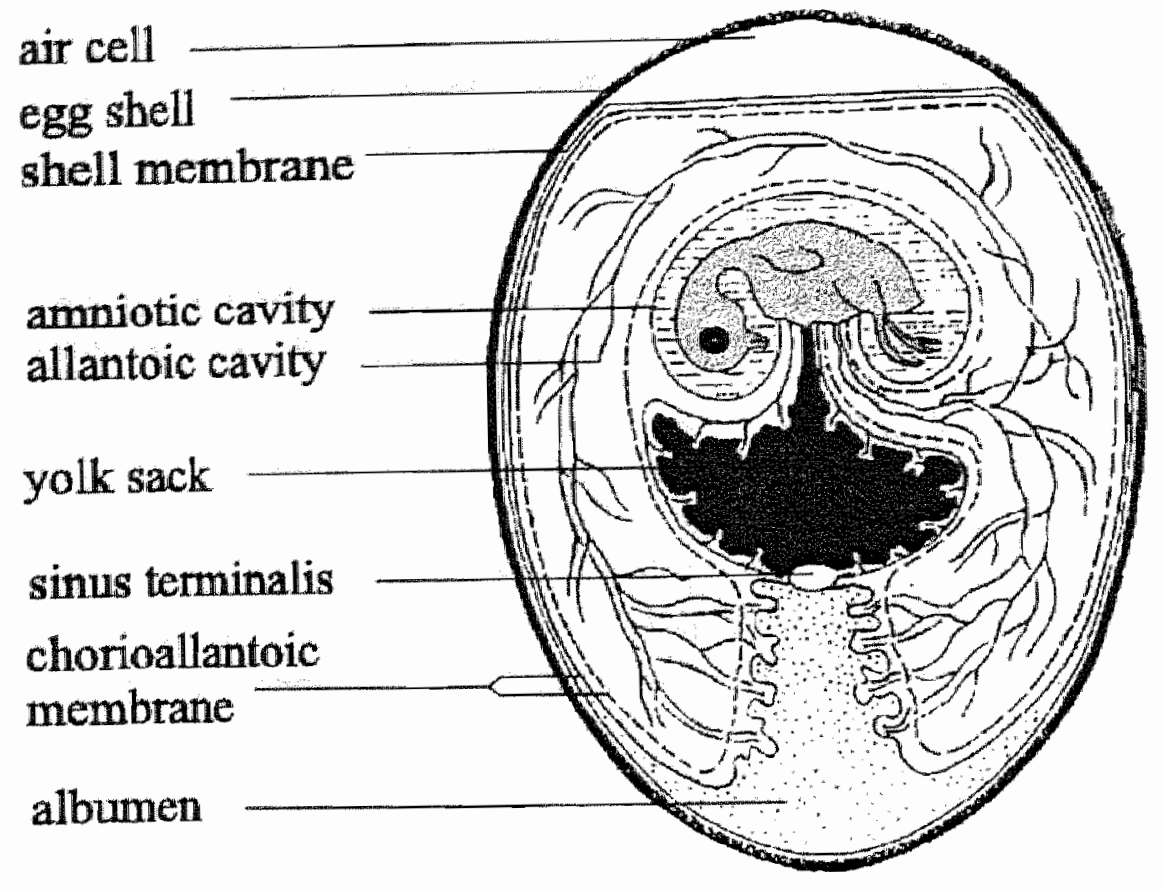

Figure 1: Schematic presentation of egg shell with pores, membranes, air cell, yolk sac in relation to the embryo.

Under continuous incubation in room air $\left(21 \% \mathrm{O}_{2}\right)$, the average daily weight gain (increase in wet weight, g/day) of the chick embryo increases continuously from day 6 to 14 (Romanoff, 1960; Vleck 1980). During the last part of the incubation period (total incubation time is 21 days) the demand of oxygen exceeds oxygen diffusing capacity of the egg shell pore system and chorioallantoic membrane (Freeman and Mission, 1970; Rahn et al., 1974), and as a consequence there occurs a decrease in $\mathrm{O}_{2}$ tension (Freeman 1970; Rahn 1974), $\mathrm{O}_{2}$ consumption $\left(\mathrm{VO}_{2}\right)$ (Prinzinger 1995; Vleck 1980;), and growth rate (Romanoff 1960; Vleck 1980). The developed respiratory acidosis is metabolically compensated by an increase of blood bicarbonate (Dawes 1969; Girard 1971; Tazawa 1981), hematocrit, hemoglobin concentration and blood $\mathrm{O}_{2}$ capacity (Barnes 1959; Bartels 1966). Due to these adjustments the $\mathrm{O}_{2}$ content of arterialized blood paradoxically 
increases up to day 18 (Tazawa 1983a-b). These adjustments appear to reach their limits on day 19 and pulmonary respiration becomes a necessity, therefore internal pipping is stimulated (beak enters the air cell), (Freeman 1970; Prinzinger 1995; Rahn 1974; Romanoff 1960; Vleck 1980). Comparison of measurements before and after external pipping (hatching) shows a considerable drop in arterialized blood $\mathrm{PCO}_{2}$ with concomitant increase in $\mathrm{pH}$, this is produced by pulmonary ventilation (Tazawa 1983a).

\subsubsection{Effect of opening of the air cell on normal gas exchange}

By means of transillumination the limits of the air cell were identified and cut with an electric saw. Afterwards the eggs were placed in a small plexiglass holder provided with a continuous gas flow of a $\mathrm{N}_{2} / \mathrm{O}_{2}$ mixture $(5 \mathrm{l} / \mathrm{min})$ adjusted to $21 \%$ oxygen at $38{ }^{\circ} \mathrm{C}$ and $60 \%$ humidity (figure 2 ).

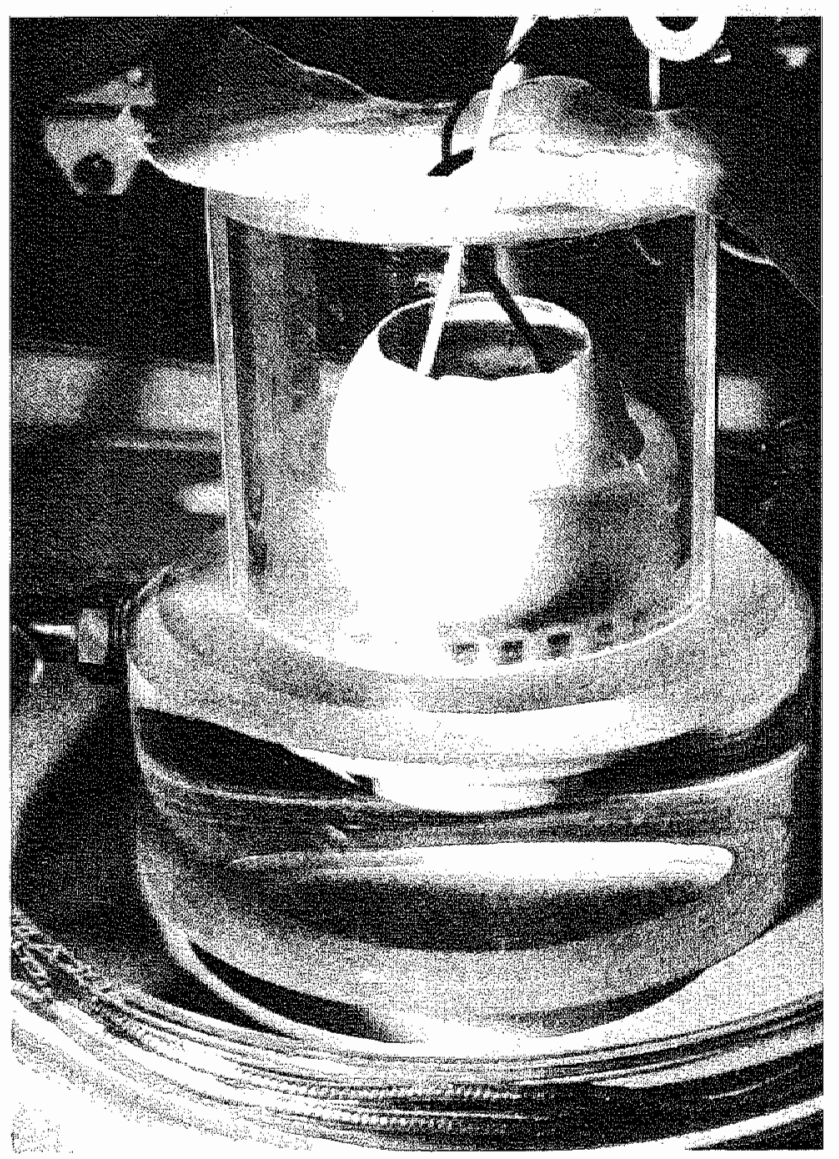

Figure 2: Egg preparation 
The opening of the air cell changes the diffusion gradient through the egg shell by' exposing the embryo directly to the environment which could induce changes in the embryonic blood gasses (Bissonnette, 1978). In order to investigate, chorioallantoic artery blood samples for $\mathrm{pH}, \mathrm{Po}_{2}$ and $\mathrm{PcO}_{2}$ were obtained from chick embryos at incubation day 14-15 (stage $40-41)(\mathrm{n}=15)$ in which the air cell was opened for respectively 10,20 and 30 minutes (Table 1). The embryos were kept in the same environmental conditions as the experimental group. For the samples the chorioallantoic artery was carefully lifted with forceps and a curved 30 gauge needle was inserted opposite to the direction of the blood stream. Blood samples $(0.2 \mathrm{ml})$ were collected into heparinized syringe and analyzed at $38^{\circ} \mathrm{C}$ (Radiometer ABL3, Copenhagen). No significant changes in the blood gas levels were observed following opening of the air cell.

Table 1: Blood gas levels in the chick embryo 10,20 and 30 min after opening of the air cell on days 14-15 (stage 40 and 41 ).

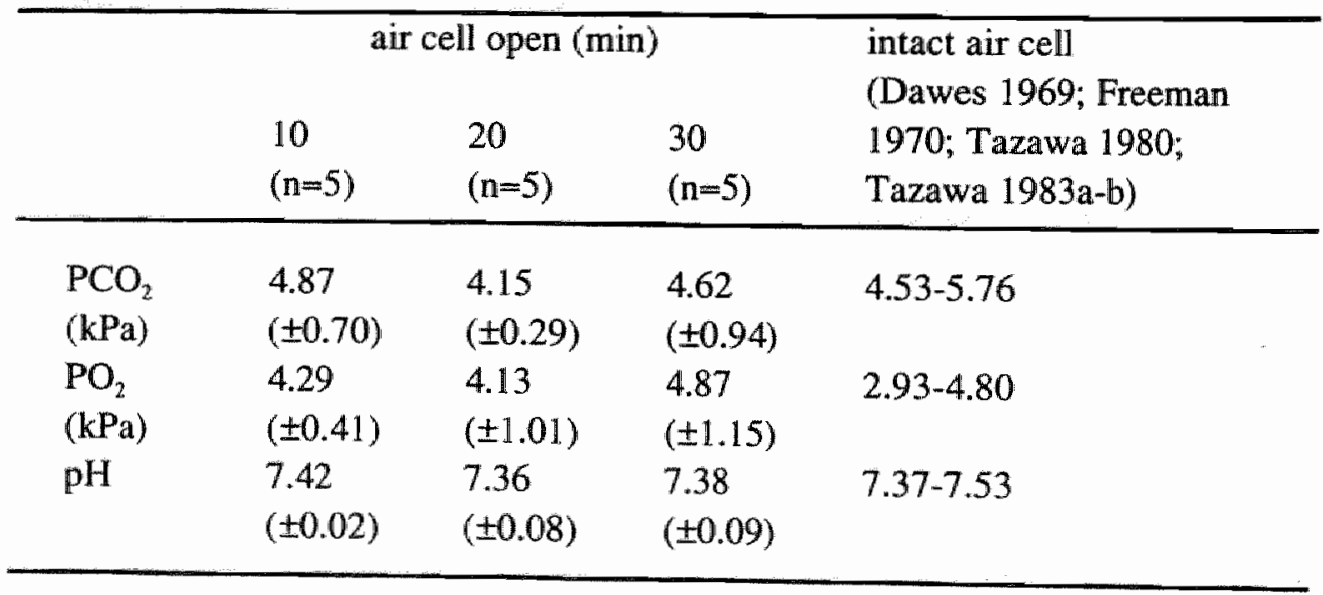

Results are expressed as mean $\pm \mathrm{SD}$. 


\subsubsection{Technique used for induction of blood gas changes}

\section{Exposure to acute hypoxia or hyperoxia}

Because of the characteristics of gas exchange of the chick embryo, it is relatively easy to expose the developing chick embryo to different gas compositions, by changing the gas compositions surrounding the egg shell. After opening of the air cell with a electrical saw, in a clinical incubator in which temperature and humidity were kept at respectively $38{ }^{\circ} \mathrm{C}$ and $60 \%$, the egg was placed in a special developed plexiglass holder. In this closed holder the oxygen concentration surrounding the egg can be varied by changing the oxygen concentration in the continuous gas flow ( $5 \mathrm{~V} / \mathrm{min} ; \mathrm{N}_{2} / \mathrm{O}_{2}$ mixture) to the holder, as shown in figure 2 . Different groups were exposed to respectively $100 \% \mathrm{~N}_{2}, 5 \% \mathrm{O}_{2}$, or $100 \% \mathrm{O}_{2}$ during 5 minutes. To determine the blood gas changes produced by acute exposure to the different environmental gas concentrations, blood samples from the chorioallantoic artery were taken after 5 minutes of exposure at days 15-16 (stages 40-41). The vessel was carefully lifted with forceps and a curved 30 gauge needle was inserted opposite to the direction of the blood stream. Blood samples $(0.2 \mathrm{ml})$ were collected into heparinized syringe and analyzed at $38^{\circ} \mathrm{C}$ (Radiometer ABL3, Copenhagen). Changes in blood gasses in the chorioallantoic artery are shown in table 2.

Table 2: Blood gas levels in chick embryo after exposure to $100 \% \mathrm{~N}_{2}$. $5 \% \mathrm{O}_{2}, 100 \% \mathrm{O}_{2}$ on days $14-15$ (stage 40 and 41 ).

\begin{tabular}{llll}
\hline & $\begin{array}{l}100 \% \mathrm{O}_{2} \\
(\mathrm{n}=9)\end{array}$ & $\begin{array}{l}5 \% \mathrm{O}_{2} \\
(\mathrm{n}=6)\end{array}$ & $\begin{array}{l}100 \% \mathrm{~N}_{2} \\
(\mathrm{n}=8)\end{array}$ \\
\hline $\mathrm{PCO}_{2}$ & 4.52 & 3.89 & 3.88 \\
$(\mathrm{kPa})$ & $( \pm 0.39)$ & $( \pm 0.17)$ & $( \pm 0.68)$ \\
$\mathrm{PO}_{2}$ & 6.60 & 1.98 & 1.2 \\
$(\mathrm{kPa})$ & $( \pm 1.30)$ & $( \pm 0.43)$ & $( \pm 0.34)$ \\
$\mathrm{pH}$ & 7.428 & 7.365 & 7.430 \\
& $( \pm 0.055)$ & $( \pm 0.017)$ & $( \pm 0.027)$ \\
\hline
\end{tabular}

Results are expressed as mean $\pm S D$. 


\section{Exposure to chronic hyperoxia}

The incubator, in which the eggs were placed until they had reached the developmental age for the subsequent experiment, allowed us to increase the oxygen concentration up to $60 \% \mathrm{O}_{2}$. The gas composition in the incubator was continuously monitored while the eggs were incubated. It is known that exposure of the eggs to hyperoxia $\left(\mathrm{F}_{\mathrm{i} 02}=0.67\right.$ ) during 3 hours leads to a significant change of $\mathrm{P}_{\mathrm{a}} \mathrm{O}_{2}(6.9 \pm 0.8 \mathrm{mmHg} * \Delta 3.7 \mathrm{mmHg})$ in the chorioallantoic artery, similar to the transition of $\mathrm{P}_{\mathrm{a}} \mathrm{O}_{2}$ levels at birth (Piiper 1980).

\subsection{Preparation for measurement of $\mathrm{CABF}$, heart rate and cardiac output distribution}

\subsubsection{Transonic flow probe}

After opening of the air cell the external membrane was visible. In order to visualize the vessels running in the CAM, the external membrane was made transparent using a cotton swab wetted with $0.9 \%$ saline. Using a dissection stereo-microscope (WILD 3M, total magnification 10X), the external shell membrane was removed with great care. A small incision was made in the CAM using a cautery to avoid hemorrhage. The embryo was now visible in the amniotic fluid. Figure 3 shows schematically the embryonic circulation and demonstrates where the flow probe was placed. The overall circulation in the chick embryo is comparable to the human fetus, but there are some differences as described by White (1978). Major differences are the vitellini veins which transport the digested yolk material to the liver, and the umbilical blood which flows directly to the left hepatic vein without entering the liver substance. The dark red pulsating chorioallantoic artery was localized near the embryonic abdomen and placed in the lumen of a $0.5 \mathrm{~mm}$ flow probe (0.5VB39. Transonic Systems Inc., Ithaca NY 14850, USA), avoiding any obstruction of the vessel.

The flow probe subtracts the downstream transit time from the upstream transit time utilizing a wide-beam ultrasonic illumination. This difference between the integrated transit times is a measure of blood flow rather than velocity (Drost, 1978). The transit time blood flow meter has certain advantages over other cufftype blood flow meters in that the detected signal gives a direct measurement of the net volume flow through the acoustic window of its implanted sensor. In contrast to the Doppler principle what measures the blood velocity, which makes the measurements critically dependent on determination of vessel diameter. The space between the vessel and the probe had to be filled with fluid without air 
bubbles or tissue in order to obtain a homogeneous ultrasound field. Because only acoustic contact is necessary, a loose fit of the probe is acceptable. This technique has been validated and tested for its variability using volume blood flow measurements with a transit time flow probe in vivo and in vitro (Lundell, 1993). A heamodynamic digitalized acquisition system (sample interval $2 \mathrm{msec}$ and system trigger $2000 \mathrm{msec}$ ) (HDAS, University of Limburg) was used for monitoring and saving, beat to beat, the blood flow and heart rate data. The heart rate was derived from the blood flow signal.

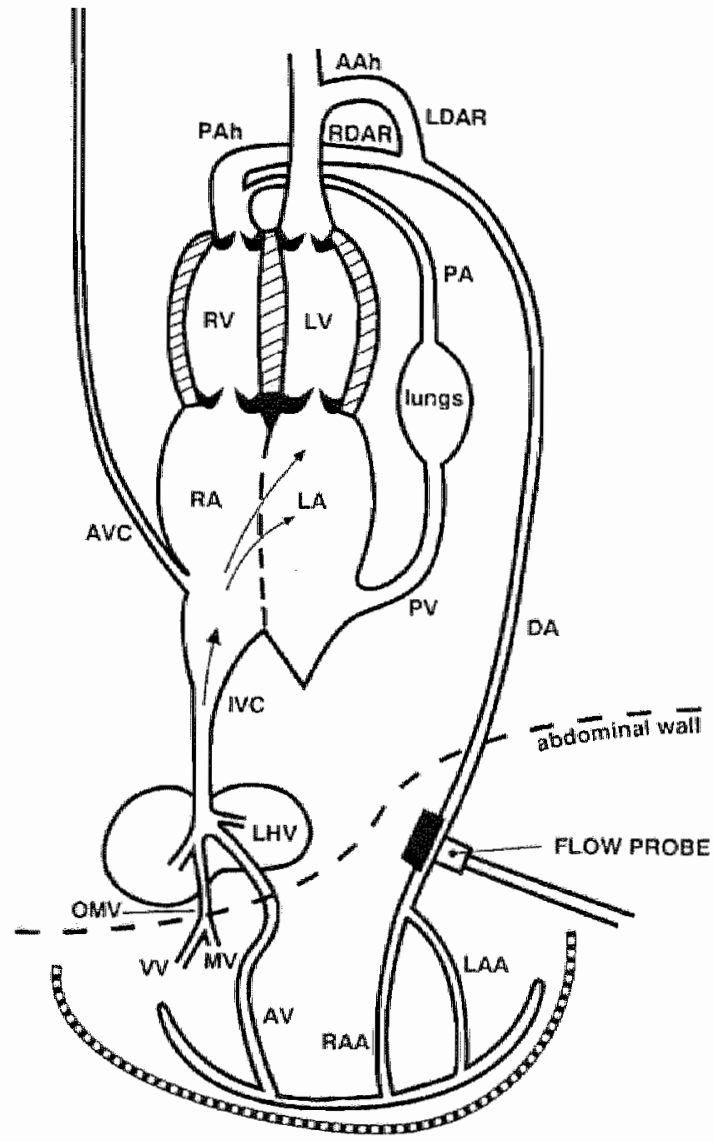

Figure 3: Schematic view of the chick embryo circullation redrawn after Romanoff (1) and White (7), Abbreviations: Aah, aortic arch; AV, allantoic vein; $A V C$, anterior vena cava; $D A$, dorsal aorta; IVC. inferior wena cava; LA and RA, left and right atrium; LAA and RAA, left and right allantoic artery; LDAr and RDAr, left and right ductus arteriosus; LHV, left hepatic vein; LV and RV, left and right ventricle; $M V$, mesenteric vein; OMV, omphallomesenteric vein; PA, pulmonary artery; PAh, pulmonary arch; $\mathbb{P V}$, pulmonary vein; VV, vitellini vein. 


\subsubsection{Fluorescent microspheres}

For the measurement of CO distribution during normoxia, hypoxia or hyperoxia periods, fluorescent microspheres were used ( Fluorspheres 7 Molecular Probes Inc. Eugene, OR, USA). In a clinical incubator, provided with a light microscope (WILD 3M, magnification $10 \mathrm{x}$ ), a branch of the chorioallantoic vein was catheterized for injections of fluorescent microspheres. The vein was identified by its bright red color and the erythrocyte stream direction. The vein was lifted using sutures, opened with a curved 30 gauge needle, and a polyethylene catheter, which was stretched by heat to a diameter of $100 \mu \mathrm{m}$, was inserted. At previously determined time points a suspension of fluorescent microspheres with a diameter of $15 \mu \mathrm{m}(0.2 \mathrm{ml}$ of a 100.000 microspheres/ $\mathrm{ml} 0.05 \%$ Tween 80 solution) were injected. Using this method cardiac output distribution could be measured in the normal developing chick embryo, but also the redistributions of the cardiac output during interventions of hypoxia or hyperoxia. The cardiac output distribution to different organs (heart, lungs, brain, CAM, intestine, liver, yolk-sac and carcass) is expressed as the fraction of the cardiac output that the tissue received.

\section{Analysis of dye distribution}

Three different fluorescent labels were used: yellow-green (497nm excitation; 507 emission), orange ( 535 excitation; 555 emission) and crimson (614 excitation; 639 emission). We determined fluorescence in whole organs (CAM, brain, heart, lungs, intestine, liver and yolk-sac) and in the remaining carcass. The tissues were digested in a $2 \mathrm{M}$ ethanolic- $\mathrm{KOH}$ solution for $48 \mathrm{~h}$ at $60^{\circ} \mathrm{C}$. The microspheres were isolated from the homogenate by repeated centrifugation, removal of the supernatant and rinsing as described by van Oosterhout et al. (1995). In the final pellet the dye was extracted by adding $3 \mathrm{ml}$ of 2-(2-ethoxyethoxy)ethylacetate and fluorescence was counted by fluorimetry using a LS-50B fluori-spectrometer (Perkin Elmer). No correction for spectral overlap was used since the excitation and emission spectra of the dyes injections were well separated from each other. During fluorimetry all samples had the same volume $(3 \mathrm{ml})$. The fraction of the $\mathrm{CO}$ that was directed to the tissue was expressed by the fraction of the fluorescence, corrected for background, of the sample divided by the sum of fluorescence of all tissues.

\subsection{Measurement of protein content and AOE activity}

Chick embryos were removed from their eggs, decapitated, weighed and classified using the Hamburger-Hamilton morphological maturity index (Hamburger \& Hamilton 1951). The brain, heart, liver, intestine, and lungs were dissected from 
the embryo, weighed and chilled in ice cold $0.9 \% \mathrm{NaCl}$-solution. Organ protein content was determined in duplicate according the procedure of Bradford (1976), using bovine serum albumin (BSA) as standard.

Remaining homogenates were centrifuged at $12000 \mathrm{rpm}$ for 5 minutes at $4{ }^{\circ} \mathrm{C}$, and the resulting supernatants were analyzed for SOD, GPX and catalase performed as described previously (Janssen, Marsh, Absher, Borm \& Mossman, 1990), using standard spectrophotometric assays. AOE activity levels were corrected for changes in protein content in the different organs. CuZn-SOD was measured in chloroform/ethanol (3:5) pre-extracted samples, using the inhibition of xantine (50 $\mu \mathrm{M})$ induced cytochrome $c(10 \mu \mathrm{M})$ reduction at $415 \mathrm{~nm}$. SOD activity was calculated from a semilog plot between reaction rate and the log of a standard SOD. Samples were diluted to obtain approximately $50 \%$ inhibition (Engelen, Borm, Sprundel \& Leenaertz, 1990). Total GPx activity was measured at 340nm for 3 minutes, using $0.3 \mathrm{mM} \mathrm{H}_{2} \mathrm{O}_{2}$ induced reduction of nicotinamide adenine dinucleotide phosphate (NADPH). Catalase was measured at $240 \mathrm{~nm}$ for 3 minutes, using the linear decrease of $\mathrm{H}_{2} \mathrm{O}_{2}(10 \mathrm{mM})$ at $\mathrm{pH} 7.0$ in $50 \mathrm{mM}$ phosphate buffer. Activity was calculated using molar extinction coefficient of $0.0394 \mathrm{mmol}^{-1} \mathrm{~cm}^{-1}$.

\subsection{Tissue preparation to measure histological changes in the intestine}

Episodes of hypoxia or hyperoxia or a combination of these two factors are assumed to play a pathogenetic role in necrotizing enterocolitis. We attempted to isolate a variable by observing the histological changes in the intestine after exposure to repetitive hypoxia, six repeated insults during 5 minutes with a recovery period of 15 minutes, in the developing chick embryo incubated under normoxic or hyperoxic conditions. The insults were performed at $50 \%, 70 \%$ and $90 \%$ of the total incubation period. Chick embryos were removed from there eggs, at five different time point post-intervention $(2,4,8,16$ and 24 hours), immediately after decapitation the intestine was dissected, fixed in $10 \%$ formalin and embedded in paraffins. The morphological changes were classified by an investigator blinded from the investigation protocol. For the convenience of presentation, the morphological changes were classified in a 0 to 5 grading scale: (0) normal mucosa; (1) subepithelial space at villus tip; (2) necrose in topper villi; (3) comprehensive necrosis with preservation of the crypts; (4) transmucosal necrosis; (5) transmural necrosis. 


\subsection{Statistics}

Data are presented as mean $\pm \mathrm{SD}$. Correlations between blood flow or heart rate and the embryonic weight during development were calculated using the Spearman rank correlation. Mean $\mathrm{CABF}$, heart rate and $\mathrm{COD}$ changes during hypoxia or hyperoxia were tested by a Wilcoxon paired sample test (parameters measured under two condition). Mann-Withney-U test was used to test differences in percentage changes of mean $\mathrm{CABF}$, heart rate, response time, $\mathrm{PF}$ and $\mathrm{CABF}$ acceleration in the different stages or between the groups exposed to $100 \% \mathrm{~N}_{2}$ or $5 \% \mathrm{O}_{2}$ (independent groups). Differences in $\mathrm{AOE}$ activity in test groups were compared to the levels at the same day in the control group, using the MannWhitney U-test. The results of the grading of mucosal injury (non-parametric data) are expressed as median and interquartile range. Significance between the groups were tested with the Mann-Whitney U test. Significance was accepted when $\mathrm{P}<0.05$. 


\section{References}

Bames AE, Jensen WN (1959) Blood volume and red cell concentration in the normal chick embryo. Am J Physiol 197, 403-405.

Bartels $H_{0}$ Hiller G, Reinhardt W (1966) Oxygen affinity of chicken blood before and after hatching. Resp Physiol $11,345-356$.

Bissonnette JM, Metcalfe J (1978) Gas exchange of the fertile hen's egg: components resistance. Resp Physiol 34, 209-218.

Bradford MN (1976) A rapid sensitive method for quantization of microgram quantities of protein utilizing the method of dye binding. Anal Biochem 72, 248-254.

Dawes C, Simkiss K (1969) The acid base status of the blood of the developing chick embryo. J Exp Biol 50, $79-86$.

Drost CJ (1978) Vessel diameter independent volume measurements using ultra sound. Proceedings of the San Diego biomedical symposium, 17, 299-302.

Engelen JJM, Borm PJA, Sprundel M, Leenaertz L (1990) Blood antioxidant parameters at different stages of preumoconiosis in coal workers. Environ Health Persp 84, 165-172.

Freeman $\mathrm{BM}$, Misson $\mathrm{BH}$ (1970). $\mathrm{PH}, \mathrm{pO}_{2}$ and $\mathrm{pCO}_{2}$ of blood from the fetus and neonate of Gallus Domesticus. Comp Biochem Physiol 33, 763-772.

Girard H (1971) Respiratory acidosis with partial metabolic compensation in chick embryo blood during normal development. Resp Physiol 13, 343-351.

Hamburger $V$, Hamilton HL (1951) A series of normal stages in the development of the chick embryo. J Morphol 88, 49-98.

Janssen YMW, Marsh JP. Absher M, Borm PJA, Mossman BT (1990) Increases in antioxidant enzymes during asbestos inhalation in rats. Free Radical Res Com 11, 53-58.

Lundell A, Bergqvist D, Mattson E, Nilsson B (1993) Volume blood flow measurements with a transit time flowmeter: an in vivo and in vitro variability and validation study. Clin Physiol 13, 5.77-557.

Pearson JT, Haque MA, Hou PCL, Tazawa $\mathrm{H}$ (1996) Developmental patterns of $\mathrm{O}_{2}$ consumption, heart rate and $\mathrm{O}_{2}$ pulse in unturned eggs. Resp Physiol 103, 83-87.

Piiper J, Tazawa H, Ar A, Rahn H (1980) Analysis of chorioallantoic gas exchange in the chick embryo. Resp Physial 39, 273-284.

Prinzinger RM, Smit M, Dietz V (1995). Embryogeny of oxygen consumption in 13 altricial and precocial birds. Resp Physiol 39, 273-284.

Rahn H, Paganelli CV, A.r A (1974). The avian egg* air-cell gas tension, metabolism and incubation time. Resp Physiol 22, 297-309.

Romanoff AL (1960) Handbook: The avian embryo; structural and functional development. New York: The Macmillan Company.

Tazawa H. Piiper J, Ar A. Rahn H (1981) Changes in acid-base balance of chick embryos exposed to

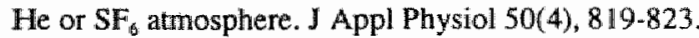

Tazawa H, Visschedijk AHJ, Wittmann J and Piiper J (1983a). Gas exchange, blood gasses and acidbase status in the chick embryo before, during and after hatching. Resp Physiol 54, 137-144.

Tazawa H. Visschedijk A.HJ, Piiper I (1983b) Blood gases and acid-base status in chicken enbryos with naturally warying egg shell conductance. Resp Physiol 54, 137-144.

Tazawa $H$, Hiraguchi $T$, Kuroda $O$, Tullett $S G$, Deeming DC (1991) Embryonic heart rate during development of domesticated birds. Physiol Zool $64(4), 1002-1022$.

Vleck C.M., Vleck D., Hoyt D.F. (1980). Patterns of metabolism and growth in avian embryos. Am Zool 20, 405-416.

White P.T. (1974). Experimental studies on the circulatory system of the late chick embryo. J Exp Biol 61, $571-592$. 


\title{
Chapter III
}

\section{The chorioallantoic artery blood flow of the chick embryo from stage 34 to 43 .}

\author{
J. van Golde, T. Mulder, H. v. Straaten and C.E. Blanco. \\ (Pediatric Research 40: 867-871, 1996)
}

\begin{abstract}
Chorioallantoic artery blood flow and heart rate were studied in the chick embryo from stage 34 until stage 43 (days $9-16$ of 21 days incubation time). Baseline blood flow profiles of the chorioallantoic artery were measured with a flow probe (Transonic) in 100 chick embryos. The eggs were opened at the air cell and placed in a small plexiglass box with a continuous gas flow of a $\mathrm{N}_{2} / \mathrm{O}_{2}$ mixture $(5 \mathrm{l} / \mathrm{min})$, at $38{ }^{\circ} \mathrm{C}$ and $60 \%$ humidity. The chorioallantoic artery was localized near the fetal abdomen and placed in the lumen of the Transonic flow probe. The heart rate was derived from the blood flow signal. The mean chorioallantoic artery blood flow rose from $0.35 \pm 0.14 \mathrm{ml} / \mathrm{min}$ (mean $\pm \mathrm{SD}$ ) at stage 34 to $3.13 \pm 1.49 \mathrm{ml} / \mathrm{min}$ at stage $43\left(R^{2}=0.69 \mathrm{p}<0.0001\right)$, which correlated with an increase in body weight ( $1.51 \pm 0.18$ to $15.08 \pm 0.76 \mathrm{~g}$ ). Heart rate increased from $195 \pm 38 \mathrm{bpm}$ at stage 34 to $289 \pm 13 \mathrm{bpm}$ at stage $43\left(\mathrm{R}^{2}=0.38 \mathrm{p}<0.0001\right)$. The chorioallantoic artery blood flow, which in avian species correlates with umbilical blood flow in mammals, increased with incubation time as reported in mammalian fetus. This study shows that the chick embryo could be useful as a preparation for further perinatal cardiovascular research.
\end{abstract}




\section{Introduction}

The avian embryo develops a structure for gas exchange with its environment that has some of the same functions as the mammalian placenta. The chorioallantoic membrane (CAM), with its capillary bed, is the respiratory organ of the chick embryo until the 19th day of incubation, at which time the embryo pips internally in the air cell and starts air breathing (Romanoff 1960). This internal pipping is the end of the prenatal period of development and initiates the transition from diffusive gas exchange of the CAM to convective gas exchange of the lungs (Romanoff 1960). Some similarities between the chick embryo and mammalian fetus have been reported, for instance (1) the chorioallantoic artery blood flow (CABF) represents about $50 \%$ of the combined cardiac output (Rahn 1985), (2) the combined cardiac output of the chick embryo is $500 \mathrm{ml} . \mathrm{kg}^{-1} \cdot \mathrm{min}^{-1}$, a value which is comparable to mammalian fetuses (Dawes 1954), (3) the distribution of the cardiac output as well as the gas tensions are also comparable to that of the sheep fetus (Rahn 1985, Olszowka 1988).

The level of gas exchange in the CAM depends on the rate of blood flow passing the exchange membrane, as in the placenta. From animal (Dawes 1954) and human fetal (Gerson 1987) studies it is known that there is an increase in umbilical blood flow with increasing gestational age. No data is available on the development of the chorioallantoic artery blood flow (CABF) of the chick embryo. In the present study chick embryos from stage 34 to stage 43 (days 9-16 of a 21 days incubation time) were used to measure the changes of the heart rate and the CABF with increasing incubation time.

\section{Methods}

Fertile White Leghorn chick eggs were incubated at $38^{\circ} \mathrm{C}$ and $60 \%$ humidity. They were rotated hourly to prevent adhesions between the embryo and its membranes (Tazawa 1981). CABF measurements from 9th to 16 th day of incubation (total incubation time 21 days), stage 34 to 43 (Hamburger and Hamilton 1951), were performed. 


\section{Preperation}

All procedures and measurements were done inside a regular clinical infant incubator, in which the temperature was kept at $38{ }^{\circ} \mathrm{C}$ and the humidity at $60 \%$. By means of transillumination the limits of the air cell were identified and cut with an electric saw. Afterwards the eggs were placed in a small plexiglass holder provided with a continuous gas flow of a $\mathrm{N}_{2} / \mathrm{O}_{2}$ mixture $(5 \mathrm{~J} / \mathrm{min})$ adjusted to $21 \%$ oxygen at $38^{\circ} \mathrm{C}$ and $60 \%$ humidity. After opening of the air cell the external membrane was visible. To visualize the vessels running in the CAM, the external membrane was made transparent using a cotton swab made wet with $0.9 \%$ saline. Using a dissection stereomicroscope (WILD 3M, total magnification 10X), the external shell membrane was removed with great care. A small incision was made in the CAM using cautery to avoid hemorrhage. The embryo was now visible in the amniotic fluid.

\section{Blood flow measurements}

Figure 1 shows schematically the embryonic circulation and demonstrates where the flow probe was placed. The overall circulation in the chick embryo is comparable to the human fetus, but there are some differences as described by White (1974). Major differences are the vitelline veins which transport the digested yolk material to the liver, and the umbilical blood which flows directly to the left hepatic vein without entering the liver substance. The dark red pulsating chorioallantoic artery was localized near the embryonic abdomen and placed in the lumen of a $0.5-\mathrm{mm}$ flow probe (0.5VB39, Transonic Systems Inc., Ithaca NY), avoiding any obstruction of the vessel. The flowmeter subtracts the downstream transit time from the upstream transit time utilizing wide-beam ultrasonic illumination. This difference between integrated transit times is a measure of blood flow rather than velocity (Drost 1978). The space between the vessel and the probe had to be filled with fluid without air bubbles or tissue in order to obtain a homogeneous ultrasound field. Because only acoustic contact is necessary, a loose fit of the probe is acceptable. This technique has been validated using mechanical calibrations or microsphere injections to measure blood flow in different vessels from several species (Bames 1983; Lundell 1993). The heart rate was derived from the blood flow signal. A hemodynamic digitalized acquisition system (sample interval $2 \mathrm{msec}$ and system trigger $2000 \mathrm{msec}$ ) was used for monitoring and saving, beat to beat, the blood flow and heart rate data. The temperature in the egg was measured using a small temperature probe (Ellab electrical thermometer, type AF6, diameter $0.8 \mathrm{~mm}$ ) placed in the amnion fluid, in order to maintain the temperature at $38{ }^{\circ} \mathrm{C}$, because of the sensitivity of the heart rate to temperature changes (Tazawa 1985; Tazawa 1986). 


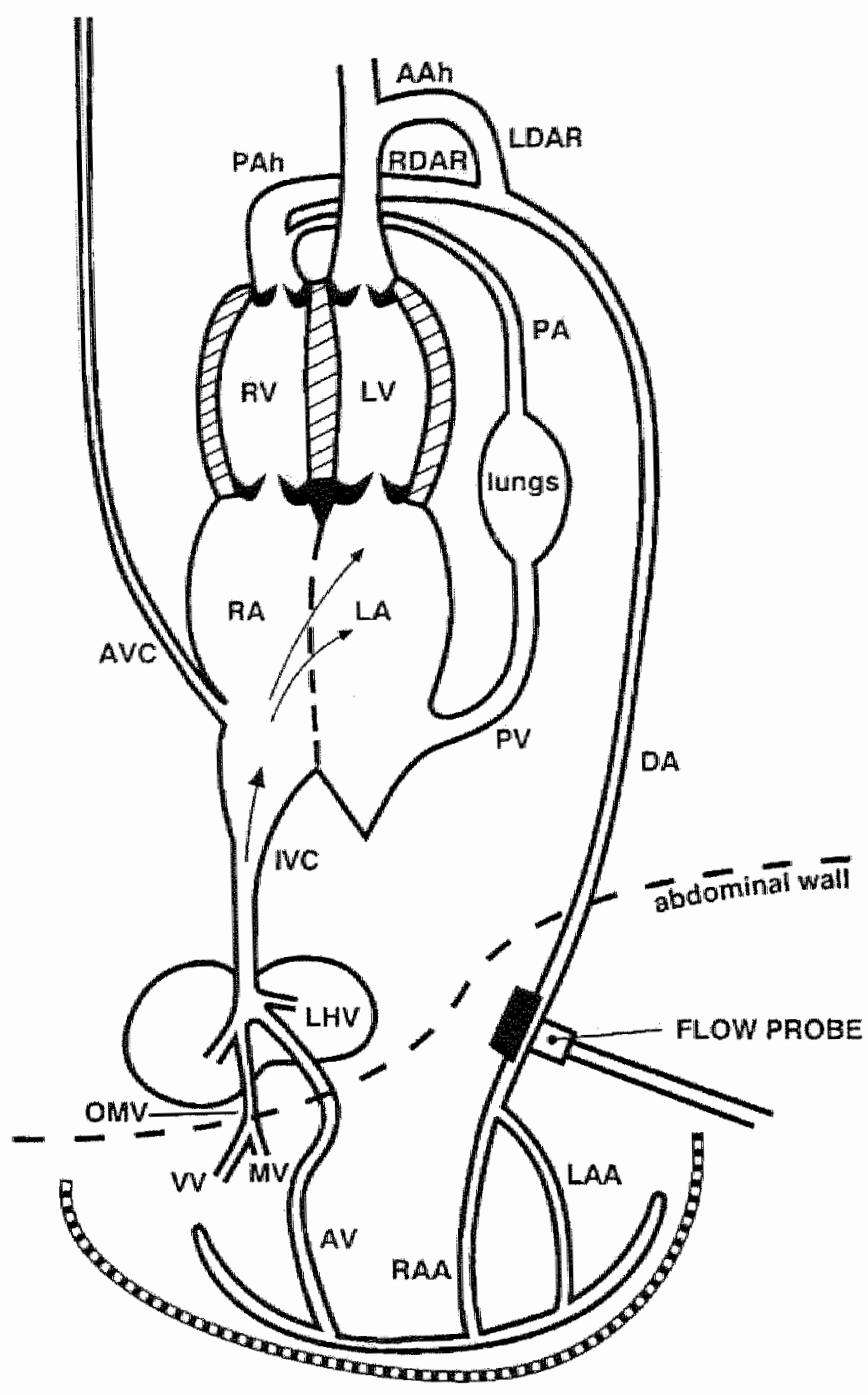

Figure 1: Schematic view of the chick embryo circulation tedrawn after Romanoff (1960) and White (1974). Abbreviatoins: Aah, aortic arch; $A V$, allantoic vein; $A V C$, anterior vena cava; DA, dorsal aorta; IVC, inferior vena cava; $L A$ and $R A$, left and right atrium; LAA and RAA, left and right allantoic artery; LDAr and RDAr, left and right ductus arteriosus; LIVV, left hepatic vein; LV and $\mathrm{RV}$, left and right ven-tricle; $M V$, mesenteric vein; $\mathrm{OMV}$, omphalomesenteric vein; $P A_{\text {, pulmonary }}$ artery; $\mathrm{PAh}$, pulmonary arch; $\mathrm{PV}$, pulmonary vein; $\mathrm{VV}$, vitelline vein. 
A total of 100 chick embryos were studied, 10 at each stage. Only those embryos which had no bleeding or malformations were included. Ten minutes recording was made after a period of stabilization of the blood flow and the heart rate. Each period of 10 minutes yielded a blood flow which was the mean value for the period. After recording embryos were removed from the egg and classified using an index of morphologic maturity (Hamburger and Hamilton, 1951). The weight of the embryo was determined using a laboratory scale (Sartorius, L2200P), after drying the embryo.

The opening of the air cell changes the diffusion gradient through the egg shell by exposing the embryo directly to the environment which could induce changes in the embryonic blood gases (Bissonette 1978). To control for this, chorioallantoic artery blood samples for $\mathrm{pH}, \mathrm{Po}_{2}$ and $\mathrm{PcO}_{2}$ were obtained from another group of chick embryos at stage $40-41 \quad(n=15)$ in which the air cell was opened for, respectively, 10,20 and 30 minutes. The embryos were kept in the same environmental conditions as the experimental group. For the samples the chorioallantoic artery was carefully lifted with forceps, and a curved 30 -gauge needle was inserted contrary the blood stream. Blood samples $(0.2 \mathrm{ml})$ were collected into heparinized syringe and analyzed at $38^{\circ} \mathrm{C}$ (Radiometer ABL3, Copenhagen).

\section{Statistical analysis}

Blood flow, the heart rate and blood gas values were expressed as mean $\pm \mathrm{SD}$. The coefficient of variation of the mean blood flow was calculated for each egg. Correlation between blood flow or heart rate and the embryonic weight was calculated using the Spearman rank correlation. Significance was accepted at $\mathrm{p}<0.01$. 


\section{Results}

To determine the effects of opening the air cell of the egg on the embryonic blood gas levels were measured at, respectively, 10,20 and 30 minutes after opening the air cell. As can be seen in table 1 the mean levels for blood $\mathrm{pH}, \mathrm{P}_{\mathrm{O} 2}$ and $\mathrm{P}_{\mathrm{CO} 2}$ did not change significantly with increasing the time of opening the air cell. The blood gas levels of our study were within the range previously reported for the chick embryo with intact air cell ( $\mathrm{pH} 7.374-7.530, \mathrm{PcO}_{2} 4.53-5.76 \mathrm{kPa}, \mathrm{Po}_{2} 2.93-4.80$ kPa) (Dawes 1969; Freeman, 1970; Tazawa 1980; Tazawa 1983a-b).

Table 1: Blood gas levels in the chick embryo 10,20 and 30 min after opening of the air cell at stage 40 and 41 .

\begin{tabular}{llll}
\hline & \multicolumn{3}{c}{ Air cell open (min) } \\
& $(\mathrm{n}=5)$ & $\begin{array}{l}20 \\
(\mathrm{n}=5)\end{array}$ & $\begin{array}{l}30 \\
(\mathrm{n}=5)\end{array}$ \\
\hline $\mathrm{PCO}_{2}$ & 4.87 & 4.15 & 4.62 \\
$(\mathrm{kPa})$ & $( \pm 0.70)$ & $( \pm 0.29)$ & $( \pm 0.94)$ \\
$\mathrm{PO}$ & 4.29 & 4.13 & 4.87 \\
$(\mathrm{kPa})$ & $( \pm 0.41)$ & $( \pm 1.01)$ & $( \pm 1.15)$ \\
$\mathrm{pH}$ & 7.42 & 7.36 & 7.38 \\
& $( \pm 0.02)$ & $( \pm 0.08)$ & $( \pm 0.09)$ \\
\hline
\end{tabular}

Results are expressed as mean $\pm \mathrm{SD}$.

Table 2 shows embryonic weight, $\mathrm{CABF}$ and heart rate at different stages. The coefficient of variation of the blood flow ranged from 1.93 to $7.8 \%$. This represented the biological and the methodological variations of the blood flow measurements. The blood flow increased 10 -fold from $0.35 \pm 0.18 \mathrm{ml} / \mathrm{min}$ at stage 34 (day 9 of incubation) to $3.13 \pm 1.49 \mathrm{ml} / \mathrm{min}$ at stage 43 (day 16 of incubation). The embryonic body weight also showed a 10 -fold increase during the same incubation period (correlation between stage and weight was $\mathrm{R}^{2}=0.875$ ). The mean ratio of $\mathrm{CABF}$ to embryonic weight did not change during the incubation. 
Table 2: CABF and heart rate of the chick embryo from stages 34 to 43

\begin{tabular}{lllll}
\hline $\begin{array}{l}\text { H-H } \\
\text { stage }\end{array}$ & $\begin{array}{l}\text { weight } \\
(\mathrm{g})\end{array}$ & $\begin{array}{l}\text { CABF } \\
(\mathrm{ml} / \mathrm{min})\end{array}$ & $\begin{array}{l}\text { heart rate } \\
(\mathrm{bpm})\end{array}$ & $\begin{array}{l}\text { CABF/weight } \\
(\mathrm{m} / \mathrm{min} . \mathrm{g})\end{array}$ \\
\hline 34 & $1.51 \pm 0.18$ & $0.35 \pm 0.14$ & $194.7 \pm 37.6$ & $0.21 \pm 0.07$ \\
35 & $2.34 \pm 0.56$ & $0.43 \pm 0.27$ & $190.4 \pm 69.5$ & $0.19 \pm 0.14$ \\
36 & $2.59 \pm 0.74$ & $0.76 \pm 0.36$ & $213.7 \pm 25.1$ & $0.30 \pm 0.17$ \\
37 & $3.80 \pm 0.63$ & $0.92 \pm 0.41$ & $252.8 \pm 29.9$ & $0.25 \pm 0.12$ \\
38 & $5.40 \pm 0.92$ & $0.88 \pm 0.31$ & $229.7 \pm 33.1$ & $0.17 \pm 0.06$ \\
39 & $6.93 \pm 1.34$ & $1.59 \pm 0.59$ & $262.8 \pm 21.9$ & $0.23 \pm 0.07$ \\
40 & $9.21 \pm 1.35$ & $2.09 \pm 0.59$ & $277.2 \pm 14.3$ & $0.25 \pm 0.07$ \\
41 & $11.55 \pm 1.40$ & $2.72 \pm 0.77$ & $290.3 \pm 14.0$ & $0.22 \pm 0.08$ \\
42 & $13.28 \pm 1.57$ & $2.53 \pm 0.73$ & $270.3 \pm 30.7$ & $0.18 \pm 0.04$ \\
43 & $15.08 \pm 0.76$ & $3.13 \pm 1.49$ & $288.8 \pm 13.5$ & $0.21 \pm 0.11$ \\
\hline
\end{tabular}

Results are expressed as mean $\pm S D ; n=10$ for all stages.

The CABF significantly correlated with the embryonic weight $\left(R^{2}=0.69\right.$ and $\mathrm{p}<0.0001$ ) (figure 2). The heart rate increased, respectively, from $194.67 \pm 37.55$ bpm at stage 34 to $288.78 \pm 13.48 \mathrm{bpm}$ at stage 43 . This increase was significantly correlated with the embryonic weight $\left(R^{2}=0.38\right.$ and $\left.p<0.0001\right)$ (figure 3 ). 


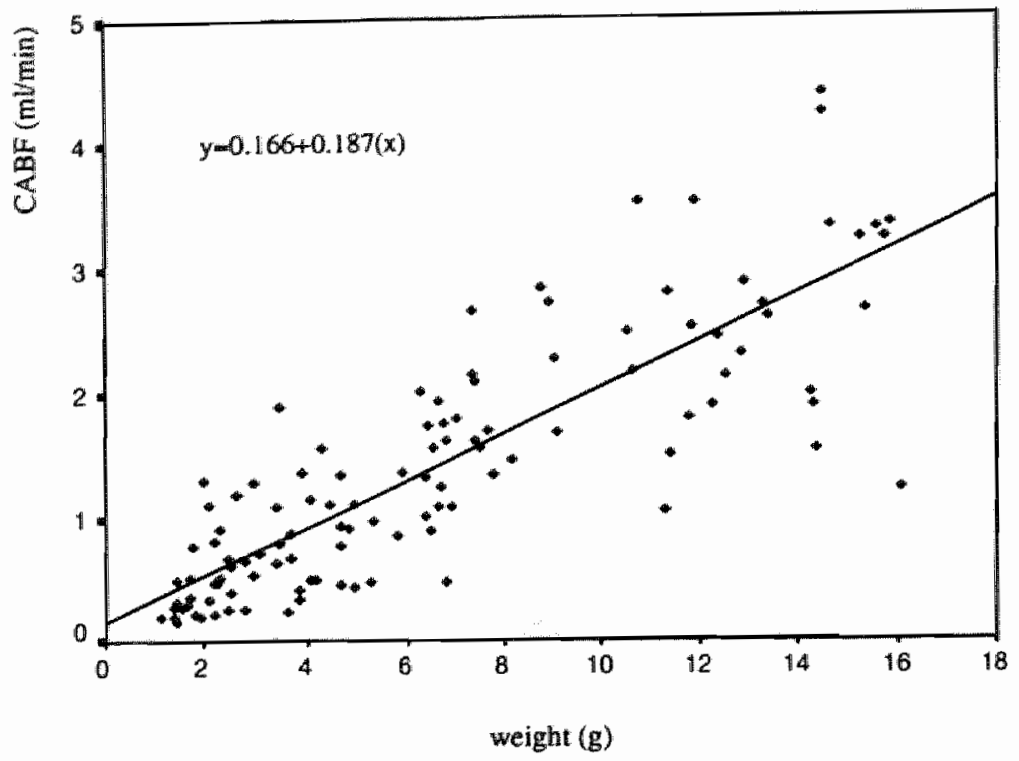

Figure 2: The $\mathrm{CABF}$ ( $\mathrm{m} / \mathrm{min}$ ) measured in the chick embryo from stage 34 to 43 (days 9-16). The CABF increases with embryonic weight $\left(\mathrm{R}^{2}=0.6886\right)$.

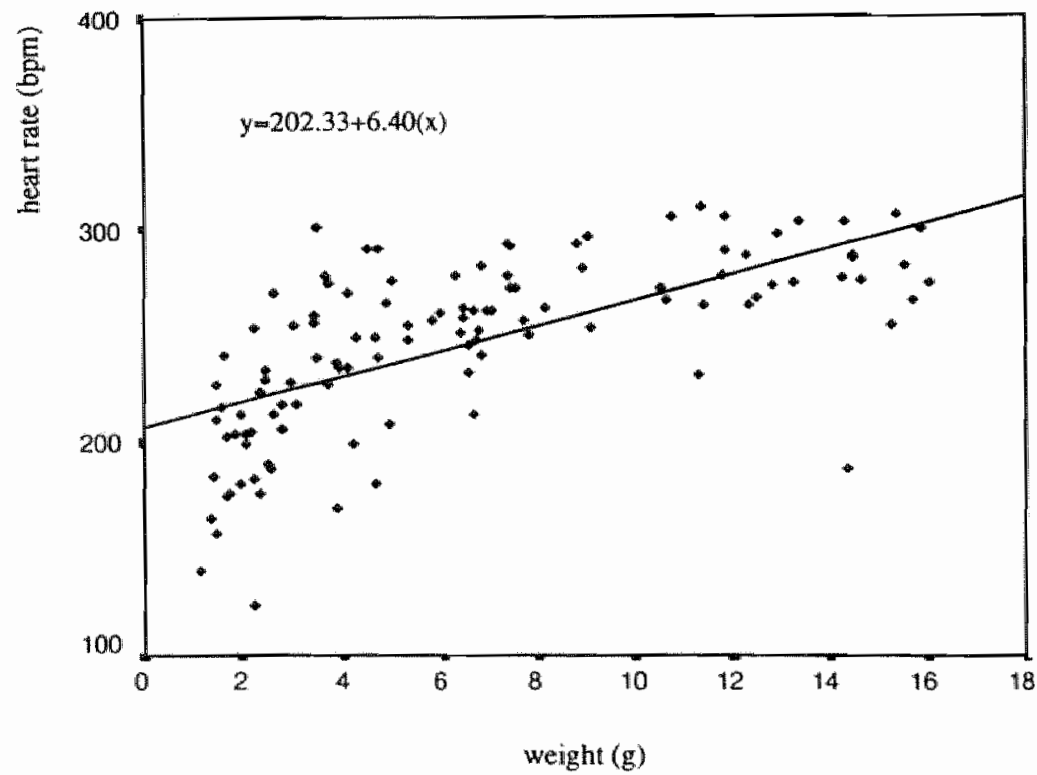

Figure 3: The heart rate (bpm) measured in the chick embryo from stage 34 to 43 (days 9-16). The heart rate increases with embryonic weight $\left(\mathrm{R}^{2}=0.3767\right)$. 


\section{Discussion}

The importance of the present study lies first, in our description of some methodological aspects of the preparation and its possible uses for hemodynamic studies during the prenatal period, and second, because we report the changes in the chorioallantoic artery blood flow and the heart rate in the chick embryo from day 9 (stage 34) to 16 (stage 43).

The chick embryo has been extensively used to answer very different questions at different stages of development. Early in development it has been used for studies of the hemodynamics of the cardiovascular system (Broekhuizen 1993; Nakazawa 1988) and the development of the central nervous system (Hu 1989). Later in development it has become an attractive model for the study of the physiology of gas diffusion and exchange (Rahn 1987; Visschedijk 1968). It has also been used for studies on the mechanisms involved in the etiology of the intestinal malformations (Tibboel 1979).

The circulation in the chick embryo is comparable to that of the mammalian fetus (Romanoff 1960; White, 1974). The left and right chorioallantoic arteries bring the deoxygenated blood into contact with CAM where gas exchange through the eggshell occurs and the chorioallantoic vein returns the oxygenated blood to the embryo. These vessels are equivalent to the umbilical circulation. After opening the air cell and the extra-embryonic membranes these vessels are of easy access. Technological developments have produced transducers that allow continuous blood flow measurements from small vessels (Drost 1978), so we thought that the chick embryo would be an attractive model for studying the development of hemodynamic variables such as CABF and heart rate at different incubation times. It would also offer possibilities for studying normal and abnormal mechanisms involved in the control of the developing circulation. The preparations necessary for these acute experiments were simple. The measurement of the blood flow was non-invasive, but all steps necessary to have access to the vessel were rather invasive. First, it is important to maintain the normal range of humidity and temperature, because of its influence on cardiovascular variables (Tazawa 1985, 1986). Second, the air cell and the external membrane had to be removed. Removing the air cell and the external membrane modifies the diffusion characteristics of the egg (Bissonette 1978). Pores of the avian egg shell are the only gas exchange organ between the developing embryo and the external environment. The passage of oxygen and carbon dioxide from and into the egg involves a series of membranes and blood barriers. When the air cell is opened hypocapnia 
might be induced, because of the higher level of the $\mathrm{P}_{\mathrm{CO} 2}$ in the air cell compared with the external environment (Visschedijk 1968). To control for that, blood samples were taken from the chorioallantoic artery after opening of the air cell for, respectively, 10,20, and 30 minutes. These time intervals were chosen to match the duration of the recordings. The values obtained for $\mathrm{PO}_{2}, \mathrm{PcO}_{2}$ and $\mathrm{pH}$ were not significantly different from those given in the literature (Dawes 1969; Freeman 1970; Tazawa 1980; Tazawa 1983a-b). However, it is important to note that both our values and those reported in the literature present great variability. Ideally it would be more accurate to measure blood gases at the beginning and at the end of the recordings to be sure that the embryonic blood gases did not change. This would require repetitive sampling from the chorioallantoic artery, which is possible (Tazawa 1980) but the use of the same vessel makes the preparation technically more complicated and the total volume of sampling, around $0.5 \mathrm{ml}$, represents $15-20 \%$ of the embryonic blood volume. This can disturb the physiological conditions of the preparation.

Our study showed an increase in the CABF and the heart rate with increasing incubation time. There was a 10 -fold increase in blood flow, from $0.35 \pm 0.18$ $\mathrm{ml} / \mathrm{min}$ at stage 34 (day 9 of incubation) to $3.13 \pm 1.49 \mathrm{ml} / \mathrm{min}$ at stage 43 (day 16 of incubation). The increase in $\mathrm{CABF}$ correlated with body weight. This correlation is not surprising since large increases in body mass will increase the total metabolic rate. This causes an increase in the chorioallantoic blood flow to achieve an adequate gas exchange and meet the new metabolic demands (Rahn 1974). Moreover it is known that the umbillical blood flow in human pregnancy increases with gestational age (Gerson 1987).

There are a few reports on the CABF measured at different incubation times. Tazawa et al. (1985) measured a CABF of $4 \mathrm{ml} / \mathrm{min}$ using an electromagnetic flow probe in chick embryos at stage 43 . This study examined the feasibility of the measurements but it did not report the number of observations or the variability of the measurements. Most information available on CABF was obtained using the Fick formula and yielded CABF of around $4.44 \mathrm{ml} / \mathrm{min}$ (Bissonette 1978; Olszowka 1988; Tazawa 1977, 1985). The measurements of the CABF obtained in our preparation using a Transonic flowmeter yield values $(3.13 \pm 1.49 \mathrm{ml} / \mathrm{min})$ that are comparable to the previous studies. The advantage of our methods is the possibility of measuring blood flow reliably and continuously for periods of 30 to 60 minutes. This offers the possibility of designing experiments to study physiological or pathophysiological mechanisms involved in embryonic cardiovascular control. This will be object of a future report. In contrast to other 
studies (Broekhuizen 1993; Romanoff 1960) we measured an increase in the heart

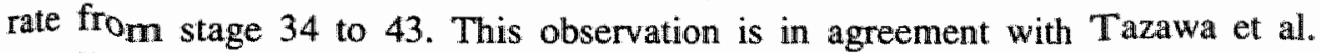
(1991). In our study the maximum heart rate at stage 43 was $288 \pm 14 \mathrm{bpm}$ which is comparable to the level of $278 \mathrm{bpm}$ at stage 43 reported by Tazawa et al. (1977, 1985). The difference in results between studies is not easy to explain but the absence of a progressive increase in heart rate in some studies could have been due to differences in ambient temperature during the recordings. Thus, the chick embryo presents a steady increase in heart rate until day 17 , which is followed by a decrease before hatching and a further increase afterwards (Romanoff 1960; Tazawa 1991). This characteristic behavior is in contrast with the gradual prenatal and postnatal decrease described in the mammalian fetus (Dawes 1954; Gerson 1987). A possible explanation for the steady increase in the heart rate in the chick embryo is the large metabolic rate per unit body weight and its increase associated with very rapid development (Prinzinger 1995; Rahn 1974), suggesting that the control of the cardiac output in the chick embryo is more dependent on heart rate than on the Starling mechanism. Furthermore, the functional autonomic innervation of the embryonic heart occurs late in the development, anatomic parasympathetic and sympathetic neurons being completely functional at stage 42 (day 16) (Higgens 1981; Pappano 1977). The increase in heart rate before this is thus associated with a relative lack of vagal control.

This study describes a technique using the chick embryo for studying $\mathrm{CABF}$ and heart rate. This technique did not interfere with gas exchange or exert obvious deleterious effect upon the embryo. The reported CABF profiles may serve as a basis for further cardiovascular research in perinatology.

\section{Acknowledgements}

The authors acknowledge Monique Broekhuizen, Dick Tibboel and Eric Heineman for their fruitful discussion, Johan Hekking and Paul van Dijk, from the Department Anatomy/ Embryology for their technical assistance. 


\section{References}

Bames RJ, Comline RS, Dobson A, Drost CJ (1983) An implantable transit-time ultrasonic blood flow meter. J Physiol 35, 2-3P.

Bissonette JM, Metcalfe J (1978) Gas exchange of the fertile hen's egg: components of resistance. Resp Physiol 34, 209-218.

Broekhuizen MLA, Mast F, Struijk PC, van der Bie W, Mulder PGH, Gittenberger deGroot $C$, Wadimiroff JW (1993) Hemodynamic parameters of stage 20 to stage 35 chick embryo. Pediatr Res $34,44-46$.

Dawes GS, Mott JC, Widdicombe JG (1954), The foetal circulation in the lamb. J Physiol 126, 563. 587.

Dawes C, Simkiss K (1969) The acid status of the blood of the developing chick embryo. J Exp Biol $50,79-81$.

Drost CJ (1978) Vessel diameter-independent volume flow measurements using witra sound. Proceedings San Diego Biomedical Symposium 17, 299-302.

Freeman, $\mathrm{BM}, \mathrm{Mission} \mathrm{BH}(1970) \mathrm{pH}_{4} \mathrm{PO}_{2}$ and $\mathrm{PCO}_{2}$ of blood from the foetus and the neonate of Gallus domesticus. Comp Biochem Physiol 33, 3.43-351.

Gerson AG, Wallace DM, Stiller RJ, Paul P, Weiner S, Bolognese RJ (1987) Doppler evaluation of umbilical venous and arterial blood flow in the second and third trimesters of normal pregnancy. Obstet Gynecol 70, 622-626.

Hamburger V, Hamilton HL (1951) A series of normal stages in the development of the chick embryo. J Morphol 88, 49-92.

Higgens D, Pappano AJ (1981) Development of transmitter secretory mechanisms by adrenergic neurons in the embryonic chick heart ventricle. Dev Biol 87, 148-162.

Hu N, Clark EB (1989) Hemodynamics of the stage 12 to stage 29 chick embryo. Circ Res 65, 16651670.

Lundell A, Bergqvist D, Maattsson E, Nilson B (1993) Volume flow measurements with a transit time flowmeter - an in vivo and in vitro variability and validation study. Clin Physiol 13, 547-557.

Nakazawa M, Miyagawa S, Ohno T, Miura S, Takao A (1988) Developmental hemodynamic changes in rat embryos at 11 to 15 days of gestation: normal data of blood pressure and the effect of caffeine compared to data from the chick embryo. Pediatr Res 23, 200-205.

Olszowka AJ, Tazawa H and Rahn H (1988) A blood-gas nomogram of the chick fetus: blood flow distribution between the chorioallantois and fetus. Resp Physiol 71, 315-330.

Pappano AJ (1977) Ontogenic development of autonomic neuroeffector transmission and transmitter reactivity in embryonic and fetal hearts. Pharmacol Rew 29, 3-33.

Prinzinger R, Schmidt M, Vollar D (1995) Embryogeny of oxygen consumption in 13 altricial and precocial birds. Resp Physiol 100, 283-287.

Rahn H, Paganelli CN, Ar A (1974) The avain egg: air cell gas tention, metabolism and incubation time. Resp Physiol 22, 297-309.

Rahn H, Matalon S, Sotherland PR (1985) Circulatory changes and oxygen delivery in the chick embryo prior to hatching. In: Johanses K and Burggren W 1985 Cardiovascular Shunts, Phylogenetic, Ontogenetic and Climical Aspects. Copenhagen: Munksgaard, pp 119-221.

Rahn H, Paganelli CV, Ar A (1987) Pores and gas exchange of avian eggs: a review. J Exp Zool 1 . $165-172$.

Romanoff AL (1960) Handbook: The avian embryo; structural and functional development. New York, pp 1111-1139. 
1 H, Mochizuki M (1977) Oxygen analyses of chicken embryo blood. Resp Physiol 31, 203215.

II H, Ar A, Rahn H, Piiper J (1980) Repetitive and simultaneous sampling from the air cell and blood vessels in the chick embryo. Resp Physiol 39, 265-272.

A (1981) Adverse effect of failure to tum the avian egg on the embryo oxygen exchange. Resp Physiol 41, 137-142.

a H. Visscchedijk AHJ, Wittmann J, Piiper J (1983A) Gas exchange, blood gases and acidbase status in the chick before, during and after hatching. Resp Physiol 53,173-185.

a H. Visschedijk AHJ, Piiper J (1983B) Blood gases and acid-base status in chicken embryos with naturally varying egg shell conductance. Resp Physiol 54, 137-144.

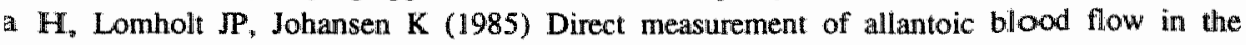
chicken, Gallus domesticus. Responses to alteration in the ambient temperature and the $\mathrm{PO}_{2}$. Comp Biochem Physiol 81 A, 641-642.

H and Takenaka $\mathrm{H}$ (1985) Cardiowascular shunt and model analysis in the chick embryo. In: Johanses K. Burggren W. Shunts, Phylogenetic, Ontogenetic and Clinical Aspects Copenhagen: Munksgaard pp $119-221$.

a H, Rahn H (1986) Tolerance of chick embryos to low temperatures in reference to the heart rate. Comp Biochem Physiol 85A, 531-534.

a H. Hiraguchi T, Kuroda O. Tullett SG, Deeming OC (1991) Embryonic heart rate during development of domesticated birds. Physiol Zool 64, 1002-1022.

"I D. Molennaar JC, Van Nie CJ (1979) New perspectives in fetal surgery" the chicken embryo. J Pediatt Surg 14, 438-440.

edijk AHJ (1968) The air space and the embryonic respiration 2. The times of pipping and hatching as influenced by an artificial changed permeability of the shell over the air space. Br Poult Sci 9, 185-196.

PT (1974) Experimental studies on the circulatory system of the late chick embryo. J Exp Biol $61,571-592$. 


\section{Chapter IV}

\section{Cardiac Output Distribution in the Chick Embryo from stage 36 to 45}

Twan LM Mulder, Jolanda C van Golde, Frits W Prinzen, Carlos E Blanco (Cardiovascular Research 34: 525-528, 1997)

\section{Abstract}

The distribution of cardiac output to different organs is well described in the mammalian fetus. Chick embryos are not often used in perinatal cardiovascular research and therefore it is not known whether they can serve as an animal model for this purpose. In this study we documented cardiac output distribution in chick embryos at increasing incubation time. Fertilized eggs from day 10 to 19 with an incubation time of 21 days were studied in three increasing incubation time groups (10-13, 14-16 and 17-19 days). For the experiment, the egg was placed in a holder in an incubator. The egg was opened at the air cell and a small vein of the chorioallantoic membrane was catheterized. Twenty thousand fluorescent $15 \mu \mathrm{m}$ microspheres in $0.2 \mathrm{ml}$ were injected. After 5 minutes, the embryo was sacrificed and the different organs were dissected and digested for microsphere isolation and subsequent fluorescence analysis. The chorioallantoic membrane, which is the placenta equivalent of the chick embryo, received a relatively large fraction of the combined cardiac output, $52.08 \%$ (Interquartile Range 12.67\%) on days 10-13 and $40.95 \%$ (IQR 27.24\%) on days 17-19. Relatively small fractions were distributed to the heart $2.03 \%$ (IQR 1.58 ) on day $10-13$ and $3.18 \%$ (IQR 1.95) on days $17-19$ and to the brain $3.20 \%$ (IQR 1.80) on days 10-13 and 5.02\% (IQR 3.39) on days 17-19. As incubation time advanced, the fraction of the combined cardiac output to the chorioallantoic membrane and yolk-sac decreased significantly in favour of the heart and brain. This distribution shows great similarity to the one found in the mammalian fetus. The chick embryo is an attractive model for perinatal cardiovascular research. 


\section{Introduction}

A fetus needs large amounts of oxygen and nutrients for development and growth. The distribution of oxygen and nutrients to the fetal organs is dependent on gas exchange area, transport vehicle and cardiac output. In the mammalian fetus, a large fraction of the cardiac output is directed to the placenta, where gas-exchange and nutrients are provided. The distribution of fetal cardiac output $(\mathrm{CO})$ has been studied in sheep (Jensen 1991; Rudolph 1970) primate (Berhman 1970) and llama fetuses (Llanos 1995) using radioactive microspheres, both under physiological conditions and abnormal events associated with birth e.g. asphyxia due to umbilical cord occlusion or hypoxia (Iwamoto 1989). The early chick embryo in particular is a well known animal model for cardiovascular research with regard to cardiac development (Clark 1989), angiogenesis (Le Noble 1993), cardiovascular pharmacology and toxicology (Bkaily 1991) and cardiovascular mechanics (Taber 1992). With regard to cardiovascular responses in the late chick embryo (e.g., cardiovascular responses to perinatal events) not much is known.

The chick embryo is not a mammalian and the main difference is the absence of placenta. In the chick embryo, gas exchange takes place in the chorioallantoic membrane (CAM). This is a well-vascularized membrane attached to the shell of the egg. This membrane, which is in direct contact with the environmental air through micropores in the shell, is the vehicle for gas exchange. Therefore, the CAM can be seen as a placenta equivalent (Metcalfe 1993). The embryonic circulation in the CAM greatly resembles the umbilical cord circulation in the mammalian fetus (Romanoff, 1960). Furthermore, the fetal shunts over ductus venosus, foramen ovale and ductus arteriosus are also present in the chick embryo. The distribution of the $\mathrm{CO}$ in the chick embryo was summarily documented by Rahn et al. (1985) using radioactive microspheres. They reported on the distribution for CAM, yolk-sac and total embryo in 18 chick embryos from day 17-19 incubation time.

For several years now, fluorescent microspheres are being used to determine organ blood flow and $\mathrm{CO}$ distribution as an alternative to radioactive microspheres (Prinzen 1994). As far as we know, this method has not been used in chick embryos. In this study we used fluorescent microspheres, injected in a chorioallantoic vein, to determine the CO distribution in the chick embryo. The aim of this study was: (a) to test the possibility of determining $\mathrm{CO}$ distribution in the chick embryo using fluorescent microspheres; (b) to examine the changes in $\mathrm{CO}$ distribution in the chick embryo during development; and (c) to evaluate whether the chick embryo is a suitable model for perinatal cardiovascular research. 


\section{Methods}

Fertilized eggs of White Leghom were incubated in a commercial incubator. The eggs were rotated constantly to avoid adhesions between the embryo and its membranes (Tazawa 1981). Incubation time until hatching for these eggs is 21 days. Since we wanted to study developmental changes we used chick embryos ranging from day 10 to day 19 of incubation time, corresponding to stage 36-45 according to Hamburger and Hamilton (1951). Three different incubation time groups were studied: 10-13, 14-16 and 17-19 days.

\section{Preparation}

To determine the distribution of the $\mathrm{CO}$, a chorioallantoic vein was catheterized to inject fluorescent microspheres. Both catheterization of the chorioallantoic vein and the injecting of fluorescent microspheres were performed in a clinical infant incubator, provided with a light microscope (WILD 3M, magnification 10x). Temperature and humidity were maintained constant at $38^{\circ} \mathrm{C}$ and $60 \%$, respectively. The eggs were candled to identify the air cell and the shell was opened with an electrical saw above the level of the CAM. After opening the egg was placed in a holder under the microscope. Now the outer shell membrane was visible. By moistening it with a $\mathrm{NaCl} 0,9 \%$ solution, the vessels of the CAM became visible. Without damaging the chorioallantoic membrane vessels, the outer shell membrane was removed. A chorioallantoic vein of approximately the same diameter was identified through its bright red collor and erythrocyte stream direction. The vein was lifted using sutures, opened with the hooked tip of a 30-Gauche needle and a polyethylene catheter, which was stretched by heat to a diameter of 100 micron, was inserted. The catheter, flushed with a heparin solution $(10 \mathrm{IU} / \mathrm{ml})$ was connected to a $1.0 \mathrm{mll}$ syringe and fixed to the egg shell with clay.

\section{Protocol}

Five minutes after catheterization, 20,000 fluorescent microspheres (Fluospheres(B) Molecular Probes Inc., Eugene, Oregon, USA) with a diameter of $15 \mu \mathrm{m}(0.2 \mathrm{ml}$ of a 100.000 microspheres $/ \mathrm{ml} 0.05 \%$ Tween 80 solution) were injected in 1 minute. The dye used was orange. After 5 minutes, the chick embryos were decapitated and the chorioallantoic membrane, brain, heart, lungs, intestine, liver and yolk sac were dissected. 


\section{Method of measurement}

We determined fluorescence in whole organs and in the remaining carcass. The tissues were placed in test tubes and digested in a $2 \mathrm{M}$ ethanolic- $\mathrm{KOH}$ solution for 48 hours at $60^{\circ} \mathrm{C}$. The microspheres were isolated from the homogenate by repeated centrifugation, removal of the supernatant and rinsing as described by van Oosterhout et al. (1995). In the final pellet the dye was extracted by adding $3 \mathrm{ml}$ of 2-(2ethoxyethoxy) ethylacetate and fluorescence was counted by fluorimetry using a LS50B fluori-spectrometer (Perkin Elmer). Since during fluorimetry all samples had the same volume $(3 \mathrm{ml})$, the absolute fluorescence measured, corrected for background, expressed the fraction of $\mathrm{CO}$ that the tissue received.

\section{Analysiss of data}

All data were processed using SPSS statistical software. Since not all data obtained were normally distributed, we found it appropriate to express the data as median with interquartile range (p25-p75). A non-parametric sample test (Mann Whitney U) was applied to compare the CO distribution within the three different groups at the different incubation times. Statistical significance was defined as $\mathrm{P}<0.05$.

\section{Results}

The placement of the catheter into the chorioallantoic vein required skill and practice. The major problems encountered were: a) difficulty to insert the catheter into the vessel lumen and $b$ ) bleeding due to damage to the vessel. Our present success rate is about $80 \%$.

We determined the $\mathrm{CO}$ distribution in a total of 72 chick embryos at different incubation times: on days 10-13 $(n=22), 14-16(n=24)$ and 17-19 $(n=26)$. None of the instrumented chick embryos showed pipping or hatching. In the chick embryo, a large fraction of the $\mathrm{CO}$ (median range for the three groups: 41-52\%) was directed to the CAM. Relatively small fractions were directed to the heart (median range: $2.0-3.8 \%$ ), brain (median range: $3.2-5.0 \%$ ), lungs (median range: $0.5-1.0 \%$ ), intestine (median range: $2.0-3.8 \%$ ), and liver (median range: $1.5-3.3 \%$ ). The fraction to the yolk-sac in the 10-13 days group is substantial (median $11.9 \%$ ), but decreases rapidly with increasing incubation time ( $\mathrm{P}<0.01$ ) (Figure 1). The $\mathrm{CO}$ distribution to the various organs changed with increasing incubation time. The fractions to the heart, brain, intestine and carcass increase significant $(\mathrm{P}<0.05)$ with increasing incubation time, whereas the fractions to CAM and yolk-sac decrease (Figure 1). 


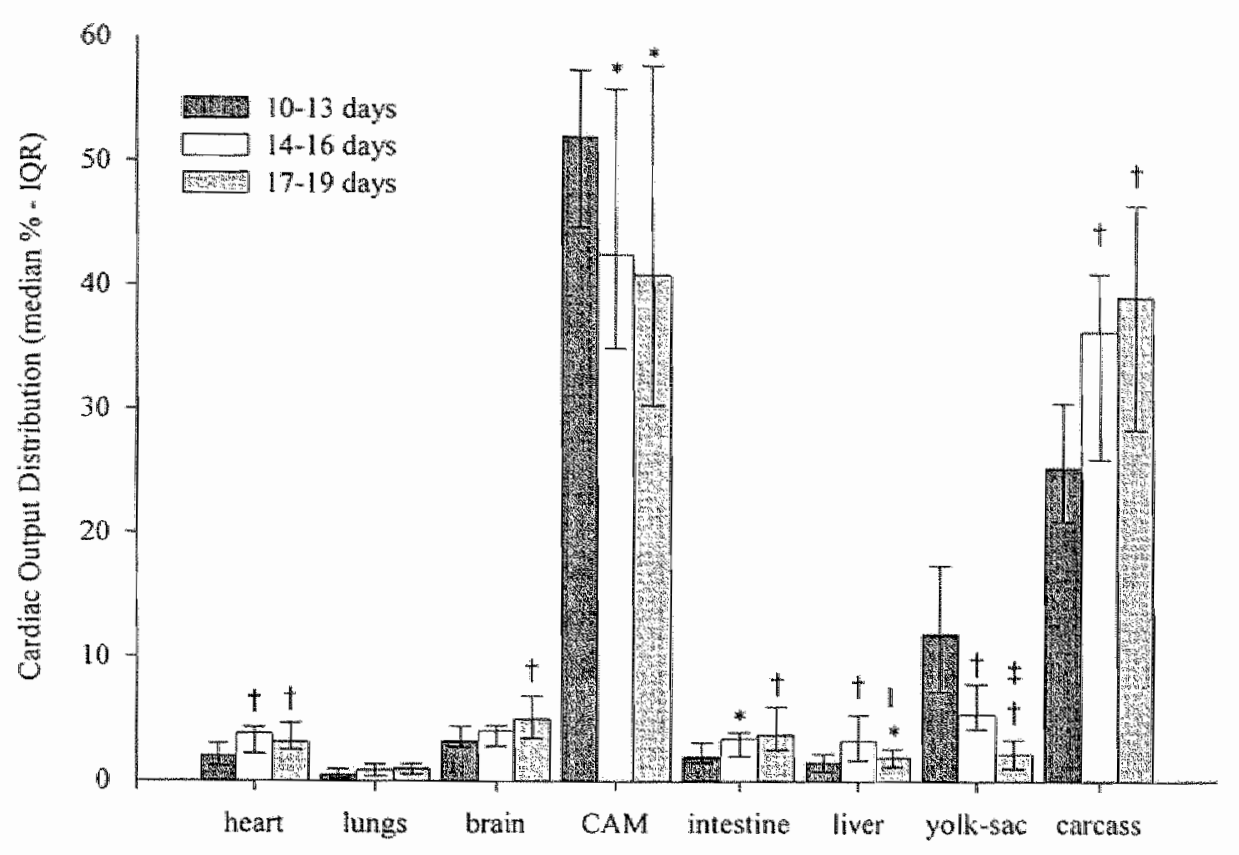

Figure 1: Cardiac output distribution for increasing incubation time. Bars represent the median, the range is the interquartile range ( 25 - p75). * Significant change $(\mathbf{P}<0.05)$ compared to 10-13 days group,

${ }^{t}$ Significant change $(\mathrm{P}<0.01)$ compared to $10-13$ days group, ${ }^{*}$ Significant change compared to 14-16 days group $(\mathrm{P}<0.05)$.

\section{Discussion}

In this study, we determined the CO distribution of the chick embryo in the second half of incubation time. Early in this period, there were two vascular beds that received the most important percentage of the combined CO: the CAM and the yolksac, both important for gas exchange and nutrition. However, later in incubation time, these percentages although remaining important, decreased in favour of other organs.

Oxygen and carbondioxide concentrations in the aircell of the egg change during incubation time. Oxygen concentration falls from $21 \%$ on day 4 to $12 \%$ on day 20 and carbondioxide concentration increases from $0.6 \%$ on day 4 to $6 \%$ on day 20 (Romijn 1938). Therefore, the opening of the egg's air cell could have had consequences on the embryonic blood gases, with a subsequent influence on the $\mathrm{CO}$ distribution. In a previous study we have shown that $\mathrm{PO}_{2}, \mathrm{PCO}_{2}$ and $\mathrm{pH}$ did not significantly change after the opening of the air cell (van Golde 1996). 
Rudolph and Heymann (1967) introduced the radioactive microsphere technique for the study of circulation in the fetal lamb. This technique is now regarded as the gold standard for determination of the $\mathrm{CO}, \mathrm{CO}$ distribution and organ blood flow. Recently, the fluorescent microspheres technique was introduced and validated, using the same principles as Rudolph and Heymann. The accuracy is similar to the radioactive microsphere method (Glenny 1993; van Oosterhout 1995). This method presents the following advantages: it does not require radioactivity and when being used in conjunction with histological techniques, offers the possibility of examining regional distributions within organs. At present, microsphere isolation and analysis is relatively time consuming (van Oosterhout 1995) but new techniques will be available in the near future. In our study, we chose to use fluorescent microspheres to determine $\mathrm{CO}$ distribution and we can now report that it is suitable for use in chick embryos; injections are possible thanks to downsizing the catheter and isolation of the microspheres and extraction of the dye is possible from chick embryo tissues.

Due to the difficult access to the chick embryo and its limited blood volume, it was impossible to take a reference blood sample simultaneously with injection of the microspheres. It was also impossible to place a flowprobe and catheterize the same embryo simultaneously. Therefore, we can not present the absolute organ flow values of individual animals. In a previous study we measured absolute blood flow to the CAM in chick embryos from day 10 to day 16 of incubation using a Transonic flow probe (van Golde 1996), and since from the present data we know the fraction of the CO to the CAM, we can estimate the mean combined cardiac output of the chick embryo from days 10-16. We calculated a mean combined CO of $472 \mathrm{ml} / \mathrm{kg} . \mathrm{min}$ (range $330-582$ ), which did not change with advancing incubation time. This is similar to the late gestation mammalian fetus (Jensen 1991).

The distribution of the $\mathrm{CO}$ in the chick embryo (16-19 days group) resembles the $\mathrm{CO}$ distribution in the near term sheep fetus (Jensen 1991). In the chick embryo the fractions of the cardiac output directed to the heart, brain, intestine and carcass are similar to the fractions found in the sheep fetus (heart: 3 vs. $3 \%$, brain: 5 vs. $3 \%$, intestine: 6 vs. $6 \%$ and carcass: 39 vs. $30 \%$ ). Also the fraction to the CAM (41\%) is similar to the fraction to the placenta $(44 \%)$ in the sheep fetus. The fractions to the lungs differ. In the chick embryo lungs receive $1.0 \%$ of the $\mathrm{CO}$ while in the sheep fetus the lungs receive $11.81 \%$.

We had expected to observe a higher fraction of the CO to the lungs in the older embryos since intemal pipping and air breathing in the chick embryo starts on around day 20. However, when opening the air cell in our experiments no internal pipping was seen. 
With increasing incubation time, we observed a change in CO distribution. The fractions to the heart, brain, liver, intestine and carcass increased significantly $(\mathrm{P}<0.05$ ). This could be explained by (a) relative lower resistance of the vascular beds in these organs. A lower vascular resistance can be the result of organ growth with subsequent growth of the vascular bed (Rudolph 1970); (b) the result of an increase in metabolic activity of these organs, demanding a greater fraction of CO controlled by local vaso-active substances producing vasodilatation (Rudolph 1970), and (c) an increase in vascular resistance in the vascular bed of the CAM and yolk sac.

Recently Hu et al. (1996) observed in early chick embryos that the CO distribution between the embryo and the extra embryonic vascular bed changed from $18.7 \%$ versus $81.3 \%$ on stage 18 to $34.2 \%$ versus $65.8 \%$ at stage 24 . Our data showed a further shift from $36 \%$ versus $64 \%$ on days $10-13$ (stages $36-39$ ) to $57 \%$ versus $43 \%$ on days $17-19$ of incubation (stages $43-45$ ). This indicates that during development of the chick embryo the fraction of the CO directed to the embryo is continuously increasing. These developmental changes were also documented in fetal sheep by Rudolph and Heymann (1970). They demonstrated in fetal lambs from 0.6 gestational age to term a significant increase in the fraction of the CO to the lungs, intestine, and brain at the expense of the placenta.

Most perinatal cardiovascular studies are performed on sheep because of the following advantages: (a) its size facilitates catheterization of fetus and (b) manipulation of its uterus does not readily trigger labor (Rudolph 1985). However, there also are some disadvantages: (a) the ewe has a long gestation (150 days); (b) it is expensive; (c) instrumentation of the fetal lamb in utero can be difficult with some failure rate and (d) it is always necessary to operate two animals: the fetus and the mother animal. Furthermore, mammalians present a close interaction between the fetus and the mother. Matemal factors can affect the fetus. The chick embryo is cheap, easy available and independent from its mother, providing an attractive model to study responses without any influence from maternal factors.

$\mathrm{CO}$ distribution in the chick embryo as determined in this study shows great resemblance to that of the mammalian fetus. Therefore, chick embryos could be considered a feasible model for further perinatal cardiovascular research. Furthermore, the fluorescent microspheres technique is appropriate to determine CO distribution. This study provides basic cardiovascular data, allowing for the design of future studies that will help in the understanding of both the consequences of hypoxia or asphyxia and their underlying mechanisms during fetal cardiovascular development. 


\section{Acknowledgments}

The authors thank Johan Hekking, Dep. Anatomy-Embryology for his assistance in instrumenting the chick embryo and Anita Rousseau, Dep. Physiology for her assistance in analyzing the fluorescence. 


\section{References}

Bkaily G, Jacques D, Sculptoreanu A, Yamamoto $T$, Carrier D, Vigneault D, Sperelakis $\mathbb{N}$ (1991) Apamin, a highly potent blocker of the TTX-and $\mathrm{Mn}^{2+}$-insensitive fast transient $\mathrm{Na}^{*}$ current in young embryonic heart. $\mathrm{J} \mathrm{Mol} \mathrm{Cell} \mathrm{Cardiol} \mathrm{23,} \mathrm{25-39.}$

Bkaily $\mathrm{G}$ (1992) Single heart cells as models for studying cardiac toxicology. In: Jolles $\mathrm{G}_{\mathrm{i}}$ Cordier $\mathrm{A}$ (eds.) In vitro methods in toxicology. Acad Press pp 289-334.

Behman RE, Lees MH, Peterson EN, de Lannoy CW, Seeds AE (1970) Distribution of the circulation in the normal and asphyxiated fetal primate Am J Obstet Gynecol 108, 956-969.

Clark EB (1989) Growth, morphogenesis and function: the dynamics of cardiac development. In: Moller $\mathbf{J H}_{n}$ Neal W, Lock $\mathbf{J}$ (eds.) Fetal, neonatal and infant heart disease. New York, AppletonCentury-Crofts, pp 1-17.

Glenny RW, Bemard S, Brinkley M (1993) Validation of fluorescent-labeled microspheres for measurement of regional organ perfusion. J Appl Physiol 74, 2585-97.

Hamburger V, Hamilton HL (1951) A series of normal stages in the development of the chick embryo. J Morpholl 88, 49-92.

Hu N, Ngo TD, Clark EB (1996) Distribution of blood flow between embryo and vitelline bed in the stage 18, 21 and 24 chick embryo. Cardiovasc Res 31, E127-E131.

Iwamoto HS, Kaufman T, Keil LC, Rudolph A (1989) Responses to acute hypoxemia in fetal sheep at 0.6-0.7 gestation. Am J Physiol 256, H613-H620.

Jensen A, Roman C, Rudolph A (1991) Effects of reducing uterine blood flow on fetal blood flow distribution and oxygen delivery. I Dev Physiol 15, 309-323.

Le Noble FAC, Schreurs NHIS, van Straaten HWM, Slaaf DW, Smits JFM, Rogg H. Struyker Boudier HAJ (1993) Evidence for a novel angiotensine II receptor involved in angiogenesis in chick embryo chorioallantoic membrane. Am J Physiol 264, R460-R465.

Llanos AJ, Riquelme RA, Moraga FA, Cabello G, Parer JT (1995) Cardiovascular responses to graded degrees of hypoxaemia in the llama fetus. Reprod Fertill Develop 7(3), 549-552.

Metcalfe J, Stock MK (1993) Current Topic: Oxygen Exchange in the Chorioallantoic Membrane, Avian Homoloque of the Mammalian Placenta. Placenta 14, 605-613.

Prinzen FW, Glenny RW (1994) Developments in non-radioactive microsphere techniques for blood flow measurements. Cardiovasc Res 28, 1467-1475.

Rahn H, Matalon S. Sotherland PR (1985) Circulatory changes and oxygen delivery in the chick embryo prior to hatching. Proceedings of cardiovascular shunts, Alfred Benzon Symposium 21, 199. 215.

Romanoff AL (1960) The avian embryo; structural and functional development. New York: The Macmillan Company 1039-1141.H725-H733.

Romijn $C_{\text {n }}$ Roos $I$ (1938) The air cell of the hen's egg and its changes during the period of incubation. J Physiol 94, 365-379.

Rudolph M, Heymann MA (1967) The circulation of the fetus in utero. Methods for studying distribution of blood flow, cardiac output and organ blood flow. Circ Res 21, 163-185.

Rudolph AM, Heymann MA (1970) Circulatory changes during growth in the fetal lamb Circ Res 26 , 289-299.

Rudolph AM, Heymann MA (1985) Methods for studying the circulation of the fetus in Litero. In:

Nathaniels $\mathrm{PW}$ (eds.) Animal models in fetal medicine (I) Perinatology Press, Ithaca pl -57.

Taber LA, Keller BB, Clark EB (1992) Cardiac mechanics in the stage 16 chick embryo. J Biomech Eng $114,427-434$.

Tazawa $\mathrm{H}$ (1981) Adverse effect of failure to turn the avian egg on the embryo oxygen exchange. Resp Physiol $41,137-142$. 
Van Golde J, Mulder T, van Straten H, Blanco CE (1996) The chorioallantoic artery blood flow of the chick embryo from stage 34 to 43 . Pediatr Res $40,867-871$.

Van Oostenout MFM, Willigers HMM, Reneman RS, Prinzen FW (1995) Fuorescent microspheres to measure organ perfusion: validation of a simplified sample processing technique. Am J Physiol 269, H725-H733. 


\title{
Chapter V
}

\section{Changes in mean chorioallantoic artery blood flow and heart rate produced by hypoxia in the developing chick embryo}

\author{
J. van Golde, T. Mulder and C.E. Blanco \\ (Pediatric Research 42: 293-298, 1997)
}

\section{Abstract}

Hypoxia in the mammalian fetus produces cardiovascular changes, such as bradycardia, systemic hypertension and changes in heart rate variability. This response was studied in 140 chick embryos ranging from stage 34 to stage 42 (days 9-16 of 21 days incubation period), by measuring the changes in mean chorioallantoic artery blood flow (CABF) and heart rate for 5 minutes in two levels of hypoxia (Group 1; $\mathrm{n}=90 ; 100 \% \mathrm{~N}_{2}$ ) or (Group 2; $\mathrm{n}=50 ; 5 \% \mathrm{O}_{2}$ ). Fertilized eggs were opened at the air cell and placed in a small plexiglass holder, which had a continuous gas flow of a $\mathrm{O}_{2} / \mathrm{N}_{2}$ mixture $(5 \mathrm{~V} / \mathrm{min})$, at $38{ }^{\circ} \mathrm{C}$ and $60 \%$ humidity. The chorioallantoic artery was placed in the lumen of a flow probe, to measure mean $\mathrm{CABF}$, heart rate, peak flow and blood flow acceleration. After baseline measurements, the gas mixture was changed to $100 \% \mathrm{~N}_{2}$ or $5 \% \mathrm{O}_{2}$ for 5 minutes. Mean $\mathrm{CABF}$ and heart rate decreased significantly in both groups (Wilcoxon paired sample test, $\mathrm{p}<0.05$ ). This response was more pronounced with the development of the chick embryo. Chorioallantoic artery peak flow (PF, $\mathrm{ml} / \mathrm{min}$ ) and CABF acceleration $\left(\mathrm{dF} / \mathrm{dt}, \mathrm{ml} / \mathrm{s}^{2}\right)$ increased with incubation time and decreased during periods of hypoxia. During recovery, heart rate returned to baseline levels whereas mean CABF showed an overshoot. The initial decrease in mean CABF and heart rate was similar in both groups. The cardiovascular response to hypoxia in the chick embryo is similar to the response in the mammalian fetus. The more pronounced response in the more developed chick embryo may represent a maturation of the cardiovascular control. 


\section{Introduction}

Reduced fetal oxygenation is an important determinant in the development of perinatal complications such as organ injury and even death after acute hypoxic events, or intra-uterine growth retardation and subsequent impaired neurodevelopment after chronic hypoxia (Rurak 1994). In the mammalian fetus, hypoxia produces a fall in heart rate mediated by an increased parasympathetic activity over the heart, due to stimulation of arterial chemoreceptors (Guissani 1994; Rurak 1994). In addition, peripheral vascular resistance increases, leading to an increase in fetal arterial pressure and further bradycardia (Rurak 1994). Furthermore, sympathetic efferent activity, blood concentrations of catecholamines and vasopressin are increased, thereby inducing a redistribution of the cardiac output in favor of the brain, heart and adrenals and at the expense of kidney, gut, carcass and lung (Guissani 1994, Rudolph 1984). These changes in cardiac output distribution are accompanied by a changing pattern of venous return and by a preferential streaming of the umbilical venous blood flow through the ductus venosus and the foramen ovale to the upper body segment. Moreover, umbilical blood flow remains constant during mild hypoxia in mature fetal lambs (Cohn 1974), but decreases during mild hypoxia at early gestational age (fetal lambs $<120$ days of gestation) (Cohn 1974) or at extremely low arterial $\mathrm{Po}_{2}$ levels at any gestational age (Walker 1976).

Lambs are used in most perinatal cardiovascular studies. To study the effects of hypoxia in the fetal lamb, the ewe must be exposed to a hypoxic gas mixture or the umbilical cord must be occluded (Guissani 1994; Rudolph 1984). These techniques can introduce variables such as, hormonal changes, acidosis and hypercapnia, which might affect chemoreceptors, vascular tone and neurohormonal mechanisms in the ewe and the fetus (Guissani 1994; Rudolph 1984). These difficulties can be avoided by using chick embryos, which develop independently of the mother. In the chick embryo, gas exchange takes place via diffusion through the micropores of the egg shell (Bissonnette 1978; Romanoff 1960). This type of gas exchange allows to induce changes in the embryonic blood gases by changing the gas composition around the egg shell.

In a previous study, we reported the measurements of the mean CABF and heart rate in chick embryos from day 9 to day 16 of incubation time (van Golde 1996). In this study, we examined whether adlaptational changes in mean CABF and heart rate occur, perhaps as a result of a chemoreflex, elicited by exposing chick 
embryos to two levels of acute hypoxia. In order to gather the data, we observed the changes in the mean $\mathrm{CABF}$ and heart rate after exposing the chick embryo either to $100 \% \mathrm{~N}_{2}$ or $5 \% \mathrm{O}_{2}$ for 5 minutes. These experiments could provide valuable data for future studies on fetal cardiovascular regulation under normal or abnormal conditions.

\section{Methods}

\section{Animal preparation}

Fertile eggs of White Leghorn were incubated at $38{ }^{\circ} \mathrm{C}$ and $60 \%$ humidity. During incubation, eggs were tumed hourly along their long axis (Tazawa 1980). The measurements were taken inside a regular infant incubator at a temperature of 38 ${ }^{\circ} \mathrm{C}$ and humidity of $60 \%$. After opening the air cell at the blunt side of the egg with an electrical saw, the egg was placed in a small plexiglass holder, which had a continuous flow of a $\mathrm{O}_{2} / \mathrm{N}_{2}$ mixture $(5 \mathrm{~V} / \mathrm{min})$ at $38{ }^{\circ} \mathrm{C}$ and $60 \%$ humidity. The chorioallantoic artery was localized near the fetal abdomen and placed in the lumen of a flow probe (0.5VB39, Transonic System Inc., Ithaca NY 14850, USA) as previously described (van Golde 1996). Temperature was monitored with a small temperature probe (Ellab electrical thermometer, type AF6, diameter 0.8 $\mathrm{mm}$ ) placed in the amnion fluid to measure embryonic temperature which was maintained at $38^{\circ} \mathrm{C}$.

\section{Experimental protocol}

Changes in the mean $\mathrm{CABF}$ and heart rate were measured before, during and after exposure to two levels of hypoxia. Group $1(\mathrm{n}=90)$ was exposed to $100 \% \mathrm{~N}_{2}$ for 5 minutes (days 9-16 of incubation time, or stages 34-42 according to Hamburger \& Hamilton (1951), and group $2(\mathrm{n}=50)$ was exposed to $5 \% \mathrm{O}_{2}$ for 5 minutes (days 9-10, stages 35-36 and days 13-15, stages 39-41). In both groups, 10 chick embryos were analyzed at each stage. Baseline levels of mean $\mathrm{CABF}$ and heart rate were measured during normoxia $\left(21 \% \quad \mathrm{O}_{2} / \mathrm{N}_{2}\right.$ gas mixture) for 10 minutes. Subsequently, the gas mixture was changed to either $100 \% \mathrm{~N}_{2}$ (Group 1) or $5 \% \mathrm{O}_{2}$ (Group 2). After 5 minutes, normoxia was re-established, and measurements were continued for 10 minutes. After the experiments, all embryos were removed from the egg, immediately decapitated, dry weighed, checked for visible external and internal malformations and classified according to Hamburger-Hamilton (1951) $(\mathrm{H}-\mathrm{H})$ stage, using an index of morphological maturity. Embryos presenting bleeding due to opening of the rich vascularized chorioallantoic membrane or visible malformations were excluded $(1 \%)$. 


\section{Data acquisition and analysis}

The flow probe used in the present work, subtracts the downstream transit time from the upstream transit time, utilizing wide-beam ultrasonic illumination. It registrates a continuous signal (Drost 1987). This difference between integrated transit times measures blood flow rather than velocity. In a former study, we found that the coefficient of variation of blood flow measurements ranged from 1.93 to $7.8 \%$, which represents the biological variation of the signal (van Golde 1996). Analog waveforms of the CABF were sampled at $500 \mathrm{~Hz}$ by a Hemodynamic Data Acquisition System (HDAS, University of Maastricht, the Netherlands). Heart rate was calculated by measuring the cycle interval time and converting this into beats per minutes (bpm). The chorioallantoic artery peak flow (PF; $\mathrm{ml} / \mathrm{min}$ ) is the maximum signal measured in the analog wave form. The $\mathrm{CABF}$ acceleration $\left(\mathrm{dF} / \mathrm{dt} ; \mathrm{ml} / \mathrm{s}^{2}\right)$ is calculated from the slope in the ascending part in the analog wave form. Inasmuch as we did not store data to analyze the $\mathrm{PF}$ and $\mathrm{CABF}$ acceleration at the beginning of the study, we can present PF and CABF data only for a certain number of chick embryos belonging to group 1 . The magnitude of the response to hypoxia was expressed as percentage change of baseline levels of mean CABF and heart rate. The response time to hypoxia $\left(t_{1}\right)$ was defined as the difference between the time of induction of hypoxia and the point of maximal decrease in mean CABF and heart rate. The mean $C A B F$ and heart rate levels during the period of hypoxia were calculated at the last minute of the period of hypoxia. Recovery time $\left(\mathrm{t}_{2}\right)$ was defined as the time needed for mean CABF and heart rate to return to the baseline levels. When an overshoot in mean $\mathrm{CABF}$ was observed during recovery, the time difference between the change to $21 \% \mathrm{O}_{2}$ and the moment of reaching maximum mean blood flow was calculated $\left(t_{3}\right)$.

\section{Statistics}

Embryonic weight, mean $\mathrm{CABF}$, heart rate, percentage changes from the baseline of mean $\mathrm{CABF}$ and heart rate, $\mathrm{PF}, \mathrm{dF} / \mathrm{dt}$ and response time were expressed as mean $\pm S D$ (at each stage $n=10$ ). Changes during hypoxia in mean $C A B F$ and heart rate were tested by a Wilcoxon paired sample test. Mann-Withney U test was used to test differences between groups exposed to $100 \% \mathrm{~N}_{2}$ or $5 \% \mathrm{O}_{2}$. Multiple comparisons between groups at the different $\mathrm{H}-\mathrm{H}$ stages were made to test differences in percentage changes of mean $\mathrm{CABF}$, heart rate, response time, $\mathrm{PF}$, and $\mathrm{CABF}$ acceleration. Bonferoni procedure was used to correct the $\mathrm{P}$-value for multiple comparisons. Significance was considered when $\mathrm{P}<0.05$. 


\section{Results}

A sudden decrease in mean blood flow and heart rate was observed after exposure to low oxygen levels $\left(100 \% \mathrm{~N}_{2}\right.$ or $5 \% \mathrm{O}_{2}$ ) (Figure 1). After returning to normoxia, mean $\mathrm{CABF}$ showed an overshoot, whereas the heart rate returned to baseline levels. The maximum fall of mean $\mathrm{CABF}$ and heart rate occured within $66 \pm 48 \mathrm{sec}$ (mean $\pm S D$ ) in both groups (table 1-2). Some embryos presented short cardiac arrhytmia. During the recovery phase, an overshoot in mean CABF was observed. The maximal mean CABF was reached within $188 \pm 100 \mathrm{sec}$ (mean $\pm S D)\left(t_{3}\right)$, and recovery occured within $61 \pm 45 \mathrm{sec}$ (mean $\pm \mathrm{SD}$ ) $\left(\mathrm{t}_{2}\right)$.
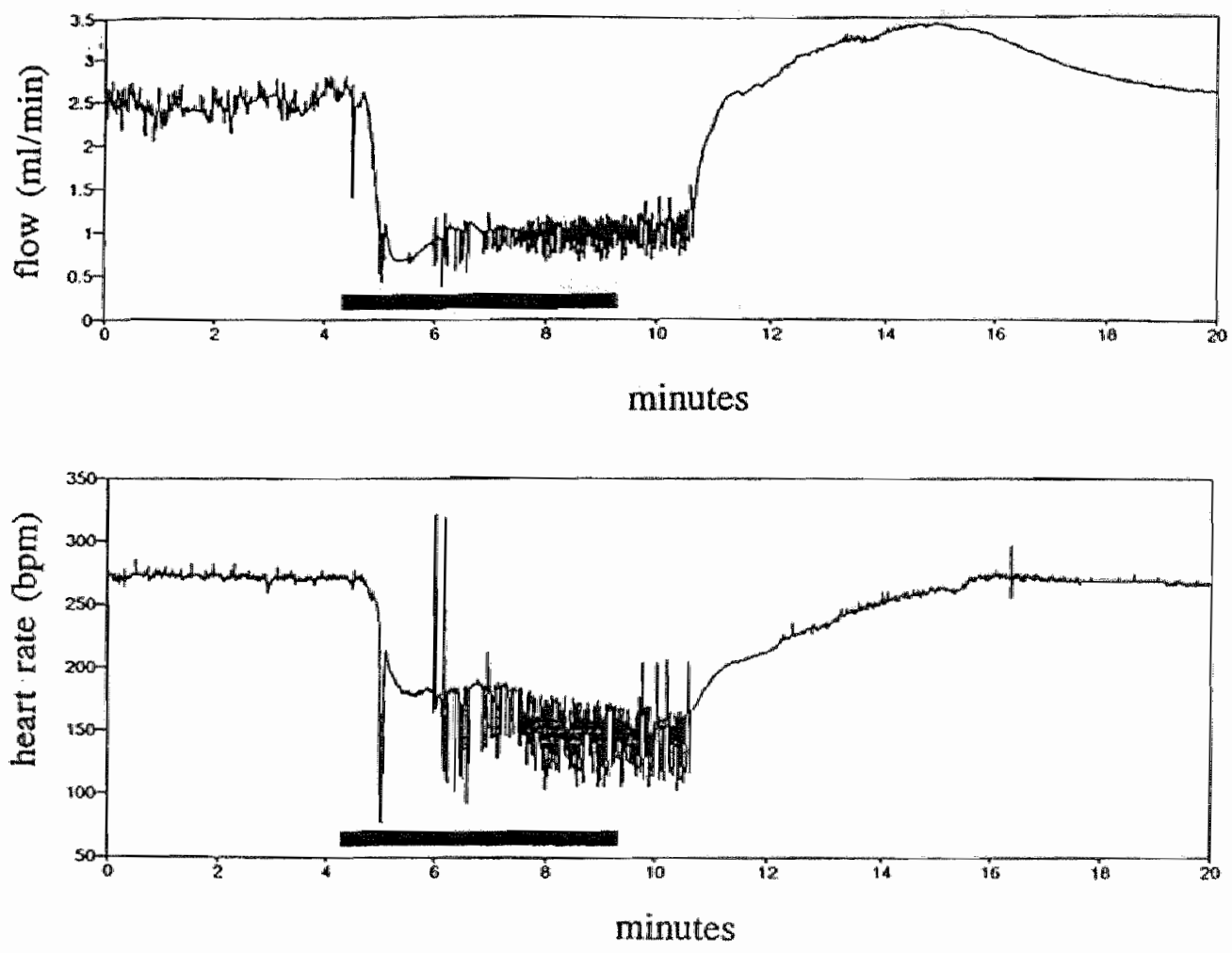

Figure 1: Recording of mean CABF (upper recording) and heart rate (lower recording) in chick embryo at stage 41 . Bar shows the time when gas mixture was changed to $100 \% \mathrm{~N}_{2}$. 
Table 1 shows embryonic weight, baseline mean CABF, heart rate, response time to anoxia (t1) and changes of mean CABF and heart rate during anoxia $\left(100 \% \mathrm{~N}_{2}\right.$, group 1). A significant decrease in mean $\mathrm{CABF}$ and heart rate was observed during anoxia (Wilcoxon paired sample test, $\mathrm{P}<0.05$ ). This decrease was significantly more pronounced in the more developed chick embryos, from stage 39 on; percentage changes in $\mathrm{CABF}$ and heart rate were respectively $-29.7 \%$ and $-4.4 \%$ in stage 34 and $-60.4 \%$ and $-40.3 \%$ in stage 42 , respectively (Mann-Whitney U test, $\mathrm{P}<0.05)$. No differences in response time were observed in different $\mathrm{H}-\mathrm{H}$ stages (Mann-Withney U test, $P>0.05$ ).

Compared with group $1\left(100 \% \mathrm{~N}_{2} ; \mathrm{n}=90\right)$, similar changes in mean CABF and heart rate at stages 35-36 and stages 39-41 were observed in group $2\left(5 \% \mathrm{O}_{2}\right.$; $\mathrm{n}=50$ ) (Table 2) (Mann-Whitney U test, $\mathrm{P}>0.05$ ). In group 2, a significant decrease in mean $\mathrm{CABF}$ and heart rate was observed during hypoxia (Wilcoxon paired sample test, $\mathrm{P}<0.05$ ). The decrease in the mean $\mathrm{CABF}$ was more pronounced in the more developed chick embryos, although not significantly different: $-39.7 \%$ in stage 34 and $-50.9 \%$ in stage 41 (Mann-Whitney $U$ test, $p>0.05$ ). In this group, the decrease in heart rate was not more pronounced in the more developed chick embryos: $-36.3 \%$ in stage 35 and $-34.4 \%$ in stage 42 (Mann-Withney-U-test, $P>0.05)$. No differences in response time were observed in the different Hamburger-Hamilton stages (Mann-Withney $U$ test, $P>0.05$ ). 
Table 1: Weight, response time (t1), and percentage changes in mean $C A B F$ and heartrateduring 5 minutes of anoxia (100\% $\mathrm{N}_{2}$, Group 1) compared to baseline in the chick embryo from stage 34 to stage 43 .

\begin{tabular}{|c|c|c|c|c|c|c|}
\hline \multirow{2}{*}{\multicolumn{2}{|c|}{$\begin{array}{l}\mathrm{H} \text {-H } \\
\text { stages weight }\end{array}$}} & \multirow[b]{2}{*}{$t 1(\sec )$} & \multicolumn{2}{|c|}{ Mean CABF } & \multicolumn{2}{|c|}{ Heart rate } \\
\hline & & & $\mathrm{mL} / \mathrm{min}$ & $\%$ change & beats/min & change \\
\hline 34 & $1.60 \pm 0.16$ & $32 \pm 7$ & $0.32 \pm 0.09$ & $-29.7 \pm 11.6^{\circ}$ & $190.5 \pm 30.5$ & $-4.4 \pm 15.87^{*}$ \\
\hline 35 & $2.20 \pm 0.46$ & $90 \pm 62$ & $0.51 \pm 0.34$ & $-42.8 \pm 3.8^{\circ}$ & $204.8 \pm 23.0$ & $-11.7 \pm 12.5^{\circ}$ \\
\hline 36 & $2.76 \pm 0.76$ & $95 \pm 62$ & $0.67 \pm 0.3$ & $-42.2 \pm 19.8^{\circ}$ & $224.6 \pm 32.6$ & $-21.5 \pm 10.4^{*}$ \\
\hline 37 & $3.55 \pm 0.56$ & $76 \pm 33$ & $0.98 \pm 0.4$ & $-41.4 \pm 15.8^{\circ}$ & $258.7 \pm 34.5$ & $-35.6 \pm 112.2^{*}$ \\
\hline 38 & $5.37 \pm 0.51$ & $68 \pm 43$ & $0.94 \pm 0.34$ & $-37.6 \pm 17.2^{\circ}$ & $241.8 \pm 37.1$ & $-36.5 \pm 8.19^{\circ}$ \\
\hline 39 & $6.86 \pm 0.41$ & $51 \pm 20$ & $1.39 \pm 0.57$ & $-47.0 \pm 13.1^{*}$ & $263.3 \pm 11.0$ & $-44.0 \pm 6.8^{*}$ \\
\hline 40 & $9.50 \pm 1.11$ & $52 \pm 29$ & $2.09 \pm 0.55$ & $-48.9 \pm 15.0^{\circ}$ & $277.6 \pm 18.6$ & $-41.6 \pm 8.8^{*}$ \\
\hline 41 & $11.98 \pm 0.64$ & $112 \pm 36$ & $2.80 \pm 0.64$ & $-54.5 \pm 10.1 "$ & $291.1 \pm 12.7$ & $-45.4 \pm 8.3^{\circ}$ \\
\hline 42 & $13.91 \pm 1.56$ & $106 \pm 88$ & $2.70 \pm 1.12$ & $-60.4 \pm 16.7^{*}$ & $269.4 \pm 12.7$ & $-40.3 \pm 14.6$ \\
\hline
\end{tabular}

Results are expressed as mean $\pm \mathrm{SD}$.

*P<0.05 compared baseline levels of CABF and heart rate, Wilcoxon paired sample test.

Table 2: Weight, response time (11), and percentage changes in mean CABF and heart rate during 5 minutes of hypoxia $\left(5 \% \mathrm{O}_{2}\right.$, Group 2) compared to baseline in the chick embryo from stage 34 to stage 43 .

\begin{tabular}{|c|c|c|c|c|c|c|}
\hline \multirow{2}{*}{\multicolumn{2}{|c|}{$\begin{array}{l}\mathrm{H}-\mathrm{H} \\
\text { stages weight }\end{array}$}} & \multirow{3}{*}{$\begin{array}{l}t 1(\mathrm{sec}) \\
55 \pm 25\end{array}$} & \multicolumn{2}{|c|}{ Mean CABF } & \multicolumn{2}{|l|}{ Heart rate } \\
\hline & & & \multirow{2}{*}{$\begin{array}{l}\mathrm{mL} / \mathrm{min} \\
0.38 \pm 0.16\end{array}$} & \multirow{2}{*}{$\begin{array}{l}\text { \% change } \\
-39.7 \pm 25.2^{*}\end{array}$} & \multirow{2}{*}{$\begin{array}{l}\text { beats } / \text { min } \\
206.4 \pm 3.4 .2\end{array}$} & \multirow{2}{*}{$\begin{array}{l}\text { o change } \\
-36.3 \pm 16.0^{\circ}\end{array}$} \\
\hline 35 & $1.78 \pm 0.42$ & & & & & \\
\hline 36 & $2.67 \pm 0.59$ & $45 \pm 27$ & $0.50 \pm 0.24$ & $-24.4 \pm 3.1^{*}$ & $194.7 \pm 21.1$ & $-26.4 \pm 10.2^{*}$ \\
\hline 39 & $7.50 \pm 0.97$ & $76 \pm 32$ & $1.42 \pm 0.61$ & $-46.6 \pm 11.7^{*}$ & $238.8 \pm 9.5$ & $-35.0 \pm 14.4^{*}$ \\
\hline 40 & $9.09 \pm 1.29$ & $4 \Perp 9$ & $2.01 \pm 0.27$ & $-47.8 \pm 17.2^{*}$ & $226.4 \pm 31.9$ & $-28.7 \pm 16.4^{\circ}$ \\
\hline 41 & $12.63 \pm 1.63$ & $43 \pm 8$ & $2.41 \pm 0.9$ & $-50.9 \pm 22.9^{*}$ & $238.5 \pm 17.6$ & $-34.4 \pm 9.1^{*}$ \\
\hline
\end{tabular}

Results are expressed as mean $\pm \mathrm{SD}$.

$* \mathrm{P}<0.05$ compared baseline levels of $\mathrm{CABF}$ and heart rate, Wilcoxon paired sample test. 
Chorioallantoic artery PF $(\mathrm{ml} / \mathrm{min})$ and $\mathrm{CABF} \mathrm{dF} / \mathrm{dt}\left(\mathrm{ml} / \mathrm{s}^{2}\right)$ were derived from the chorioallantoic blood flow signal by means of digital differentiation. Table 3 and 4 show the chorioallantoic artery $\mathrm{PF}$ and $\mathrm{CABF}$ acceleration for chick embryos exposed to $100 \% \mathrm{~N}_{2}$ or $5 \% \mathrm{O}_{2}$ (groups 1 and 2). Because we did not analyze PF and $\mathrm{CABF}$ acceleration at the beginning of the project, we can present $\mathrm{PF}$ and CABF acceleration data only for a certain number of chick embryos from group 1. $\mathrm{PF}$ and $\mathrm{dF} / \mathrm{dt}$ increased with incubation time (Tables 3 and 4) (Mann-Withney $\mathrm{U}$ test, $\mathrm{P}<0.05$ ). At all stages, except stage 41 in group 1 and stage 40 in group 2, $\mathrm{PF}$ and $\mathrm{dF} / \mathrm{dt}$ were significantly decreased during exposure to $5 \% \mathrm{O}_{2}$ (Wilcoxon paired sample test, $P<0.05$ ).

Table 3: Peak flow $(\mathrm{ml} / \mathrm{min})$ and acceleration $\left(\mathrm{ml} / \mathrm{s}^{2}\right)$ of the CABF in the dleveloping chick embryo (stage 37-41) exposed to anoxia for 5 minutes. (Results are expressed as mean \pm SD).

\begin{tabular}{|c|c|c|c|c|}
\hline \multirow{2}{*}{$\begin{array}{l}\mathrm{H}-\mathrm{H} \\
\text { stages }\end{array}$} & \multicolumn{2}{|c|}{$\begin{array}{l}\text { chorioallantoic artery } \\
\text { peak flow (ml/min) }\end{array}$} & \multicolumn{2}{|c|}{$\begin{array}{l}\text { CABF acceleration } \\
\left(\mathrm{d} / \mathrm{F} / \mathrm{dt} ; \mathrm{ml} / \mathrm{s}^{2}\right)\end{array}$} \\
\hline & normoxia & anoxia & normoxia & anoxia \\
\hline 37 & $2.4 \pm 0.8$ & $1.7 \pm 0.6^{*}$ & $47.1 \pm 15.8$ & $28.5 \pm 11.9^{*}$ \\
\hline 38 & $2.4 \pm 0.1$ & $1.9 \pm 0.4^{*}$ & $5.9 \pm 11.9$ & $42.6 \pm 18.1^{*}$ \\
\hline 39 & $3.3 \pm 1.1$ & $2.5 \pm 0.9^{\circ}$ & $66.0 \pm 20.6$ & $45.1 \pm 13.4^{*}$ \\
\hline 41 & $4.0 \pm 1.3$ & $3.4 \pm 1.5$ & $81.4 \pm 20.0$ & $70.5 \pm 26.4$ \\
\hline 42 & $5.5 \pm 1.6$ & $3.5 \pm 1.1^{*}$ & $103.7 \pm 38.3$ & $74.1 \pm 38.9^{*}$ \\
\hline
\end{tabular}

" $\mathrm{P}<0.05$ compared to normoxia period, Wilcoxon paired sample test.

Table 4: Peak flow (ml/min) and acceleration $\left(\mathrm{ml} / \mathrm{s}^{2}\right)$ of the CABF in the developing chick embryo (stage 35-41) exposed to hypoxia for 5 minutes. (Results are expressed as mean $\pm \mathrm{SD}$ ).

\begin{tabular}{|c|c|c|c|c|}
\hline \multirow{2}{*}{$\begin{array}{l}\mathrm{H}-\mathrm{H} \\
\text { stages }\end{array}$} & \multicolumn{2}{|c|}{$\begin{array}{l}\text { chorioallantoic artery } \\
\text { peak flow (ml/min) }\end{array}$} & \multicolumn{2}{|c|}{$\begin{array}{l}\text { CABF acceleration } \\
\left(\mathrm{dF} / \mathrm{dt} ; \mathrm{ml} / \mathrm{s}^{2}\right)\end{array}$} \\
\hline & normoxia & anoxia & normoxia & anoxia \\
\hline 35 & $1.1 \pm 0.3$ & $0.9 \pm 0.3^{\circ}$ & $43.6 \pm 15.0$ & $28.5 \pm 11.9^{*}$ \\
\hline 36 & $1.3 \pm 0.5$ & $1.2 \pm 0.5^{\circ}$ & $57.4 \pm 21.1$ & $40.1 \pm 18.5^{\circ}$ \\
\hline 39 & $3.1 \pm 1.1$ & $2.6 \pm 1.1^{\circ}$ & $114.1 \pm 35.5$ & $90.2 \pm 33.2^{\circ}$ \\
\hline 40 & $4.3 \pm 0.5$ & $3.6 \pm 1.0^{*}$ & $163.2 \pm 24.9$ & $129.1 \pm 38.1^{\circ}$ \\
\hline 41 & $4.7 \pm 1.5$ & $4.0 \pm 1.7^{\mathrm{m}}$ & $163.5 \pm 46.1$ & $143.8 \pm 64.7^{*}$ \\
\hline
\end{tabular}




\section{Discussion}

The major objectives of this study were: a) to observe whether the chick embryo presented a cardiovascular response elicited by decreased oxygen levels and b) whether this response, if present, was influenced either by incubation time or by level of oxygenation. The response was studied by measuring changes in mean CABF and heart rate produced by anoxia $\left(100 \% \mathrm{~N}_{2}\right)$ or hypoxia $\left(5 \% \mathrm{O}_{2}\right)$ in the chick embryo from $\mathrm{H}-\mathrm{H}$ stage 34 to 43 . The main results of this study are as follows. There was a cardiovascular response to anoxia or hypoxia, seen as a decrease in mean CABF and heart rate in the chick embryo in stages 34 to 42 . This response became more evident with advancing incubation time and was similar in both levels of oxygen studied.

Fetal cardiovascular research has been mainly performed using large mammalian fetus such as fetal lambs (Guissani 1994; Rudolph 1984; Rurak 1994). The use of chick embryos could offer some advantages over that of large animals: low costs, large number of embryos can be studied in short periods of time, gas exchange in the chick embryos takes place through micropores of the eggshell and therefore blood gases can be changed easily by exposing eggs to the desired gas concentration and with no maternal involvement.

In the present study, we measured mean $\mathrm{CABF}$, the equivalent of the umbilical artery blood flow in the mammalian fetus (Metcalfe 1993) and heart rate to characterize the cardiovascular response to hypoxia. Decreased oxygen levels $\left(100 \% \mathrm{~N}_{2}\right.$ or $\left.5 \% \mathrm{O}_{2}\right)$ induced a decrease in mean CABF and heart rate within $66 \pm$ $48 \mathrm{sec}$ (mean $\pm \mathrm{SD}$ ). No differences in response time were observed between the groups exposed to different oxygen concentrations. The magnitude of this response increased with incubation time of chick embryos, but not with the severity of hypoxia. The more pronounced percentage change in CABF and heart rate, which tails off at the end of the incubation period might be explained by a maturation of the peripheral chemoreceptors or the efferent pathways, which control the cardiovascular system as described in the fetal lamb (Wakatsuki 1992). From fetal lamb studies, it is known that hypoxia induces a complex series of changes, and that the initial cardiovascular responses in late gestational sheep fetus $>120$ day of gestation) are reflex in nature suggested by the short latency time (Guissani 1993, 1994; Hanson 1988; Rudolph 1984, Rurak 1994). During hypoxia fetal compensatory mechanisms are known to be activated in order to minimize deleterious effects (Guissani 1993; Hanson 1988). Hypoxia causes a decrease in heart rate by 
stimulation of the arterial chemoreceptors, mediated by an increase in parasympathetic activity. Also during hypoxia cardiac output is redistributed in favour of vital organs. Peripheral resistance and fetal arterial pressure increase as well, stimulating baroreceptor activity causing bradycardia. The initial reponse to acute hypoxia in the chick embryo, e.g. sudden decrease in mean CABF and heart rate, is comparable to what is observed in the mammalian fetus (Cohn 1974, Guissani 1994; Rudolph 1984; Walker 1976). Furthermore, additional information from another study performed in our laboratory, showed that the cardiac output redistribution during hypoxia in the developing chick embryo ranging from stage 34 to 43 was very similar to that described in mammalian fetus (van Golde 1996).

From adult chicken studies, it is known that receptors in the carotid body play an important role in controlling breathing, since carotid bodies contain chemoreceptors to detect low arterial $\mathrm{pO}_{2}$ and possibly elevated arterial $\mathrm{pCO}_{2}$ (Jones 1970). However, it is not known when the peripheral chemoreceptor or its afferent pathway or intergrating system in the brainstem become functional in the chick embryo. There is, however, information over the efferent pathway regulating cardiovascular control. Hu \& Clark (1989) reported that the parasympathetic and sympathetic control in the developing chick embryo was not completely functional until stage 42 (day 16) (Hu 1989). The changes in CABF and heart rate in stages 34 to 43 , observed in the present study, may therefore have been mediated by vasoactive sustances (Hu 1989). From fetal lamb studies, it is known that circulating catecholamines influence the fetal cardiovascular system prior to the development of mature sympathetic innervation (Iwamoto 1989; Jones 1970). In chick embryos, adrenergic receptors function long before the presence of autonomic nerve fibers (4th incubation day) (Clark 1985; Girard, 1973; Higgens 1981). Thus adrenergic receptors are probably important in the modulation and control of the cardiovascular system early in the development of chick embryos (Hu 1995; Nakazawa 1990; Tazawa 1992). We observed a decrease in mean CABF during hypoxia at all incubation times in the chick embryo. In contrast, in fetal lambs the umbilical blood flow is remarkably constant and unresponsive to a variety of acute stress, including fetal hypoxia (Cohn 1974; Walker 1976). In fetal lambs $>120$ days of gestation, umbilical-placental blood flow is maintained during hypoxia because other vascular beds, mainly the musculoskeletal and cutaneous areas, vasoconstrict and perfusion pressure increases (Walker 1976). However, in a study by Iwamoto et al. (1989) it was shown that in less developed fetal lambs, a peripheral vasoconstrictor response to hypoxia was largely absent (Iwamoto 1989). As a consequence, arterial blood pressure did not change significantly, and 
umbilical-placental blood flow decreased (Iwamoto 1989). This different response at different gestational ages may indicate immaturity of the chemoreceptor function, the neurohormonal modulators or the regional receptor-effector mechanisms (Iwamoto 1989; Wakatsuki 1992). Furthermore, decrease in umbilical flow was also observed during extreme hypoxia (Walker 1976). Since we did not measure arterial blood pressure, we do not know if lack of hypertension was the mechanism involved in the fall of the mean CABF observed in our study. However, we could speculate that both immaturity and the level of hypoxia played a role.

There are few studies which report cardiovascular changes produced by hypoxia in the developing chick embryo (Ar 1991; Laughlin 1978; Tazawa 1981, 1985). Due to differences in experimental conditions and embryonic age, it is difficult to compare the present results to those of previous studies. However, some aspects of the responses are comparable. Tazawa (1985) measured CABF and heart rate directly using an electromagnetic flow probe around the chorioallantoic artery. CABF was measured at the 15 th incubation day $(n=2)$ and was insensitive to hypoxic exposure (6\% and 11\% oxygen) (Tazawa 1985). However, continuation of hypoxia resulted in bradycardia, cardiac arrythmia and reduced CABF. These responses are similar to our observations. In another study heart rate and blood pressure decreased progressively with a decrease in $\mathrm{O}_{2}$ concentration (Tazawa 1981). A decrease in heart rate was also observed in chick embryos that were made hypoxic by waxing a part of the egg shell (Laughlin 1978). Other investigators reported a $31 \%$ decrease in CABF during acute hypoxia (15\% oxygen) in chick embryos at day 15 (Laughlin 1978). This is similar to our observations.

Peak flow velocity and the $\mathrm{dF} / \mathrm{dt}$ are indirect data to evaluate myocardial contractility since both parameters depend on peripheral vascular resistance (Pfeffer 1973). In both groups an increase in PF and dF/dt was observed. In group 1 mean CABF increased 3-fold, heart rate 1.05 -fold and embryo weight 4 -fold. At the same time $\mathrm{PF}$ and $\mathrm{dF} / \mathrm{dt}$ increased respectively 2 -fold from stage 35 to 41 . In group 2 mean $\mathrm{CABF}$ increased 9-fold, heart rate 1.5-fold and embryo weight 7 fold whereas $\mathrm{PF}$ and $\mathrm{dF} / \mathrm{dt}$ increased respectively 4-fold from stage 35 to 41 . This suggests an increase in stroke volume together with an increase in heart size, since mean flow increased more than heart rate. During periods of decreased oxygen levels, $\mathrm{PF}$ and $\mathrm{dF} / \mathrm{dt}$ decreased significantly and mean $\mathrm{CABF}$ fell more than heart rate, suggesting a fall in stroke volume due to a decreased myocardial performance. However, from our study, it is not possible to differentiate between 
intrinsic contractile properties of cardiac muscle and changes that occur as a result of altered preload or afterload (Pfeffer 1973).

Hypoxia induced a fast and reversible response consisting in bradycardia, decrease in mean $\mathrm{CABF}, \mathrm{PF}$ and $\mathrm{dF} / \mathrm{dt}$ in chick embryos. This response is similar to the chemoreflex described in mammalian fetus. Since in chick embryos (para)sympathetic control is not completely functional before the 16 th incubation day the response observed before this day could have been mediated by circulating catecholamines. The response to hypoxia became more pronounced at later stages of incubation suggesting maturation of afferent mechanisms such as peripheral chemoreceptors or by maturation of the (para)sympathetic cardiac control. The present work offers basic physiological data on chick embryos in the last period of development. This will allow to design future experiments to study the impact of insults during fetal life on cardiovascular development.

\section{Acknowledgements}

The authors acknowledge Department of Anatomy/Embryology and Jan Geilen for their technical assistance. 


\section{References}

Ar A, Girard H, Rodeeau JL (1991) Oxygen uptake and chorioallantoic blood flow changes during acute hypoxia and hyperoxia in the 16 day chicken embryo. Resp Physiol 83, 295-312.

Bissonnette JM, Metcalfe J (1978) Gas exchange of the fertile hen's egg: components of resistance. Resp Physiol 34, 209-218.

Clark EB, Hu N, Dooley JB (1985) The effect of isoproterenol on cardiovascular function in the stage 24 chick embryo. Teratology 31, 41-47.

Cohn HE, Sacks EJ, Heyman MA, Rudolph AM (1974) Cardiovascular responses to hypoxemia and acidemia in fetal lambs. Am J Obstet Gynecol 120,817-824.

Drost CJ (1987) Vessel diameter independent volume flow measurements using ultrasound. Proceedings San Diego Biomedical Symposium 17, 299-302.

Girard H (1973) Adrenergic sensitivity of circulation in the chick embryo. Am J Physiol 224, 461 469.

Giussani DA, Spencer AD, Moore PJ, Bennet L, Hanson MA (1993) Afferent and efferent components of the candiovascular reflex responses to acute hypoxia in term fetal sheep.

J Physiol 461, 431-449.

Guissani A, Spencer JAD, Hanson MA (1994) Fetal cardiovascular reflex responses to hypoxaemia. Fetal and Maternal Medicine Review 6,17-37.

Hamburger V, Hamilton HL (1951) A series of normal stages in the development of the chick embryo. J Morphol 88, 209-218.

Hanson MA (1988) The importance of baro- and chemoreflexes in the control of the fetal cardiovascular system. J Dev Physiol 10, 491-511.

Higgens D. Pappano J (1981) Development of transmitter secretory by adrenergic neurons in the embyonic chick heart ventricle. Dev Bioll 87, 148-162.

Hu N. Clark EB (1989) Hemodynamics of the stage 12 to 29 chick embryo. Circ Res 65, 1665-1670.

Hu N, Hansen AL, Clark EB, Keller BB (1995) Effect of atrial natriuretic peptide on diastolic filling in the stage 21 chick embryo. Pediatr Res 37, 465-468.

Iwamoto HS, Kuafman T, Keil LC, Rudolph AM (1989) Responses to acute bypoxemia in fetal sheep at 0.6-0.7 gestation. Am J Physiol 256, H613-H620.

Jones DR, Purves MJ (1970) The effect of carotid body denervation upon the respiratory response to hypoxia and hypercapnia in the duck. J Physiol $211,295-309$.

Metcalfe J, Stock MK (1993) Current topic: oxygen exchange in the chorioallantoic membrane, avian homoloque of the mamalian placenta. Placent $14,605-613$.

Laughlin KF (1978) The effects of restricted gas exchange on embryo heart rate. In:Piiper J (eds.)

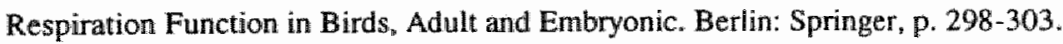

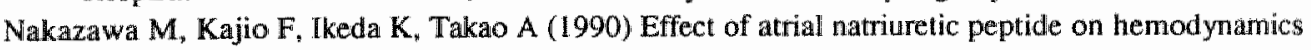
of the stage 21 chick embryo. Pediatr Res 27, 557-560.

Pfeffer MA, Frohlich ED (1973) Hemodynamic and myocardial function in young and old normotensive and spontanously hypertensive rats. Circ Res 32, suppl 1, 28-35.

Romanoff AL (1960) Handbook: The avian embryo, structural and functional development. New York, pp 1041-1140.

Rudolph AM (1984). The fetal circulation and its response to stress. J Dev Physiol 6, 11-192.

Rurak DW (1994) Fetal oxygenation, carbon dioxide homeostatis, and acid-base balance. In: Thorburn GD. Harding R (eds.) Textbook of fetal physiology, Oxford University Press Inc., New York, pp $131-139$. 
Tazawa H (1980) Adverse effect of fallure to tum the awian egg on the embryonic oxygen exchange. Resp Physiol 41, 137-142.

Tazawa $\mathrm{H}(1981)$ Effect of $\mathrm{O}_{2}$ and $\mathrm{CO}_{2}$ in $\mathrm{N}_{2}$, He and $\mathrm{SF}_{6}$ on chick embryo blood pressure and heant rate. J Appl Physiol 51, 1017-1022.

Tazawa H (1985) Direct measurement of allantoic blood flow in the chick, Gallus Domesticus, responses to alteration in ambient temperature and $\mathrm{PO}_{2}$. Comp Biochem Physiol 81, 641-642.

Tazawa H, Hashimoto $Y$, Doil K (1992) Blood pressure and heart rate of the chick embryo (Gallus domesticus) within the egg. Responses to autonomic drugs. In: Hill RB, Kuwasawa $\mathrm{K}$, McMahon BR, Kuramto T (eds.): Phylogenetic Models in Functional Coupling of the CNS and the Cardiovascular Systemi. Comp Physiol. Basel, Karger, 11: pp 86-96

van Golde $\mathbb{J}_{3}$ Mulder $\mathrm{T}$, Blanco CE (1996A) Cardiovascular changes in response to acute hypoxia in the chick embryo from stage 34 to 43 . I Physiol 494, 30P.

van Golde $\mathbb{J}_{\text {, }}$ Mulder T, van Straaten $\mathbf{H}_{3}$ Blanco CE (1.996B) The chorioallantoic artery blood flow of the chick embryo from stage 34 to 43 . Pediatr Res 40, 867-871.

Wakatsuki A, Murata $Y_{*}$. Ninomiya $Y$, Masaoka N, Tyner JG, Kutty KK (1992) Autonomic nervous system regulation of baseline heart rate in the fetal lamb. Am J Obstet Gynecol 167, 519-523.

Walker AM, Oakes G, Ehrenkranz RA, McLaughlin MK, Chez RA (1976) Effects of hypercapnia on uterine and umbilical circulations in conscious pregnant sheep. J Appl Physiol 41, 727-733. 


\title{
Chapter VI
}

\section{Cardiac output distribution in response to hypoxia in the chick embryo in the second half of the incubation time}

\author{
A.L.M. Mulder, J.C. van Golde, F.W. Prinzen, C.E. Blanco \\ (Journal of Physiology 508 (part 1): 281-287, 1998)
}

\section{Abstract}

The fetus develops cardiovascular adaptations to protect vital organs in situations such as hypoxia and asphyxia. These include bradycardia, increased systemic blood pressure and redistribution of the cardiac output. The extent to which they involve matemal or placenta influences is not known. The objective of the present work was to study the cardiac output distribution in response to hypoxia in the chick embryo, which is independent of the mother. Fertilized eggs were studied on three incubation times (10-13 days, 14-16 days and 17-19 days of a normal incubation time of 21 days). Eggs were placed in a plexiglas box in which the oxygen concentration could be changed. Eggs were opened at the air cell and a chorioallantoic vein was catheterized. Cardiac output distribution was measured with $15 \mu \mathrm{m}$ fluorescent microspheres injected during normoxia, during the last minute of a 5 minute period of hypoxia and after 5 minutes of subsequent reoxygenation. Hypoxia caused a redistribution of the cardiac output in favour of heart $(+17 \%-+160 \%$ of baseline) and brain $(+21 \%-+57 \%$ of baseline) at the expense of liver $(-3 \%-65 \%$ of baseline), yolk sac $(-46 \%-77 \%$ of baseline) and carcass $(-6 \%-33 \%$ of baseline). The magnitude of the changes in cardiac output distribution to the heart, brain, liver and carcass in response to hypoxia increased with advancing incubation time. The data demonstrate the development of a protective redistribution of the cardiac output in response to hypoxia in the chick embryo from day 10 of incubation. 


\section{Introduction}

Hypoxia produces a range of protective mechanisms in the mature fetus, in particular effects on the cardiovascular system (Giussani 1988; Hanson 1988). The first component of the response to acute hypoxia involves a chemoreflex, mediated by the peripheral (particularly the carotid) arterial chemoreceptors: their activation initiates an increase in vagal efferent activity to the heart, which produces a bradycardia, and an increase in sympathetic activity, which produces a vasoconstriction in the carcass and a rise in systemic blood pressure. Endocrine mechanisms then contribute to the response, in particular the rise in fetal plasma vasopressin and catecholamines, which contribute to the bradycardia and the vasoconstriction respectively (Rurak 1978; Cohen 1984). In addition, the rise in blood pressure may contribute to the bradycardia via a baroreflex, but the fall in heart rate is only transient and $\beta$-adrenergic influences to the heart produce an increase in heart rate after a few minutes of hypoxia.

In contrast to the fall in blood flow to the carcass, blood flow to vital organs, particularly the brain, heart and adrenal glands, increases (Cohn 1974; Peeters 1979). This appears to be mediated predominantly by the release of local vasodilator substances such as NO (van Bel 1995) and adenosine (Kurth 1992). The description above concentrates on responses initiated within the fetus. However, because the experimental production of fetal hypoxia usually necessitates making the mother (Boddy 1974) or the placenta (Jensen 1991) hypoxic, it is possible that a substantial component of the fetal responses are not initiated in the fetus itself. For example, hypoxia might produce a rise in maternal catecholamines (Boddy 1974) which will easily cross the placenta. Substances such as prostaglandins (Thorburn 1992) will also be produced by the placenta during hypoxia and can enter the fetal circulation to produce cardiovascular effects.

Therefore, we decided to study the response to hypoxia in the chick embryo, a developing animal that is independent of its mother in that gas exchange takes place by diffusion through micropores in the egg shell to the vascular bed in the chorioallantoic membrane (CAM), which can be seen as an equivalent to the placenta (Metcalfe 1993). The chick embryo has the advantage that hypoxia can be simply induced by lowering the oxygen concentration of its environment, it has a short incubation time, is relatively resistant to infections, gives easy access to the arteries and veins of the CAM, and is cheap. Therefore, the chick embryo is an attractive animal model for perinatal cardiovascular research. 
Not much is known about the response of the chick embryo to hypoxia during the second half of its incubation period, although Tazawa (1981) reported a decrease in heart rate and blood pressure in response to hypoxia in embryos at 14-16 days. In a previous study, we found that heart rate and blood flow to the CAM decreased in response to hypoxia in chick embryos at 9-16 days (van Golde 1996). This fall in blood pressure appears to contrast with the fetus, in which hypoxia produces an increase.

The aim of the present study was to examine whether the redistribution of the $\mathrm{CO}$ in response to hypoxia in the chick embryo is similar to that found in the mammalian fetus and to examine whether the response to hypoxia changes during the development of the chick embryo. This would permit us to evaluate further the use of the chick embryo for perinatal cardiovascular research by using fluorescent microspheres.

\section{Methods}

White Leghom fertilized eggs were incubated in a commercial incubator at a temperature of $38^{\circ} \mathrm{C}$ and a humidity of $60 \%$. Eggs were rotated constantly to avoid adhesions between embryo and its membranes (Tazawa 1981). For White Leghorn eggs, incubation time until hatching is 21 days. In the present study, we used chick embryos of 10-19 days incubation, corresponding to stages 36-45 of Hamburger and Hamilton (1951). To document the response to hypoxia, we used 35 chick embryos at three different incubation times: 10-13 days $(n=10), 14-16$ days $(n=13), 17-19$ days $(n=12)$.

\section{Preparation}

To determine the distribution of the $\mathrm{CO}$, a chorioallantoic vein was catheterized for injections of fluorescent microspheres. Both catheterisation of the chorioallantoic vein and the injection of fluorescent microspheres were performed in a clinical infant incubator, provided with a light microscope (WILD $3 \mathrm{M}$, magnification $10 \mathrm{x}$ ). Temperature and humidity were maintained constant at $38^{\circ} \mathrm{C}$ and $60 \%$ respectively. Eggs were opened with an electrical saw at the air cell and placed in a holder within a Plexiglas box. The oxygen concentration in the box was changed by supplying different mixtures of $\mathrm{O}_{2}$ and $\mathrm{N}_{2}$ at a constant flow of $5 \mathrm{~V} / \mathrm{min}$. After opening the shell. the outer shell membrane became visible. Moistening the CAM with a $\mathrm{NaCl} 0.9 \%$ solution made its vessels visible. Without damaging the chorioallantoic membrane vessels, the outer shell membrane was removed. A chorioallantoic vein was identified by its bright red colour and erythrocyte flow direction. The vein was lifted using 
sutures, opened with the tip of a 30 Gauge needle and a polyethylene catheter, stretched by heat to a diameter of $100 \mu \mathrm{m}$, was inserted. The catheter, flushed with heparin used saline $(10 \mathrm{IU} / \mathrm{ml})$, was connected to a $1.0 \mathrm{ml}$ syringe and fixed to the egg shell with clay.

\section{Protocol}

For the measurement of $\mathrm{CO}$ distribution, fluorescent microspheres were used (Fluospheres Molecular Probes Inc., Eugene, Oregon, USA) with a diameter of $15 \mu \mathrm{m}$. Spheres were suspended in saline and $0.05 \%$ Tween $80(100,000 \mathrm{spheres} / \mathrm{ml})$. Five minutes after catheterisation, $0.2 \mathrm{ml}(20,000$ spheres) of the suspension of orange fluorescent microspheres was injected. One minute later, the oxygen concentration was changed to $0.0 \%$ by supplying $100 \% \mathrm{~N}_{2}$ to the box. In the last minute of a 5 minute period of hypoxia, 20,000 yellow-green fluorescent microspheres were injected. Normoxia was re-established and after 5 minutes in reoxygenation 20,000 red fluorescent microspheres were injected. The chick embryos were decapitated immediately after the experiment without any prior manipulation and the CAM, brain, heart, lungs, intestine, liver and the yolk sac were dissected.

Since we injected $0.6 \mathrm{ml}$ fluid in each experiment, it could have affected the $\mathrm{CO}$ distribution in the embryo. Furthermore, the injected microspheres could have occluded part of a vascular bed, which could have effects on the distribution of the following microsphere injection. In order to document any effect of the volume and amount of microspheres injected, we carried out the same protocol as described above without changing the environmental oxygen supply in 11 chick embryos, in three incubation time groups: $10-13$ days: $n=3,14-16$ days: $n=4,17-19$ days: $n=4$.

In a further group of chick embryos at incubation time 13-15 days $(\mathrm{n}=8)$, blood samples were obtained for blood gas analysis by puncturing the chorioallantoic artery. $\mathrm{pH}$ and $\mathrm{PO}_{2}$ values were determined after 2 and 5 minutes of hypoxia. Values were corrected for embryo temperature.

\section{Microspheres distribution of measurement}

Organs and remaining carcass were digested in test tubes in a $2 \mathrm{M}$ ethanolic- $\mathrm{KOH}$ solution. The microspheres were isolated from the homogenate by centrifugation, a method shown to result in recovery of close to $100 \%$ of microspheres (van Oosterhout 1995). The dye was extracted with $3 \mathrm{ml}$ of 2-(2-ethoxyethoxy) ethylacetate and the fluorescence measured by fluorimetry using a LS-50B fluorospectrometer (Perkin, Elmer). No correction for spectral overlap was used since the excitation and emission spectra of the three dyes were well separated. During fluorimetry, all samples had the 
same volume of $3 \mathrm{ml}$. The fraction of the $\mathrm{CO}$ that was directed to the tissue was expressed as the level of the fluorescence, corrected for background, of the sample divided by the sum of fluorescence of all tissues.

\section{Analysis of data}

All data were processed using SPSS statistical software. Since not all data obtained were normally distributed, we expressed it as median with interquartile range. For analysis of the changes in CO distribution in response to hypoxia, a non-parametric sample test (Wilcoxon signed rank test) was applied. For analysis of changes during development, we used the Mann Whitney $U$ rank sum test. Significance was accepted by $\mathrm{P}<0.05$.

\section{Results}

To study the possible effects of the amount of microspheres and the volume injected during the experiment, we determined the $\mathrm{CO}$ distribution after each of three injections of fluorescent microspheres without changing the environmental oxygen supply. We did not find any statistically significant difference between the $\mathrm{CO}$ distributions measured after each injection for each organ and each incubation time. In normoxia a large fraction of the cardiac output was directed to the CAM (median range for the three groups: $40.5-55.6 \%$ ) with relatively small fractions directed to the heart (range: $1.7-4.0 \%$ ), lungs ( range: $0.4-1.1 \%$ ), brain (range: $3.0-4.2 \%$ ), intestine (range: $1.9-3.6 \%$ ), and liver (range: 1.3-3.1\%) (Figure 1).

The exposure of the egg to $100 \% \mathrm{~N}_{2}$ induced an isocapnic hypoxaemia with mean $\mathrm{PaO}_{2}$ values after 2 minutes of $9.3 \mathrm{~mm} \mathrm{Hg}$ (IQR: $6.4-11.2 \mathrm{mmHg}$ ) and after 5 minutes of $8.1 \mathrm{mmHg}$ (IQR: 7.3-10.1 mmHg) with pH values of 7.43 (IQR: 7.41-7.45) and 7.41 (IQR: 7.41-7.43) respectively. 


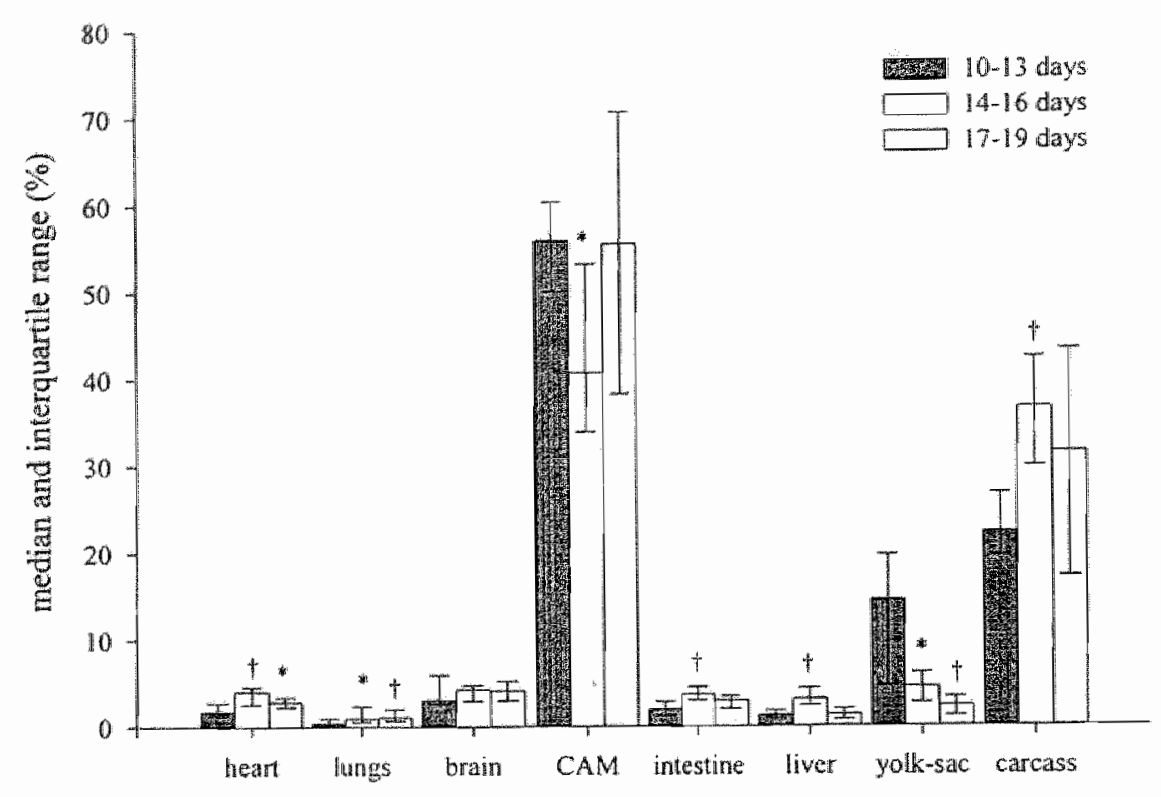

Nigure 1: Cardiac output distribution tor increasing incubation time. Bars represent median with interquartile range ( $\mathrm{p} 25$-p 75). ${ }^{*} \mathrm{P}<0.05$ compared with 10-13 days group; ${ }^{\dagger} \mathbf{P}<0.01$ compared with $10-13$ days group.

In response to hypoxia, we found a redistribution of the cardiac output in favour of heart, brain and CAM at the expense of intestine, liver, yolk-sac and carcass in all groups except in the 10-13 days group (Table 1 and Figure 2). The fractions of $\mathrm{CO}$ directed to heart and brain in both the 14-16 and the 17-19 days groups increased significantly $(\mathrm{P}<0.05)$. The fraction distributed to the CAM increased in the 14-16 days group, but not in the 17-19 days group. The fractions to liver, yolk-sac and carcass decreased in the 14-16 day group in response to hypoxia. In the 17-19 days group, the fractions to intestine, liver and carcass decreased. The changes observed in the organs of the youngest 10-13 days group were statistically not significant and the fraction of the CO directed to the lungs did not change in any group. 


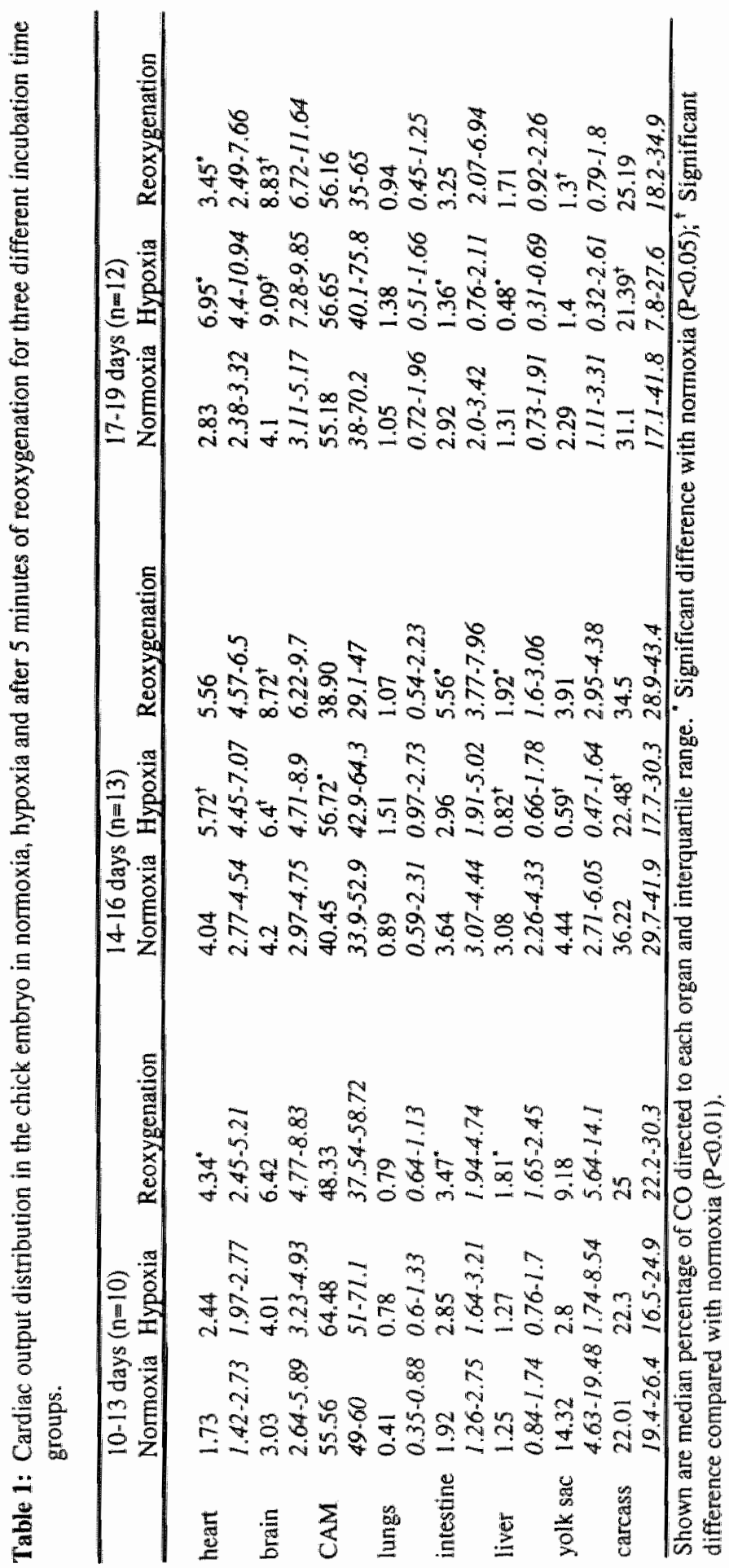



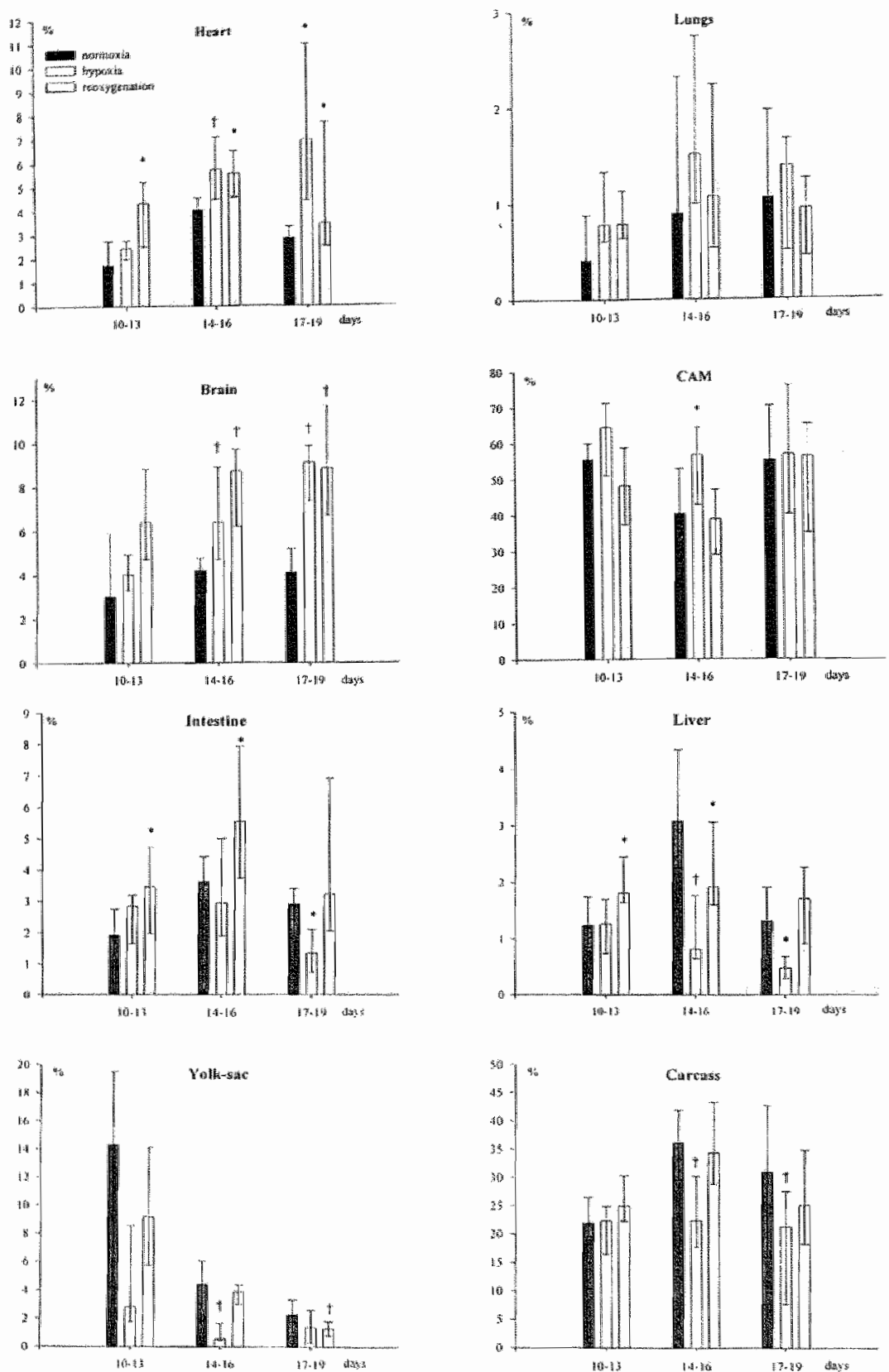

Figure 2: Cardiac output distribution in the chick embryo in nomoxia, hypoxia and after 5 minutes of reoxygenation for three different incubation time groups. Bars represent median percentage of $\mathrm{CO}$ directed to each organ and interquartile range (p25-p75). ${ }^{*}$ Significant difference compared to normoxia $(p<0.05)_{n}{ }^{\dagger}$ Significant difference compared to normoxia $(p<0.01)$. 
Five minutes after the start of reoxygenation, we found that $\mathrm{CO}$ distribution had still not retumed to baseline level (Table 1 and Figure 2). The fraction of the CO directed to the heart was significantly greater than baseline level $(P<0.05)$ in all three groups. The same was found for the fractions to the brain in the 14-16 days and 17-19 days groups. In the organs in which flow had fallen in hypoxia, it increased during reoxygenation, even being significantly greater than control in the intestine in the 1013 and 14-16 days groups and liver in the 10-13 days group. Flow remained below control in the yolk sac in the 17-19 days group.

The magnitude of the response expressed as percentage of baseline level increased with increasing incubation time. We found a statistically significant $(\mathrm{P}<0.05)$ increase in response between the 10-13 day group and the 17-19 day group for heart, brain, intestine, liver and carcass (Figure 3 ).

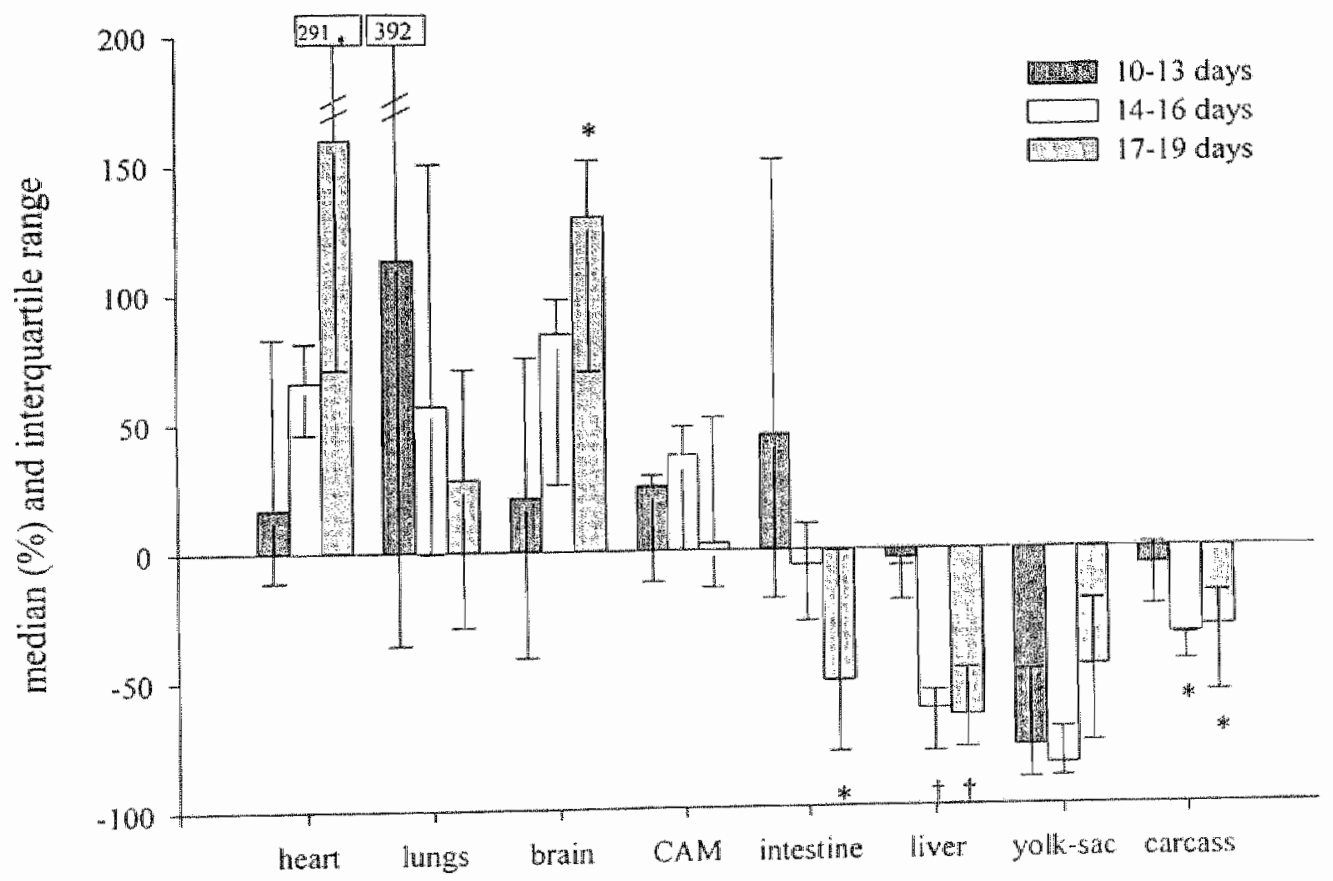

Figure 3: Magnitude of response to hypoxia for increasing incubation time. Bars represent median change expressed as percentage of baseline level with interquatile range (p25-p75). "P<0.05 compared with 10-13 days group; ${ }^{4} \mathrm{P}<0.01$ compared with 10-13 days group. 


\section{Discussion}

In the present study, we found that there was a redistribution of the $\mathrm{CO}$ in response to hypoxia in the chick embryo after 13 days of incubation. During hypoxia the fractions of the CO directed to heart, brain and CAM increased at the expense of intestine, liver, yolk sac and carcass. The increase in the fraction directed to the heart ranged from $17 \%$ to $160 \%$ to the brain from $21 \%$ to $130 \%$ and to the CAM from $3 \%$ to $37 \%$ of baseline level. The changes in the 10-13 days group were not statistically significant, but became larger and significant in the older groups. This suggests that there is a development in the compensatory ability of the chick embryo to provide oxygen delivery to these vital organs under hypoxic conditions. The redistribution of the $\mathrm{CO}$ in response to hypoxia, favouring the heart and brain at the expense of intestine, liver and carcass is similar to that found in mammalian fetuses of the sheep (Jensen 1991; Peeters 1979), mesus monkey fetus (Jackson 1987) and llama (Giussani 1996). Since the chick embryo is independent of the mother, the similarity in response to hypoxia suggests that in the mammalian fetus such responses may occur independently of maternal or placental factors.

The magnitude of the response to hypoxia increased significantly $(\mathrm{P}<0.05)$ as incubation time advanced. In the youngest (10-13 days) group, there was no change compared to baseline ( $>0.05$ ). However, the magnitude of the response in the older groups increased significantly $(\mathrm{P}<0.05)$. These data suggest a maturation of this protective reflex in the second half of the incubation time. Iwamoto et al. (1989) have described a similar maturation in the response to hypoxia in the sheep fetus, comparing the response at 0.6 gestation with that at 0.7 gestation and near term. In the 0.6 gestation sheep fetus there was no change in blood flow to the carcass in response to hypoxia, whereas in the 0.7 gestation fetus there was a decrease in blood flow to the carcass, suggesting that peripheral vasoconstrictor response have developed by this time (Iwamoto 1989). Not much is known about the development of oxygen sensitive chemoreceptors, like the aortic and carotid bodies, during gestation, but it is reported that afferent chemoreceptor activity is present in fetal sheep at 90 days of gestation ( 0.6 gestation) (Blanco 1984). In the chick embryo sympathetic nerve axons reach the heart at day 13 but they do not release sufficient neurotransmitter to change cardiac function until day 16 (Hu 1989). Parasympathetic neurons reach the heart at day 13 but are also not functional until day 16 (Hu 1989). However, adrenergic and cholinergic receptors have been identified in the myocardium and peripheral vascular beds as early as day 3 (Hu 1989). Girard (1973) demonstrated an increasing blood pressure response to noradrenaline in the chick embryo from day 6 to 17 . It is not yet clear how much hormonal and neural 
mechanisms contribute to the distribution of the $\mathrm{CO}$ during hypoxia in the developing chick embryo. Further studies are being conducted to answer this question.

The cardiac output distribution determined after 5 minutes of reoxygenation differs from baseline level in some tissues. The fraction of the $\mathrm{CO}$ directed to heart, brain, intestine and liver were above baseline and those to CAM, yolk sac and carcass were below baseline. In a previous study, we reported an overshoot in CAM blood flow during reoxygenation, after a 5 minute period of hypoxia (van Golde 1996). This suggests that in the reoxygenation phase, $\mathrm{CO}$ increases and blood flow to heart, brain, intestine and liver increase, providing more oxygen and nutrients to these tissues than in normoxia before hypoxia. The effect may be the result of circulating catecholamines and local factors as nitric oxide and adenosine released during the hypoxia period and the immediate posthypoxic period. Recently, a similar response was reported in the 0.75 gestation sheep 1 hour after an 8 hour period of hypoxia (Richardson 1996), in that heart rate and carcass blood flow were increased compared with baseline. They did not find increased blood flow to the brain. Interestingly, we observed changes in $\mathrm{CO}$ distribution in the reoxygenation phase in the youngest (1013 days) group, whereas we did not observe a response to hypoxia in this group. An explanation might be that the vasodilatory properties of the different vascular beds develop at an earlier stage than the vasoconstrictory properties.

Under normoxic conditions, the distribution of $\mathrm{CO}$ in the chick embryo is comparable to that reported in the sheep fetus. Two vascular beds received major percentage of the combined cardiac output: the CAM and yolk-sac, responsible for gas exchange and nutrient delivery to the chick embryo respectively, and therefore comparable to the placenta in the mammalian fetus (Metcalfe 1993). Relatively small fractions are distributed to heart, brain, lungs and abdominal organs. This distribution of the cardiac output is similar to the data we previously found in a larger group of chick embryos (Mulder 1997). A similar distribution was reported in the late gestation sheep fetus by Jensen (1991).

In this study we found that in the second half of its incubation time, the chick embryo is a feasible animal for perinatal cardiovascular research in that determining $\mathrm{CO}$ distribution in normoxia, hypoxia and after reoxygenation using fluorescent microspheres is possible.

Fluorescent microspheres were introduced and validated for the study of $\mathrm{CO}, \mathrm{CO}$ distribution and organ blood flow and their accuracy is similar to that of the radioactive microspheres method. They have the advantage that they do not require 
radioactivity. (Glenny 1993; van Oosterhout 1995) but a slight disadvantage is that the dye concentration can not be measured directly. Instead, microspheres have to be isolated from the tissues by digestion. This was successful in all chick embryo tissues in the present and previous study (Mulder 1997) as for many organs of adult animals (van Oosterhout 1995). The microspheres method would permit determination of absolute organ blood flow data if an arterial reference blood sample could be obtained simultaneously with the microspheres injection. This was not possible due to the difficult access to the chick embryo and the limited blood volume; therefore we are unable to present actual organ blood flow rates. In order to document any effect of the microspheres and volume injection itself we examined 11 chick embryos, in which we injected the same three dyes of microspheres in the same volume, without inducing hypoxia. Since no significant change was observed we conclude that the injection of fluorescent microspheres and the volume injected did not affect the measurement of the $\mathrm{CO}$ per se.

During incubation, oxygen and carbon dioxide concentrations in the air cell of the egg change. Oxygen concentration falls from $21 \%$ on day 4 to $12 \%$ on day 20 and the carbon dioxide concentration increases from $0.6 \%$ on day 4 to $6 \%$ on day 20 (Romijn 1938). Therefore, the opening of the air cell of the egg could have had consequences on the embryonic blood gases, influencing $\mathrm{CO}$ distribution. However, in a previous study we could not demonstrate any change in arterial $\mathrm{pO}_{2}, \mathrm{pCO}_{2}$ and $\mathrm{pH}$ resulting from the opening of the air cell (van Golde 1996). We showed that the chick embryo shows a redistribution of the $\mathrm{CO}$ in response to hypoxia and subsequent reoxygenation. Hypoxia favours blood flow to heart and brain at the expense of intestine, liver, yolk sac and carcass. The observed redistribution of the $\mathrm{CO}$ in reponse to hypoxia is not significant on 10-13 days incubation time but develops during the last third of incubation. In the reoxygenation phase $\mathrm{CO}$ is redistributed in favour of heart, brain, intestine and liver compared to baseline measurements, a response which is already present on 10-13 days of incubation.

The present study provides a feasible animal model for hypoxia studies in perinatal cardiovascular research, due to its simplicity and the independence of the chick embryo from maternal influences. This model opens new possibilities for future studies that will help us to understand the consequences of hypoxia and asphyxia and their underlying mechanisms during fetal cardiovascular development.

\section{Acknowledgements}

We thank the staff of the laboratories of Anatomy-Embryology and Physiology for their assistance in the study. 


\section{References}

Bel F van, Sola A, Roman C, Rudolph A M (1995) Role of nitric oxide in the regulation of the cerebral circulation in the lamb fetus during normoxemia and hypoxemia. Biol Neonate 68, 200-210.

Blanco C E, Dawes GS, Hanson M A, Mc Cooke H B (1984) The response to hypoxia of arterial chemoreceptors in fetal sheep and new-bom lambs. J Physiol 351 25 -37.

Boddy $\mathbf{K}$, Dawes GS, Fisher $\mathbf{R}$, Pinter S, Robinson IS (1974) Foetal respiratory movements, electrocortical and cardiovascular responses to hypoxaemia and hypencapnia in sheep. J Physiol 243 , $599-618$.

Boddy K, Jones CT, Mantell C, Ratcliffe JG, Robinson JS (1974) Changes in plasma ACTH and Corticosteroid of the Maternal and Fetal Sheep During Hypoxia. Endocrinology 94, 588-59 I.

Cohen WR, Piasecki GJ, Cohn HE. Young JB, Jackson BT (1984) Adrenal secretion of catecholamines during hypoxemia in fetal lambs. Endocrinology 114, 383-390.

Cohn HE, Sacks EJ, Heymann MA, Rudolph AM (1974) Cardiovascular responses to hypoxemia and acidemia in fetal lambs. Am J Obstet Gynecol 120, 817-824.

Girard H (1973) Adrenergic sensitivity of circulation in the chick embrya. Am J Physiol 224, 461-469.

Giussani DA, Spencer JAD, Hanson M A (1994) Fetal cardiovascular reflex responses to hypoxaemia. Fetal and Matemal Medicine Review 6, 17-37.

Giussani DA, Riquelme RA, Moraga FA, Mc Garrigle HH, Gaete CR, Sanhueza EM, Hanson MA, Llanos AJ (1996) Chemoreflex and endocrine components of cardiovascular responses to acute hypoxemia in the llama fetus. Am J Physiol 271, R73-R83.

Glenny RW, Bernard S, Brinkley M (1993) Validation of fluorescent-labeled microspheres for measurement of regional organ perfusion. Appl Physiol 74, 2585-2597.

Hamburger V, Hamilton H L (1951) A series of normal stages in the development of the chick embryo. J Morphol 88, 49-92.

Hanson M A (1988) The importance of baro- and chemoreflexes in the control of the fetal cardiovascular system. J Devel Physiol 10, 491-511.

Hu N, Clark EB (1989) Hemodynamics of the stage 12 to stage 29 chick embryo. Circ Res 65, 1665 1670.

Iwamoto HS, Kaufman T, Keil L C, Rudolph AM (1989) Responses to acute hypoxemia in fetal sheep at 0.6-0.7 gestation. Am J Physiol 256, H613-620.

Jackson BT, Piasecki GJ, Novy MJ (1987) Fetall responses to altered maternal oxygenation in rhesus monkey. Am J Physiol 252, R94-R 101.

Jensen A, Roman C, Rudolph AM (1991) Effects of reducing uterine blood flow on fetal blood flow distribution and oxygen delivery. J Devel Physiol 15, 309-323.

Kurth CD, Wagerle L, C (1992) Cerebrovascular reactivity to adenosine analoques on 0.6-0.. 7 gestation and near-term fetal sheep. Am J Physiol 262, H1 338-H1342.

Metcalfe J, Stock M K (1993) Current Topic: Oxygen Exchange in the Chorioallantoic Membrane, Avian Homoloque of the Mammalian Placenta. Placenta 14,605-613.

Mulder A LM, van Golde JC. Prinzen FW, Blanco C E (1997) Cardiac output distribution the chick embryo stage 36 to 45. Cardiovasc Res $34,525-528$.

Peeters LLH, Sheldon R E, Jones MDJ, Makowski EL, Meschia G (1979). Blood flow to fetal organs as a function of arterial oxygen content. Am J Obstet Gynecol 135, 637-646.

Richardson B, Korkola S, Asano H, Challis J, Polk D, Fraser M (1996) Regional blood flow and the endocrine response to sustained hypoxemia in the preterm ovine fetus. Pediatr Res 40, 337-343.

Romijn C, Roos J (1938). The air space of the hen"s egg and its changes during the period of incubation. J Physio: 94, 365-379. 
Rirak DW (1978) Plasma vasopressin levels during hypoxaenia and the cardiovascular effects of exogenous vasopressin in foetal and adult sheep. I Physiol $277,341-357$.

Tazawa $H$ (1981) Adverse effect of failure to turn the avian egg on the embryo oxygen exchange. Resp Physiol $41,137-142$.

Tazawa $\mathrm{H}$ (1981) Effect of $\mathrm{O} 2$ and $\mathrm{CO} 2$ in $\mathrm{N} 2$, He and SF6 on chick embryo blood pressure and heant rate: J Appl Physiol 51, 1017-1022.

Thorbum GD (1992) The placenta, PGE 2 and parturition. Early Human Development 29, 63-73.

Van Golde J, Mulder T, Blanco CE (1996) Changes in mean chorioallantoic blood flow and heart rate elicited by hypoxia in the developing chick embryo. Pediatr Res 39, 69A.

Van Golde J, Mulder T, Van Straaten H, Blanco CE (1996) The chorioallantoic artery blood flow of the chick embryo from stage 34 to 43 . Pediatr Res 40, 867-871.

Van Oosterhout MFM, Willigers HMM, Reneman R. S, Prinzen FW (1995). Fluorescent microspheres to measure organ perfusion: validation of a simplified sample processing technique. Am J Physio] 269, H725-733. 


\section{Chapter VII \\ Hyperoxia and local organ blood flow in the developing chick embryo}

Jolanda MCG van Golde, Twan ALM Mulder, Esther Scheve, Frits W Prinzen, Carlos E Blanco (Accepted Joumal of Physiology)

\section{Abstract}

Hyperoxia can cause local vasoconstriction in adult animal organs as a protective mechanism against hyperoxia-induced toxicity. It is not known at what time in development this vasoconstrictor capacity is present. Therefore, we measured the cardiac output $(\mathrm{CO})$ distribution in different organs during a period of acute hyperoxia $\left(100 \% \mathrm{O}_{2}\right)$ in the developing chick embryo. Fertile eggs were divided into five incubation time groups (10-11,12-13,14-15, 16-17 and 18-19 days of a normal incubation time of 21 days). Eggs were opened at the air cell and a branch of the chorioallantoic vein was catheterized for injections of $15 \mu \mathrm{m}$ fluorescent microspheres during normoxia and at the end of 5 min (test group 1 (TG1), $\mathrm{n} \approx 39$ ) or $20 \mathrm{~min}$ (test group 2 (TG2), $\mathrm{n}=21$ ) of hyperoxia exposure $\left(100 \% \mathrm{O}_{2}\right.$ ). The fraction of $\mathrm{CO}$ to a organ was calculated as the ratio of the fluorescence of the organ sample and that of the sum of all organs. Only in embryos of 18-19 days old, hyperoxia did cause a decrease in fraction of $\mathrm{CO}$ to the heart and carcass, and an increase to the yolk sac and CAM. This response was more pronounced after 20 min (TG2) then after $5 \mathrm{~min}$ (TG1) of hyperoxia with an additional decrease in fractions of $\mathrm{CO}$ to the brain, intestine and liver (TG2). These data indicate that local mechanisms for hyperoxia induced vasocon-striction in the heart, brain, liver, intestine and carcass develop late, after $85 \%$ of incubation time, in the developing chick embryo. 


\section{Introduction}

The response to hypoxia in the developing fetal lamb (see for review Giussani 1994; Hanson 1988; Jensen 1991) is characterized by hypertension, bradycardia and cardiac output $(\mathrm{CO})$ redistribution to the heart, brain and adrenals at expense of peripheral organs. A comparable response has been observed in the developing chick embryo when exposed to anoxia (Mulder 1998; van Golde 1997). Organs that are crucial to fetal survival, the brain, heart and adrenals, respond directly to local changes in $\mathrm{PO}_{2}$ to maintain $\mathrm{O}_{2}$ delivery at the expense of delivery to other areas of the body. Blood flow to the peripheral organs, decreases secondary to increases in activity of the sympathetic nervous system and increases in catecholamine and vasopressin concentrations (Hanson 1988). In contrast, as described in adults the response to hyperoxia is the opposite of that to hypoxia. Increases in $\mathrm{PaO}_{2}$ cause a decrease in the fraction of the $\mathrm{CO}$ to the brain, heart and adrenals, probablly as a result of local vasoconstriction (Ashwal 1984; Bendeck 1992; Blanco 1988; Gleason 1988; Iwamoto 1987; Jackson 1987; Lundstrфm 1995; Menke 1993; Peeters 1979). However, this response was observed in adults and late in gestation fetuses, but it is unknown at what time vasoconstriction occurs in response to hyperoxia exposure during development.

Oxygen is not only life giving but might also be toxic during hyperoxic conditions due to increased production of reactive oxygen species (ROS), therefore it is important to regulate the oxygen supply. Hyperoxia and the resulting increase in aerobic metabolism are known to generate ROS that can interact with proteins, DNA and lipids resulting in cellular oxidative damage (Frank 1985; Saugstad 1990). Several harmful effects of hyperoxia have been observed after oxygen treatment of newborn babies, such as bronchopulmonary dysplasia, retinopathy of prematurity, necrotizing enterocolitis and patent ductus arteriosus (Saugstad 1990). A vasoconstrictor response during hyperoxia might serve two goals: regulation of tissue oxygen supply (Iwamoto 1987) and protection against an increase in metabolic rate (Frank 1985).

Because the chick embryo has been shown to be a feasible model in fetal physiology due to easy controllable gas exchange, rapid development compared to the fetal sheep (Mulder 1998, van Golde 1997), this model was used to determine the changes in the fractions of $\mathrm{CO}$ to different organs in response to an increased arterial $\mathrm{PO}_{2}$ level, during the second half of the incubation period in the chick embryo. The first aim was to determine the age when the vasoconstriction response to 5 minutes of hyperoxia was present. The second aim was to determine 
the temporal effects of the response by applying two different durations of hyperoxia exposure ( 5 or 20 minutes exposure to $100 \% \mathrm{O}_{2}$ ) in the older groups.

\section{Methods}

\section{Animals}

Fertilized White Leghorn eggs were incubated at $38{ }^{\circ} \mathrm{C}$ and $60 \%$ humidity. During incubation, eggs were turned hourly along their long axis to prevent adhesions between the embryo and its membranes and to avoid abnormal development (Pearson 1996; Tazawa 1981). Chick embryos were studied during second half of the incubation period, corresponding to stage 36 to 44 , according to Hamburger and Hamilton (1951). To document the response to 5 minutes of hyperoxia we studied 39 chick embryos (test group 1) at five different incubation periods: 10-11 days $(n=6), 12-13$ days $(n=8), 14-15$ days $(n=8), 16-17$ days $(n=6), 18-19$ days $(n=11)$. The response to 20 minutes hyperoxia was studied in 21 chick embryos (test group 2) at two different incubation periods: 16-17 days $(n=7) 18-19$ days $(n=14)$.

\section{Preparation}

The measurements were done inside a clinical infant incubator at a temperature of $38{ }^{\circ} \mathrm{C}$ and humidity of $60 \%$. After opening the air cell at the blunt side of the egg with an electric saw, the egg was placed in a small plexiglass holder, which had a continuous flow of a $\mathrm{N}_{2} / \mathrm{O}_{2}$ mixture $(5 \mathrm{l} / \mathrm{min})$ at $38{ }^{\circ} \mathrm{C}$ and $60 \%$ humidity. A branch of the chorioallantoic vein was catheterized for injections of fluorescent microspheres, as previously described (Mulder 1997).

\section{Protocol}

At each injection $0.2 \mathrm{ml}$ of a 100.000 microspheres in $1 \mathrm{ml} 0.05 \%$ Tween 80 suspension was used $(15 \mu \mathrm{m}$; Fluospheres, Molecular Probes Inc.. Eugene, Oregon, USA). Five minutes after catheterization, yellow-green fluorescent micropheres were injected (normoxia level). Three minutes later the chick embryo was exposed to hyperoxia by supplying $100 \% \mathrm{O}_{2}\left(5 \mathrm{l} / \mathrm{min}\right.$, at $38{ }^{\circ} \mathrm{C}$ and $60 \%$ humidity) to the plexiglass holder. In test group 1 , the second microsphere injection (orange) was performed in the last minute of a 5 minutes hyperoxia period. In test group 2 , the second injection was performed in the last minute of a 20 minutes hyperoxia period. After the experiment, chick embryos were removed from the egg shell and membranes and immediately decapitated. Afterwards CAM (chorioallantoic membrane, placenta equivalent), brain, heart, lungs, intestine, liver and yolk sac were dissected. 
In another group of chick embryos on days $16-17(n=10)$ of the incubation period blood samples were obtained for blood gas analysis of the experimental conditions. $\mathrm{pH}, \mathrm{PO}_{2}$, and $\mathrm{PCO}_{2}$ were determined after $5(\mathrm{n}=5)$ and $20(\mathrm{n}=5)$ minutes of hyperoxia $\left(100 \% \quad \mathrm{O}_{2}\right)$ exposure. The embryos were exposed to the same environmental conditions as the experimental group. For the samples the chorioallantoic artery was carefully lifted with forceps and a curved 30 gauge needle was inserted contrary the blood stream. Blood samples $(0.2 \mathrm{ml})$ were collected in a heparinized syringe and analyzed at $38{ }^{\circ} \mathrm{C}$ (Radiometer ABL3, Copenhagen). Values were corrected for embryonic temperature.

\section{Analysis of microspheres distribution}

Fluorescence in whole organs (CAM, brain, heart, lungs, intestine, liver and yolksac) and in the remaining carcass was determined. The organs were digested in a $2 \mathrm{M}$ ethanolic- $\mathrm{KOH}$ solution for $48 \mathrm{~h}$ at $60^{\circ} \mathrm{C}$. The microspheres were isolated from the homogenate by centrifugal sedimentation, as described by van Oosterhout et al. (1995). In the final pellet the dye was extracted by adding $3 \mathrm{ml}$ of 2-(2ethoxyethoxy)ethylacetate and fluorescence was determined by fluorimetry using a LS-50B fluori-spectrometer (Perkin Elmer). No correction for spectral overlap was used since the excitation and emission spectra of the injected microsphere dyes were well separated from each other (Dye characteristics: yellow-green, $490 \mathrm{~nm}$ excitation max, 506 emission max; orange, $530 \mathrm{~nm}$ excitation max, 552 emission max). During fluorimetry all samples had the same volume $(3 \mathrm{ml})$. The fraction of $\mathrm{CO}$ to an organ was calculated as the ratio of the fluorescence in the tissue, after correction for background and the sum of fluorescence of all organs.

\section{Statistics}

The data are expressed as median with interquartile range (p25-p75). Significant differences in $\mathrm{CO}$ distribution during hyperoxia $\left(100 \% \mathrm{O}_{2}\right)$ exposure as compared to $\mathrm{CO}$ distribution during normoxia, were analysed by a non-parametric sample test (Wilcoxon signed rank test). Differences were considered significant at $P<0.05$. 


\section{Results}

Exposure of eggs to $100 \% \mathrm{O}_{2}$ caused an increase in chorioallantoic artery oxygen tension, while $\mathrm{pH}$ and arterial $\mathrm{PcO}_{2}$ remained unchanged. Median $\mathrm{Po}_{2}$ values after hyperoxia exposure for 5 minutes were $5.65 \mathrm{kPa}(\mathrm{IQR}: 5.04-7.71 \mathrm{kPa})$ and after 20 minutes were $6.56 \mathrm{kPa}$ (IQR: $6.03-8.13 \mathrm{kPa}$ ), compared to the $\mathrm{Po}_{2}$ ranges 3.12-6.02 $\mathrm{kPa}$ during normoxia previously reported (van Golde 1996).

During normoxic conditions, in both test groups, a large fraction of the CO was directed to the CAM and a relatively small fraction to the heart, brain, intestine and liver (Table 1 and 2). No significant changes in fractions of $\mathrm{CO}$, in response to hyperoxia were observed in the chick embryo younger than 18 days in both groups. In embryos of 18-19 days, 5 minutes of hyperoxia (test group 1) produced a significant decrease in the fraction of the CO directed to the heart $(-50.43 \%)$ and carcass $(-31.47 \%)$, and an increase to CAM $(+40.09 \%)$ and yolk sac $(+58.29 \%)$ on days $18-19$ (two-related sample test, $* \mathrm{P}<0.05$ vs normoxia) (Table 1 ). When the duration of exposure to hyperoxia was prolonged to 20 minutes (test group 2), not only the fraction of the $\mathrm{CO}$ to the heart $(-61.71 \%)$ and carcass $(-25.69 \%)$ decreased significantly, but also that to the brain $(-32.86 \%)$, intestine $(-47.09 \%)$ and liver $(-30.09 \%)$. In these embryos the fraction of $\mathrm{CO}$ to the lungs $(+42.75 \%)$, CAM $(+38.28 \%)$ and yolk sac $(+25,0 \%)$ increased significantly (two-related sample test, $* \mathrm{P}<0.05$ vs normoxia) (Table 2). Figure 1 illustrates the relative percentage changes in $\mathrm{CO}$ distribution after $20 \mathrm{~min}$ hyperoxia. 


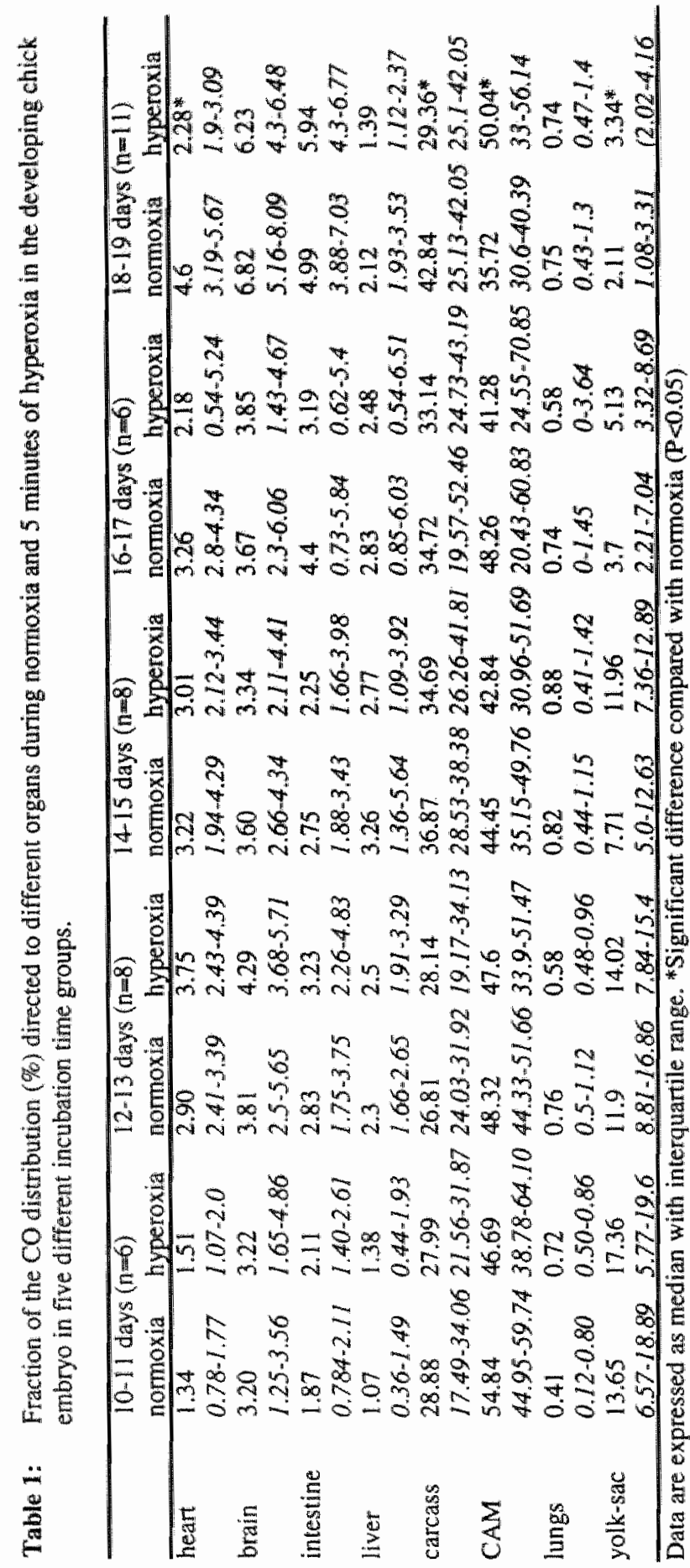


Table 2: Fraction of the CO distribution ( $\%$ ) directed to the different organs during nomoxia atd 20 minutes of hyperoxia in the developing chick embryo in two different incubation time groups

\begin{tabular}{lllll}
\hline & $10-11$ days $(\mathrm{n}=6)$ & \multicolumn{2}{l}{$12-13$ days $(\mathrm{n}=8)$} \\
& Normoxia & Hyperoxia & Normoxia & Hyperoxia \\
\hline heart & 4.38 & 2.96 & 4.03 & $1.43^{\circ}$ \\
& $1.53-5.35$ & $1.3-4.64$ & $2.93-6.36$ & $1.14-2.59$ \\
brain & 4.13 & 5.09 & 5.63 & $3.78^{\circ}$ \\
& $3-6.65$ & $3.66-6.8$ & $4.99-10.57$ & $2.37-5.64$ \\
intestine & 3.92 & 5.41 & 6.54 & $3.46^{\circ}$ \\
& $2.68-5.06$ & $2.11-8.57$ & $3.39-9.81$ & $2.79-6.23$ \\
liver & 4.48 & 3.1 & 4.11 & $2.84^{\circ}$ \\
& $2.26-6.07$ & $1.76-5.7$ & $3.36-4.94$ & $1.84-4.32$ \\
carcass & 37.11 & 29.69 & 42.32 & $31.45^{\circ}$ \\
& $34.5-48.4$ & $25.6-50.1$ & $34-54.9$ & $22.6-43.4$ \\
lungs & 1.0 & 2.29 & 1.38 & $1.97^{\circ}$ \\
& $0.58-1.77$ & $0.31-3.9$ & $0.53-2.0$ & $1.1-2.5$ \\
cam & 40.33 & 36.16 & 28.79 & $39.81^{\circ}$ \\
& $35.1-46.8$ & $18.7-46.2$ & $20.2-36.1$ & $25.5-54.4$ \\
yolk sac & 3.49 & 8.93 & 3.28 & $4.1^{\circ}$ \\
& $1.8-8.1$ & $0.6-15.8$ & $2.11-3.74$ & $2.66-7.31$ \\
\hline
\end{tabular}

Data are expressed as median with interquartile range. *Significant difference compared with normoxia $(\mathrm{P}<0.05)$ 


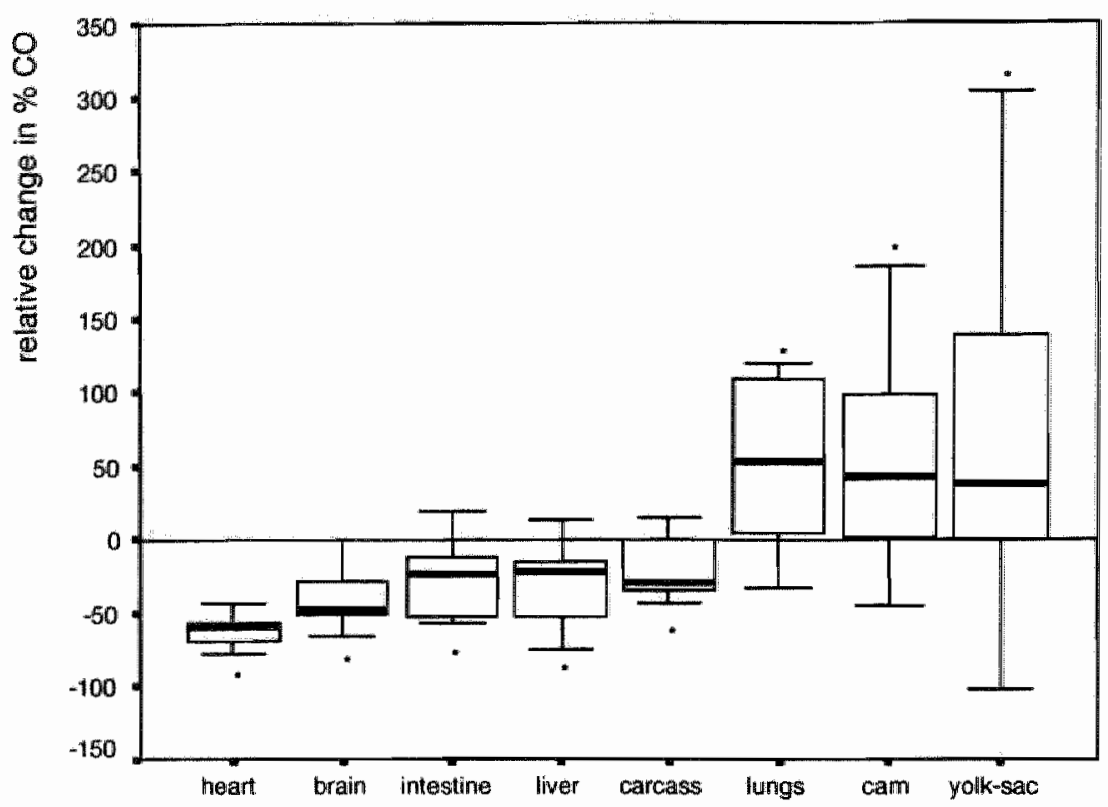

Figure 1: Magnitude of response to $20 \mathrm{~min}$ hyperoxia on incubation days 18-19. The bars represent the median change expressed as percentage of normoxia level with the interquartille range (p25-p75). * Significant difference compared with normoxia $(\mathrm{P}<0.05)$. 


\section{Discussion}

CO distribution during normoxic conditions, was similar to data reported previously in a larger group of chick embryos (Mulder 1997) and in the late gestation sheep fetus (Jensen 1991). A large fraction of the CO was directed to the CAM and a relatively small fraction to the brain, heart, liver and intestine. This study showed that hyperoxia for 5 or 20 minutes, only late in incubation, produced a decreased fraction of the $\mathrm{CO}$ to the heart and carcass of the chick embryo, whereas it increased to the CAM and yolk-sac. When the hyperoxia exposure was prolonged to 20 minutes, the response was augmented, and also a decrease of $\mathrm{CO}$ fraction to the brain, intestine and liver was observed. Hyperoxia had no effect on organ perfusion before $85 \%$ of the incubation period of the developing chick embryo.

At the time of birth the $\mathrm{PO}_{2}$ increases from about 25 to $85 \mathrm{mmHg}$ which reduces the perfusion demands, and may contribute to decreased blood flow to skeletal muscles, brain, skin, bone, carcass and adrenal glands mediated by a local vasoconstriction (Bendeck 1992; Lundstrфm 1995). Regional blood flow is also redistributed during maternal hyperoxygenation late in gestation (Almstrom 1996; Niijima 1988). Studies on chronically catheterized fetal sheep (Blanco 1988; Gleason 1988; Iwamoto 1987; Peeters 1979) and fetal rhesus monkey (Jackson 1987) showed a decreased blood flow to the adrenals, brain and heart with increased oxygenation. All these studies were performed late in gestation or in the newborn. To our knowledge, the effects of hyperoxia on organ perfusion have not been investigated early in gestation to determine when vasoconstriction is caused by hyperoxia. In the present study the developing chick embryo was used to investigate the maturation of the vasoconstriction response to hyperoxia. Our study demonstrates that in the developing chick embryo redistribution of the $\mathrm{CO}$, in response to hyperoxia exposure, does not occur before $85 \%$ of incubation.

Development of the response to hypoxia is better described than to hyperoxia. In the developing chick embryo anoxia $\left(100 \% \mathrm{~N}_{2}\right.$, causing isocapnic hypoxaemia with mean $\mathrm{PaO}_{2} 1,2 \mathrm{kPa}$ ), causes $\mathrm{CO}$ redistribution in favour of the heart and brain at the expense of the intestine, liver, yolk-sac and carcass from day 14 (Mulder 1998). From fetal sheep studies it is known that this response is mediated by neurohormonal mechanisms (Hanson 1988). Increased levels of catecholamines, but also vasopressin, opioids and prostaglandins cause vasoconstriction in vascular smooth muscle cells (Espinoza 1989; Faucher 1987; Hanson 1988; Jones 1975; Millard 1979). 
Vasoconstriction during hyperoxia exposure has been attributed to direct effect of oxygen on the vessel wall (Sparks 1980; Lewis 1968) or by release of vasoconstrictor factors, such as leukotrienes, prostaglandin $F_{2 \alpha s}$ and thromboxane $A_{2}$ (Gurtner 1985; Stuart 1984; Wagerle 1988). Furthermore, increased release of reactive oxygen species (ROS) during hyperoxia, generated by cyclooxygenase-1 in endothelial cells, might produce vasoconstriction by inhibiting the synthesis or the action of vasodilatory components such as prostacyclin $\left(\mathrm{PGI}_{2}\right)$ or nitric oxide (Stuart 1984). In contrast, it is also reported that ROS could reduce vascular reactivity, by inhibition of calcium transport and reduction of the vasoconstrictor response to thromboxane (dependent upon $\mathrm{Ca}^{2+}$ influx) (Gurtner 1985; Hardy 1994). These conflicting reports do not help to explain the role of ROS on the vasomotor responses in our model, but further research should clarify this. Furthermore, differences in vasoconstrictor response after changes in oxygen tension at different stages of development and in different organs might be explained by different ion channel densities in vascular smooth muscle cells (Weir 1997).

In summary, we can conclude that, hyperoxia causes a decrease in the fraction of the $\mathrm{CO}$ to the brain, heart, liver, intestine and carcass, but only after 18 days of incubation in the chick embryo. Diversity of response in vascular smooth muscle cells to changes in oxygen tension at different stages of development and different organs might be determined by the capacity for production of vasoconstrictor factors, the distribution of a variety of ion channels in the vascular smooth muscle cells and production of ROS. Further studies are needed to determine the exact mechanisms underlying the vascular response to hyperoxia. 


\section{References}

Almstrom H, Sonesson SE (1996) Doppler echocardiographic assessment of fetal blood flow redistribution during maternal hyperoxygenation. Ultrasound Obstetrics Gynecology 8 (4), 256-261.

Ashwal, S, Dale, PS, Longo LD (1984) Regional cerebral blood flow. Studies in the fetal lamb during hypoxia, hypercapnia, acidosis and hypotension. Pediatr Res 18, 1309-1316.

Bendenk MP, Langille BL (1992) Changes in blood flow distribution during the perinatal period in fetal sheep and lambs. Can J Physiol Pharm 70, 1576-1582.

Blanco CE, Martin CB, Rankin J, Landauer M, Pherretton $T$ (1988) Changes in fetal organ flow during intrauterine mechanical ventilation with or without oxygen. J Dewel Physiol, $1988,10,53-62$.

Espinoza M, Riquelme R, Germain AM, Tevah J, Parer JT, Llanos AJ (1989) Role of endogenous opioids in the cardiovascular responses to asphyxia in fetal sheep. Am J physiol 256 , 1063-1068.

Faucher DJ, Lowe TW, Magness RR, Laptook AR, Porter JC, Rosenfeld CR (1987) Vasopressin and catecholamines secretion during metabolic acidemia in the ovine fetus. Pediatr Res 21 , 38-43

Frank L (1985) Effects of oxygen on the newbom. Federation Proceedings 44, 2328-2334.

Gleason CA, Jones MD, Traystman RJ, Notter RH (1988) Fetal cerebral responses to ventilation and oxygenation in utero. Am J Physiol 255, R1049-R1054.

Giussani DA, Spencer JAD, Hanson MA (1994) Fetal cardiovascular reflex responses to hypoxaemia. Fetal and Matemal Medicine Review 6, 17-37.

Gurtner GH, Michael JR, Famukh IS, Sciuto AM, Adkinson NF (1985) Mechanism of hyperoxia induced pulmonary vascular paralysis: effect of antioxidant pretreatment. I Appl Physiol $59(3), 953-958$.

Hamburger V, Hamilton HL (1951) A series of normal stages in the development of the chick embryo. J Morphol 88, 49-92.

Hanson MA (1988) The importance of baro- and chemoreflexes in the control of the fetal cardiovascular system. J Dev Physiol 10, 491-511.

Hardy P, Abran D, Li D, Femandez H, Varma DR, Chemtob S (1994) Free radicals in retinal and choroidal blood flow autoregulation in the piglet: Interaction with prostaglandins. Invest Ophth Vis Sci $35,580-591$.

Iwamoto HS, Teitel D, Rudolph AM (1987) Effect of birth-telated events on blood flow distribution. Pediatr Res 22, 634-640.

Jackson BT, Piasecki GJ, Novy MJ (1987) Fetal responses to altered matemal oxygenation in rhesus monkey. Am J Physiol 252, R94-101.

Jensen $A_{2}$, Roman C, Rudolph AM (1991) Effects of reducing uterine blood flow on fetal blood flow distribution and oxygen delivery. J Develop Physiol 15, 309-323.

Jones CT, Robinson JO (1975) Plasma catecholamines in foetal and adult sheep. J Physiol 248.15-33.

Lewis, BV (1968) The response of isolated sheep and human umbilical anteries to oxygen and drugs. Brit $J$ Obstet and Gynaec 75, 87-91.

Lundstrom KE, Pryds $\mathrm{O}$, Greisen $\mathrm{G}$ (1995) Oxygen at birth and prolonged cerebral vasoconstriction in preterm infants. Arch Dis Child 73, F81-86.

Menke J Rabe MH, Bresser BW, Grohs B, Schmitt RM, Jorch G (1993) Simultaneous influence of blood pressure, $\mathrm{PO}_{2}$ on cerebral blood flow velocity in preterm infants of less than 33 weeks gestation. Pediatr Res 34, 173-177. 
Millard RW, Baig $H_{*}$ Vatner SF (1979) Prostaglandin control of the renal circulation in response to hypoxemia in the lamb in utero. Circ Res $45,172-179$.

Mulder TLM, van Colde JC, Prinzen FW, Blanco CE (1997) Cardiac output distribution in the chick embryo from stage 36 to 45. Cardiovasc Res 34, 525-528.

Mulder ALM, van Golde JC. Prinzen FW, Blanco CE (1998) Cardiac output distribution in response to hypoxia in the chick embryo in the second half of the incubation. I Physiol 508 (part 1), $281-287$.

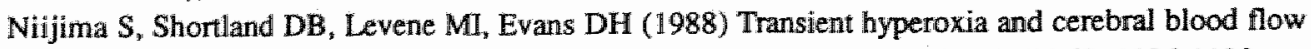
velocity in infants born prematurely and at full term. Arch Disn Child 63, 1126-1130.

Peeters LLH, Sheldon RE, Douglas MD, Jones MD, Makowski EL, Meschia G (1979) Blood flow to fetal organs as a function of arterial oxygen content. Am J Obstet Gynecol 135, 637-646.

Pearson IT, Haque MA, Hou PCL, Tazawa $\mathrm{H}$ (1996) Developmental patterns of $\mathrm{O}_{2}$ consumption, heart rate and $\mathrm{O}_{2}$ pulse in unturned eggs. Resp Physiol 103, 83-87.

Saugstad OD (1990) Oxygen toxicity in the neonatal period. Review. Acta Paediatr Scan 79, $881-892$.

Sparks HV (1980) Effect of local metabollic factors on vascular smooth muscle. In: Bohr DF, Somylo AP, Sparks HV (eds.). Handbook of Physiology, The Cardiovascular System, Vol II. American Physiology Society, Bethesda, MD, pp 475-513.

Stuart MJ. Setty BNY, Walenga RW, Graeber JE, Ganley C (1984) Effects of hyperoxia and hypoxia on vascular prostacyclin formation in vitro. Pediatrics 74,548-553.

Tazawa $H$ (1980) Adverse effect of failure to turn the avian egg on the embryo oxygen exchange. Resp Physiol 41, 137-142.

van Golde I, Mulder T, Straaten van $\mathrm{H}$, Blanco $\mathrm{CE}$ (1996) The chorioallantoic artery blood flow of the chick embryo from stage 34 to 43 . Pediatr Res $40,867-871$.

wan Golde J, Mulder T, Blanco CE (1997) Changes in mean chorioallantoic artery blood flow and heart rate produced by hypoxia in the developing chick embryo. Pediatr Res 42, 293-298.

van Golde $J_{*}$ Borm PJ, Wolfs MC, Rhijnsburger EH, Blanco CE (1998) Induction of antioxidant enzyme activity by hyperoxia $\left(60 \% \mathrm{O}_{2}\right)$ in the developing chick embryo. J Physiol-509 (part 1), 289-296.

van Oosterhout MFM, Willigers HMM, Reneman RS, Prinzen FW (1995) Fluorescent microspheres to measure organ perfusion: validation of a simplified sample processing technique. Am J Physiol 269, H725-733.

Wagerle LC, Mishra OP ( 1988 ) Mechanism of $\mathrm{CO}_{2}$ reponse in cerebral arteries of the newborn pig: role of phospholipase, cyclooxygenase and lipoxygenase pathways. Circ Res 62, 1019 1026.

Weir EK, Reeve HL, Comfield DN, Tristani-Firouzi M, Peterson DA, Archer SL (1997) Diversity of response in vascular smooth muscle cells to changes in oxygen tension. Kidney Int 51 , $462-466$ 


\section{Chapter VIII}

\section{Induction of antioxidant enzyme activity by hyperoxia $\left(60 \% \mathrm{O}_{2}\right)$ in the developing chick embryo}

Jolanda C. van Golde, Paul J. Borm, Marion C. Wolfs, Els H. Rhijnsburger,

Carlos E. Blanco (Journal of Physiology 509 (part 1): 289-296, 1998)

\section{Abstract}

At birth, premature born man and animals are exposed to relatively high oxygen levels, compared to intra-uterine conditions, at a time when their antioxidant enzyme (AOE) system is still immature. Using the chick embryo as a study model, we investigated changes in $\mathrm{AOE}$ in response to hyperoxia applied at different timepoints during the incubation. Relations between hyperoxia and AOE activity were studied in selected organs (brain, heart, liver, intestine and lungs) of developing chick embryos (during the second half of the incubation period). Incubated White Leghom eggs were classified into four groups: control group $(n=100)$ and three test groups exposed for 48 hours to $60 \% \mathrm{O}_{2}$ on day 10 (test group $1, \mathrm{n}=80$ ), day 14 (test group 2, $\mathrm{n}=60$ ) and day 18 (test group $3, \mathrm{n}=30$ ). Superoxide dismutase (SOD), catalase and glutathione peroxidase (GPx) enzyme activity were measured in homogenates of the brain, heart, liver, intestine and lungs. Exposure to hyperoxia at different time points during incubation resulted in a 2 - to 10 -fold increase in SOD in all organs, but the brain. Catalase and GPx enzyme activity, were only induced in test group 1, 48 hours after initiation of hyperoxia. In developing chick embryo hyperoxia can produce a temporary induction of the AOE activity, which is dependent on $\mathrm{AOE}$, organ, incubation time and time point of exposure. 


\section{Introduction}

When born prematurely, the fetus is abruptly exposed to a much higher arterial oxygen level $\left(\mathrm{P}_{\mathrm{a}} \mathrm{O}_{2} 50-100 \mathrm{mmHg}\right)$ compared with intra-uterine conditions $\left(\mathrm{P}_{\mathrm{a}} \mathrm{O}_{2}\right.$ $25 \mathrm{mmHg}$ ), which results in an increased production of reactive oxygen species (ROS) (Frank, 1985). ROS such as, superoxide radicals $\left(\mathrm{O}_{2}{ }^{\circ}\right)$, hydrogen peroxide $\left(\mathrm{H}_{2} \mathrm{O}_{2}\right)$ and hydroxyl radicals ( $\left.\mathrm{HO}\right)$, are normal products of the aerobic metabolic processes in the cell (Saugstad 1990; Varsila 1994; Yu 1994). Under physiological conditions, these ROS are detoxified by various antioxidant enzyme (AOE) defense systems, including specific enzymes such as superoxide dismutase (SOD), glutathione peroxidase (GPx) and catallase (Saugstad, 1990; Varsila 1994; Yu 1994). If ROS are not detoxified efficiently, interactions with cell components such as lipids, protein or DNA may occur, causing cellular damage or even cell death (Frank 1985; Janssen 1993; Yu 1994). Production and activity of AOEs increase markedly in the final days before birth, and even more so after birth (Frank 1987).

However, when the organism is immature, response from the AOE system may be insufficient, thereby confronting the premature newborn infant with oxidative stress (Frank 1985; Vasila et al. 1994) The latter has been associated with bronchopulmonary dysplasia, necrotizing enterocolitis and intracranial hemorrhage (Saugstad, 1990).

In order to study the ability of hyperoxia to induce the AOE system in immature organ systems, we used the developing chick embryo model. In this study the chick embryo is exposed to hyperoxia on days 10,14 and 18 of the incubation period of a normal incubation time of 21 days. Since gas exchange in the chick embryo occurs through micropores of the egg shell, hyperoxia can easily be induced (Bissonette 1987). We describe the developmental changes of SOD, GPX and catalase in fetal brain, heart, liver, intestine and lungs under physiological conditions as well as after exposure to hyperoxia at three different time points in the last $50 \%$ of the total incubation period. 


\section{Methods}

\section{Chemicals}

Purified standards for SOD (bovine erythrocytes, EC 1.15.1.1) and catalase (bovine, EC 1.11.1.6) were obtained from Boehringer Mannheim (Biochemicals, Indianapolis) and glutathione peroxidase (bovine erythrocytes, lyophilized) from Sigma. All other chemicals and reagents were of analytical grade.

\section{Protocol}

Fertile White Leghorn eggs were incubated at $38^{\circ} \mathrm{C}$ and $60 \%$ humidity. The oxygen concentration in the incubator could be increased up to $60 \% \mathrm{O}_{2}$. The gas composition in the incubator was continuously monitored during incubation. Exposure of the egg to hyperoxia (inspired oxygen fraction $\left(\mathrm{F}_{\mathrm{i02}}\right)=0.67$ ) for 3 hours leads to a significant change of $\mathrm{P}_{\mathrm{a}} \mathrm{O}_{2}$ (to $52 \pm 6 \mathrm{mmHg} ; \Delta 28 \mathrm{mmHg}$ ) in the chorioallantoic artery, similar to the transition of $\mathrm{P}_{\mathrm{a}} \mathrm{O}_{2}$ levels at birth (Piiper 1980). During incubation, eggs were turned hourly along their long axis. Chick embryos were classified into four groups: control $(n=100)$ and three test groups. In the control group, which was incubated at $21 \% \mathrm{O}_{2}, \mathrm{SOD}, \mathrm{GPx}$ and catalase enzyme activity was measured in the brain, heart, liver, intestine and lungs from day 10 to 21 (each day, 10 chick embryos were decapitated, except on days 13 and 17). Test groups were also incubated at $21 \% \mathrm{O}_{2}$, but exposed at different time points to $60 \%$ $\mathrm{O}_{2}$ for 48 hours. Test group 1 was exposed to $60 \% \mathrm{O}_{2}$ on days $10-11(\mathrm{n}=80)$, test group 2 was exposed to $60 \% \mathrm{O}_{2}$ on days 14-15 $(\mathrm{n}=60)$ and test group 3 was exposed to $60 \% \mathrm{O}_{2}$ on days 18-19 (test group 3, $\mathrm{n}=30$ ). In all test groups, first measurements of SOD, GPx and catalase enzyme activity in the brain, heart, liver, intestine and lungs were started 24 hours after initiation of hyperoxia (at each chosen time 10 chick embryos were decapitated for measurements). In test group 1 , measurements were performed on days $11,12,14,16,18,19,20$ and 21 , in test group 2, measurements were performed on days $15,16,18,19,20$ and 21 and in test group 3 measurements were performed on days 19,20 and 21 .

\section{Tissue preparation and enzyme determinations}

On each determined day, 10 chick embryos were removed from their eggs, decapitated, weighed and classified using Hamburger-Hamilton morphological maturity index (Hamburger \& Hamilton, 1951). Brain, heart, liver, intestine, and lungs were dissected from embryos, weighed and chilled in ice-cold $0.9 \% \mathrm{NaCl}$-solution. Subsequently, tissues were homogenated in $10 \mathrm{mM}$ potassium phosphate buffer ( $4^{\circ} \mathrm{C}, 1.36 \mathrm{~g} . \mathrm{L}^{-1} \mathrm{KH}_{2} \mathrm{PO}_{4}$ and $1.78 \mathrm{~g} . L^{-1} \mathrm{Na}_{2} \mathrm{HPO}_{4}$ titrated to $\mathrm{pH} 7.4$, supplemented with $30 \mathrm{mM} \mathrm{KCL}$ and $1 \mathrm{mM}$ EDTA), using a Polytron Teflon homogenizer 
(Brinkman, Westbury, NY) ( 2 X 60 seconds at the highest speed), and stored at $-70^{\circ} \mathrm{C}$ untill AOE assays were performed.

Protein content was determined in an aliquot of tissue homogenate, according to Bradford (1976), using bovine serum albumin (BSA) as standard. Remaining homogenates were centrifuged at $12000 \mathrm{rpm}$ for 5 minutes at $4{ }^{\circ} \mathrm{C}$, and the resulting supernatants were analyzed for SOD, GPx and catalase performed as described previously (Janssen 1990), using standard spectrophotometric assays. AOE activity levels were corrected for changes in protein content in the different organs.

CuZn-SOD was measured in chloroform/ethanol (3:5) pre-extracted samples, using inhibition of xanthine $(50 \mu \mathrm{M})$-induced cytochrome $c(10 \mu \mathrm{M})$ reduction at 415 $\mathrm{nm}$. SOD activity was calculated from a semilog plot between reaction rate and log of a standard SOD. Samples were diluted to obtain approximately $50 \%$ inhibition (Engelen 1990). Total GPx activity was measured at 340 $\mathrm{nm}$ for 3 minutes, using $0.3 \mathrm{mM} \mathrm{H}_{2} \mathrm{O}_{2}$ induced reduction of nicotinamide adenine dinucleotide phosphate (NADPH). Catalase was measured at $240 \mathrm{~nm}$ for 3 minutes, using the linear decrease of $\mathrm{H}_{2} \mathrm{O}_{2}(10 \mathrm{mM})$ at $\mathrm{pH} 7.0$ in $50 \mathrm{mM}$ phosphate buffer $\left(6.8 \mathrm{~g} . \mathrm{L}^{-1} \mathrm{KH}_{2} \mathrm{PO}_{4}\right.$ and $8.9 \mathrm{~g} . \mathrm{L}^{-1} \mathrm{Na}_{2} \mathrm{HPO}_{4}$ ) titrated to $\mathrm{pH} 7.0$. Activity was calculated using the molar extinction coefficient of $0.0394 \mathrm{mmol}^{-1} \mathrm{~cm}^{-1}$.

\section{Statistics}

Data are presented as mean $\pm \mathrm{SD}$. Differences in AOE levels in different organs during normal development were tested using the Mann-Whitney $U$ test. Antioxidant enzyme levels in test groups were compared to the levels at the same day in the control group, using the Mann-Whitney U-test. Significance was accepted when $\mathrm{P}<0.05$. 


\section{Results}

\section{Control Group Development}

The normal development of SOD and GPx in the developing chick embryo (in the brain, heart, liver, intestine and lungs) are characterized by a rapid increase in activity in the final $20 \%$ to $30 \%$ of the incubation (Tables 1 and 2). In contrast, catalase activity in these organs did not increase during incubation (Table 3).

SOD enzyme activity increased from day 15 onwards, and continued to do so until the end of the measured period in all organs, except the liver. In the liver, the maximum level of SOD enzyme activity was reached on day 18 of incubation time. Enzyme activity in brain and heart was significantly higher than that in lungs and intestine $(\mathrm{P}<0.05)$.

$G P x$ enzyme activity increased steadily as of day 12 up until the end of the measured period. The highest levels of GPx enzyme activity were found in liver tissue $(P<0.05)$. All other organs presented similar levels of GPx enzyme activity.

Catalase enzyme activity presented no changes in the measured period and its activity was much lower than that of SOD and GPx enzymes $(P<0.05)$.

The maximum SOD, GPx and catalase enzyme activity was reached earliest in liver. 
Table 1. SOD enzyme activity (units (mg protein) $)^{-1}$ ) in the brain, heart, liver, intestine and lung of chick embryos in control and test groups.

\begin{tabular}{lllllll}
\hline & Day & Brain & \multicolumn{1}{l}{ Heart } & \multicolumn{1}{l}{ Liver } & \multicolumn{1}{l}{ Intestine } & \multicolumn{1}{l}{ Lung } \\
\hline Control & 10 & n.d. & n.d. & n.d. & n.d. & n.d. \\
(nim 100) & 11 & $5.8 \pm 1.1$ & \multicolumn{1}{l}{ n.d } & $1.0 \pm 0.4$ & n.d & n.d \\
& 12 & $13.5 \pm 2.4$ & $1.3 \pm 0.2$ & $3.2 \pm 1.3$ & $1.1 \pm 0.6$ & $0.3 \pm 0.2$ \\
& 14 & $15.3 \pm 2.1$ & $14.8 \pm 1.8$ & $13.6 \pm 1.4$ & $6.9 \pm 0.8$ & $13.9 \pm 3.2$ \\
& 15 & $52.4 \pm 2.9$ & $32.8 \pm 6.4$ & $26.1 \pm 5.7$ & $8.9 \pm 3.8$ & $24.5 \pm 3.1$ \\
& 16 & $125.6 \pm 9.9$ & $78.4 \pm 4.6$ & $102.3 \pm 10.3$ & $19.4 \pm 2.6$ & $33.9 \pm 2.8$ \\
& 18 & $167.8 \pm 8.7$ & $130.7 \pm 11.5$ & $365.6 \pm 64.2$ & $50.4 \pm 3.1$ & $83.9 \pm 13.7$ \\
& 19 & $218.5 \pm 22.2$ & $190.8 \pm 16.5$ & $335.0 \pm 23.7$ & $96.4 \pm 14.7$ & $87.1 \pm 9.6$ \\
& 20 & $228.4 \pm 18.4$ & $316.9 \pm 45.8$ & $298.5 \pm 28.1$ & $118.6 \pm 21.9$ & $82.0 \pm 19.9$ \\
& 21 & $302.6 \pm 28.4$ & $430.4 \pm 111.0$ & $226.3 \pm 35.5$ & $137.6 \pm 18.8$ & $81.9 \pm 21.8$
\end{tabular}

$\begin{array}{lcccccc}\text { Test group 1 11 } & 6.1 \pm 2.8 & 3.9 \pm 2.4^{*} & 4.6 \pm 0.8^{*} & 2.1 \pm 1.3^{*} & 1.8 \pm 1.1^{*} \\ (\mathrm{n}=8.0) & 12 & 21.6 \pm 2.1^{*} & 14.9 \pm 5.7^{*} & 8.7 \pm 2.8^{*} & 6.8 \pm 3.4^{*} & 13.2 \pm 1.4^{*} \\ & 14 & 88.2 \pm 7.6^{*} & 60.9 \pm 11.9^{*} & 61.4 \pm 9.0^{*} & 16.2 \pm 6.8^{*} & 24.6 \pm 10.5^{*} \\ & & & & & & \\ & 16 & 149.7 \pm 13.2^{*} & 123.8 \pm 12.3^{*} & 289.0 \pm 18.9^{*} & 45.8 \pm 5.1^{*} & 73.4 \pm 14.4^{*} \\ & 18 & 213.1 \pm 12.5^{*} & 186.5 \pm 45.8^{*} & 335.7 \pm 31.7 & 88.1 \pm 17.4^{*} & 91.6 \pm 20.0 \\ & 19 & 264.2 \pm 16.7^{*} & 215.4 \pm 21.7^{*} & 293.8 \pm 5.0^{*} & 105.2 \pm 116.6 & 85.0 \pm 11.8 \\ 20 & 235.7 \pm 25.8 & 300.1 \pm 37.1 & 235.8 \pm 27.3 & 112.6 \pm 26.8 & 87.1 \pm 9.9 \\ & 21 & 280.3 \pm 22.2 & 398.5 \pm 32.4 & 208.9 \pm 28.1 & 129.9 \pm 12.7 & 83.5 \pm 15.5\end{array}$

$\begin{array}{lrccccc}\text { Test group 2 } & 15 & 10.9 \pm 2.4^{*} & 20.5 \pm 7.3^{*} & 19.7 \pm 10.7 & 10.8 \pm 2.3 & 8.5 \pm 1.1^{+} \\ (\mathrm{n}=60) & 16 & 29.9 \pm 7.1^{*} & 380.9 \pm 45.2^{*} & 310.9 \pm 23.4^{*} & 180.5 \pm 48.3^{*} & 130.9 \pm 21.8^{*} \\ & 18 & 3.8 \pm 1.9^{*} & 519.6 \pm 38.7^{*} & 1485.2 \pm 53.8^{*} & 410.1 \pm 23.9^{*} & 277.9 \pm 32.1^{*} \\ & 19 & 20.9 \pm 5.3^{\dagger} & 189.5 \pm 41.8 & 312.1 \pm 32.1 & 43.5 \pm 3.2 & 38.0 \pm 4.7 \\ & 20 & 76.9 \pm 1.3 .3^{\dagger} & 326.8 \pm 29.1 & 440.5 \pm 17.3^{*} & 95.7 \pm 19.8 & 115.0 \pm 18.2^{*} \\ & 2 \| & 125.7 \pm 21.5^{\dagger} & 445.3 \pm 35.3 & 425.7 \pm 28.4^{*} & 130.6 \pm 16.4 & 110.2 \pm 13.3^{*}\end{array}$

$\begin{array}{llllll}\text { Test group } 319 & 21.4 \pm 5.6^{*} & 588.0 \pm 45.7^{*} & 102.6 \pm 28.6 & 100.3 \pm 12.9 & 56.6 \pm 8.6\end{array}$ $\begin{array}{lllllll}(\mathrm{n}=30) & 20 & 43.3 \pm 10.0^{\dagger} & 1133.3 \pm 63.9^{*} & 491.5 \pm 32.6^{*} & 315.2 \pm 38.5^{*} & 130.3 \pm 19.9^{*}\end{array}$

TG1, hyperoxia on day 10 and 11; TG2, hyperoxia on days 14 and 15; TG3, hyperoxia on days 18 and 19. Each data point is mean \pm SD of ten chick embryos. n.d., not detectable (AOE activity level $<0.001$ units). $P<0.05, S O D$ enzyme activity significantly increased compared with contral group; ${ }^{\top} \mathrm{P}<0.05$, SOD enzyme activity significantly decreased compared with control group. 
Table 2. GPx enzyme activity (units (mg protein) $)^{4}$ ) in the brain, heart, liver, intestine and lung of chick embryos in control and test groups.

\begin{tabular}{lllllll}
\hline & Day & Brain & Heart & \multicolumn{1}{l}{ Liver } & Intestine & \multicolumn{1}{l}{ Lung } \\
\hline Control & 10 & $21.6 \pm 9.5$ & n.d. & $103 \pm 10.4$ & $0.03 \pm 0.04$ & $9.8 \pm 7.1$ \\
$(\mathrm{n}=100)$ & 11 & $27.7 \pm 9.4$ & $0.2 \pm 0.6$ & $139 \pm 19.1$ & $4.9 \pm 4.24$ & $17.6 \pm 8.5$ \\
& 12 & $32.7 \pm 11.8$ & $1.5 \pm 1.5$ & $147 \pm 10.4$ & $31.7 \pm 18.3$ & $64.3 \pm 5.4$ \\
& 14 & $46.5 \pm 6.7$ & $1.7 \pm 1.5$ & $157 \pm 12.9$ & $66.3 \pm 17.5$ & $135 \pm 17.9$ \\
& 15 & $49.5 \pm 9.8$ & $39.9 \pm 12.4$ & $192 \pm 17.6$ & $83.4 \pm 8.5$ & $146 \pm 28.4$ \\
& 16 & $54.7 \pm 7.5$ & $75.4 \pm 10.2$ & $255 \pm 15.3$ & $92.2 \pm 17.4$ & $178 \pm 32.2$ \\
& 18 & $56.1 \pm 10.3$ & $124.0 \pm 29.9$ & $252 \pm 18.6$ & $95.3 \pm 14.5$ & $126 \pm 23.1$ \\
& 19 & $49.5 \pm 10.9$ & $98.8 \pm 21.7$ & $252 \pm 13.2$ & $93.1 \pm 22.2$ & $115 \pm 24.3$ \\
& 20 & $36.2 \pm 9.39$ & $76.8 \pm 11.8$ & $247 \pm 26.7$ & $92.1 \pm 12.6$ & $111 \pm 16.2$ \\
& 21 & $32.2 \pm 14.1$ & $42.9 \pm 16.9$ & $192 \pm 25.3$ & $43.1 \pm 12.3$ & $72.1 \pm 15.1$
\end{tabular}

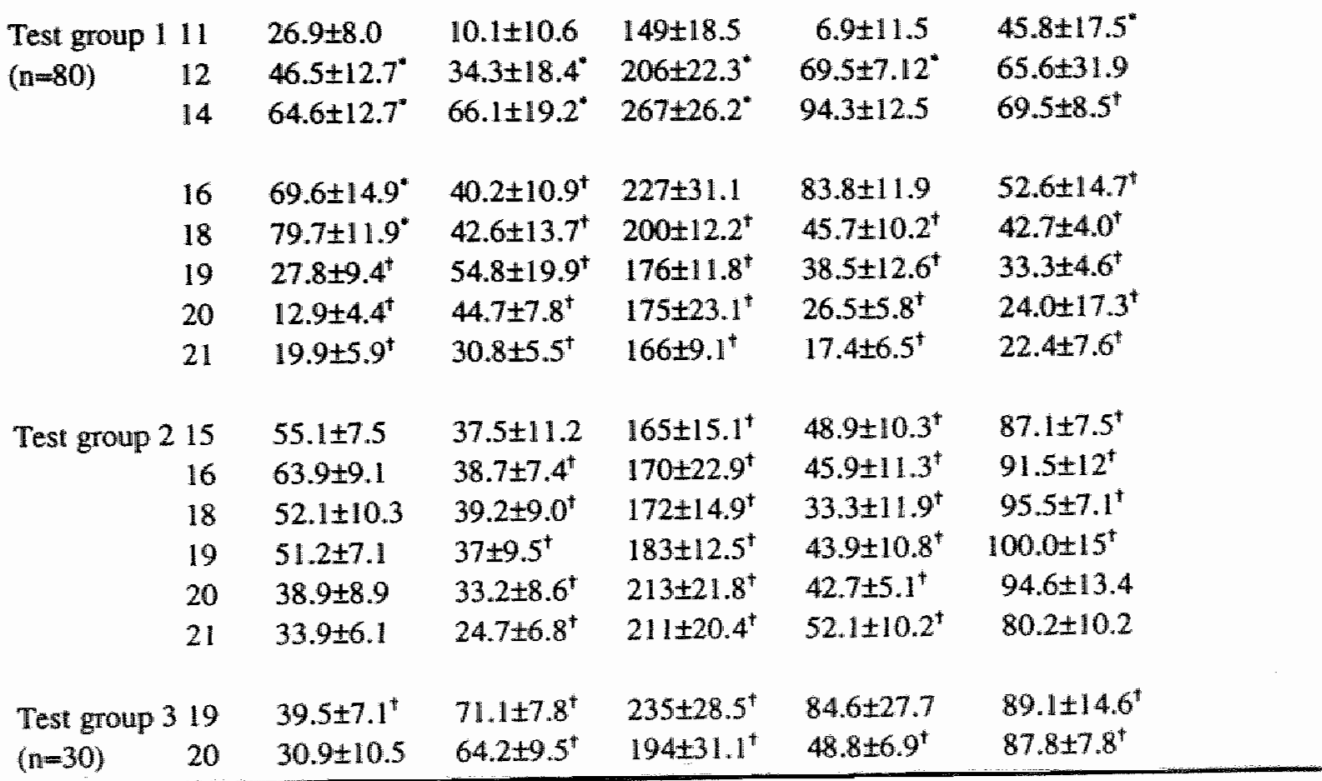

TG1, hyperoxia on days 10 and 11 ; TG2, hyperoxia on days 14 and 15 ; TG3, hyperoxia on days 18 and 19. Each data point is mean \pm SD of ten chick embryos. n.d., not detectable (AOE activity level $<0.001$ units). "P<0.05, GPx enzyme activity significantly increased compared with control group; ${ }^{T} \mathbb{P}<0.05$, SOD enzyme activity significantly decreased compared with control group. 
Table 3. Catalase enzyme activity (units (mg protein) $)^{-1}$ ) in the brain, hear, liver, intestine and lung of chick embryos in control and test groups.

\begin{tabular}{|c|c|c|c|c|c|c|}
\hline & Day & Brain & Heart & Liver & Intestine & Lung \\
\hline Control & 10 & $0.5 \pm 0.1$ & $9 \pm 2.3$ & $74 \pm 11.2$ & $5 \pm 0.2$ & $0.3 \pm 0.1$ \\
\hline \multirow[t]{9}{*}{$(\mathrm{n}=100)$} & 11 & $0.7 \pm 0.2$ & $11 \pm 3.2$ & $75 \pm 14.8$ & $7 \pm 1.8$ & $0.4 \pm 0.2$ \\
\hline & 12 & $3.0 \pm 0.5$ & $21 \pm 4.4$ & $77 \pm 21.5$ & $8 \pm 3.3$ & $0.5 \pm 0.1$ \\
\hline & 14 & $2.8 \pm 0.6$ & $22 \pm 4.6$ & $70 \pm 18.2$ & $13 \pm 3.6$ & $0.4 \pm 0.2$ \\
\hline & 15 & $2.1 \pm 0.6$ & $23 \pm 3.7$ & $95 \pm 113.8$ & $14 \pm 2.8$ & $2.5 \pm 0.4$ \\
\hline & 16 & $2.3 \pm 0.4$ & $22 \pm 4.6$ & $102 \pm 23.7$ & $11 \pm 3.8$ & $2.6 \pm 0.4$ \\
\hline & 18 & $2.5 \pm 0.6$ & $17 \pm 4.6$ & $117 \pm 19.3$ & $12 \pm 2.8$ & $3.7 \pm 0.4$ \\
\hline & 19 & $2.5 \pm 0.6$ & $14 \pm 4.0$ & $82 \pm 9.6$ & $14 \pm 3.6$ & $4.2 \pm 0.5$ \\
\hline & 20 & $3.1 \pm 0.8$ & $11 \pm 2.7$ & $55 \pm 14$ & $14 \pm 3.5$ & $5.5 \pm 0.7$ \\
\hline & 21 & $3.2 \pm 0.6$ & $12 \pm 3.2$ & $63 \pm 8$ & $13 \pm 3.2$ & $5.2 \pm 0.6$ \\
\hline \multicolumn{2}{|c|}{ Test group 111} & $1.9 \pm 0.5^{*}$ & $7 \pm 1.8^{\dagger}$ & $43 \pm 11.9^{*}$ & $5 \pm 0.8^{*}$ & $0.9 \pm 0.2^{*}$ \\
\hline \multirow[t]{7}{*}{$(n=80)$} & 12 & $3.7 \pm 0.5^{*}$ & $9 \pm 2.8^{\dagger}$ & $142 \pm 19.4^{\circ}$ & $12 \pm 2.0^{\circ}$ & $1.6 \pm 0.3^{\circ}$ \\
\hline & 14 & $1.4 \pm 0.4^{t}$ & $12 \pm 2.7^{\dagger}$ & $134 \pm 14.1^{\circ}$ & $9 \pm 3^{t}$ & $2.1 \pm 0.1^{\circ}$ \\
\hline & 16 & $1.9 \pm 0.3^{*}$ & $15 \pm 3.8^{+}$ & $124 \pm 12^{*}$ & $6 \pm 1.1^{t}$ & $1.7 \pm 0.5^{+}$ \\
\hline & 18 & $2.3 \pm 0.8$ & $15 \pm 3.1$ & $103 \pm 15.3$ & $8 \pm 2.2^{t}$ & $2.2 \pm 0.8^{t}$ \\
\hline & 19 & $2.2 \pm 0.9$ & $13 \pm 3.4$ & $54 \pm 6.1^{\dagger}$ & $9 \pm 2.8^{t}$ & $1.9 \pm 0.4^{*}$ \\
\hline & 20 & $2.4 \pm 0.7$ & $10 \pm 0.7$ & $54 \pm 7.9$ & $13 \pm 2.3$ & $2.9 \pm 0.6^{t}$ \\
\hline & 21 & $3.4 \pm 0.8$ & $12 \pm 2.4$ & $63 \pm 13.4$ & $13 \pm 2.5$ & $2.3 \pm 0.6^{t}$ \\
\hline \multicolumn{2}{|c|}{ Test group 215} & $2.7 \pm 1$ & $12 \pm 3.4^{\dagger}$ & $44 \pm 4^{\dagger}$ & $9 \pm 2.6^{\pi}$ & $2.9 \pm 0.9$ \\
\hline \multirow[t]{5}{*}{$(n=60)$} & 16 & $2.9 \pm 0.9$ & $8 \pm 1.1^{+}$ & $52 \pm 6.4^{+}$ & $8 \pm 1.2^{\pi}$ & $3.0 \pm 0.5^{+}$ \\
\hline & 18 & $3.3 \pm 0.6$ & $8 \pm 1.7^{\dagger}$ & $62 \pm 9.8^{t}$ & $9 \pm 2.1^{4}$ & $3.4 \pm 1.0$ \\
\hline & 19 & $2.9 \pm 0.8$ & $9 \pm 2^{+}$ & $67 \pm 10.1^{*}$ & $9 \pm 2.9^{\dagger}$ & $4.5 \pm 0.6$ \\
\hline & 20 & $3.1 \pm 0.4$ & $9 \pm 1.9$ & $55 \pm 5.1$ & $10 \pm 2.9^{4}$ & $4.9 \pm 0.8$ \\
\hline & 21 & $2.9 \pm 0.5$ & $11 \pm 2.5$ & $59 \pm 10.8$ & $12 \pm 2.8$ & $4.9 \pm 0.8$ \\
\hline Test group & 19 & $2.9 \pm 0.8$ & $12 \pm 3.1$ & $63 \pm 7.5^{+}$ & $9 \pm 1.9^{*}$ & $2.9 \pm 0.8^{*}$ \\
\hline$(n-30)$ & 20 & $3.3 \pm 1$ & $10 \pm 2.4$ & $47 \pm 4.1$ & $11 \pm 2.1$ & $3.2 \pm 0.9^{t}$ \\
\hline
\end{tabular}

TG1, hyperoxia on days 10 and 11 ; TG2, hyperoxia on days 14 and 15 ; TG3, hyperoxia on days 18 and 19. Each data point is mean $\pm \mathrm{SD}$ of ten chick embryos. n.d., not detectable (AOE activity level $<0.001$ units). $P<0.05$, Catalase enzyme activity significantly increased compared with control group; $\mathrm{P}<0.05, \mathrm{SOD}$ enzyme activity significantly decreased compared with control group. 


\section{Test Groups: changes induced by hyperoxia}

An increase in SOD enzyme activity was observed in all organs, except in the brain (Table 1). Observations were remarkably similar in heart, liver, intestine and lungs. A significant increase of SOD enzyme activity was reached $24 \mathrm{hrs}$ after initiation of hyperoxia in test group 1 and after 48 hours in test groups 2 and 3 . In test group 2 compared to test group 1, the increase of SOD enzyme activity on days 16-18 was significantly higher $(P<0.05)$. An increase in SOD enzyme activity was observed in embryos in test group 3 on days 19 and 20 . However, because all embryos died when hyperoxia was stopped, SOD levels could not be measured on day 21. It follows therefore that maximum SOD level and duration of significant increase could not be measured either. Interestingly, in brain tissue hyperoxia induced an increase in SOD enzyme activity in test group 1 only. In more developed chick embryos, no increase in enzyme activity was observed after initiation of hyperoxia. In fact, contrary to what was observed in all other organs, the brain showed, a significant decrease in SOD enzyme activity was observed in the brain $(\mathrm{P}<0.05)$.

An increase in GPx enzyme activity was observed in all organs, only in test group 1 (Table 2). This increase occurred 48 hours after the initiation of hyperoxia $(P<0.05)$ and its duration was 3 days in the heart, liver, and intestine and 6 days in the brain. In lung tissue significant increase of GPx enzyme activity was observed $24 \mathrm{hrs}$ after initiation of hyperoxia. However, levells of enzyme activity, in test group 1, decreased from days 19 to 21 in the brain, from days 16 to 21 in the heart, liver and intestine and from days 14 to 21 in the lungs $(P<0.05)$. In contrast, in test group 2, in the heart, liver, intestine and lungs a significant decrease in GPx enzyme activity was observed for 6 days $(P<0.05)$. Also in test group 3, a significant decrease in GPx enzyme activity was observed $24-48$ hours after the initiation of hyperoxia in the brain, heart, liver and intestine.

An increase in catalase enzyme activity was observed in all organs, but the heart, only in test group 1 (Table 3). This occurred $24-48$ hours after the initiation of hyperoxia $(\mathrm{P}<0.05)$ and its duration was: 24 hours in the intestine, 2 days in the brain, 5 days in the lungs and the liver. In test group 1, the heart showed a decrease in catalase enzyme activity from days 11 to $16(\mathrm{P}<0.05)$. In test group 2, a significant decrease in catalase enzyme activity in the heart, liver and intestine was observed for 5-6 days $(\mathrm{P}<0.05)$. In test group 3, a significant decrease in catalase enzyme activity in the liver, intestine and lungs was observed on day 19 and on day 20 in the lungs $(P<0.05)$. 


\section{Discussion}

This study describes the normal development of the primary antioxidant enzyme system (SOD, GPx and catalase enzyme activity) in the brain, heart, liver, intestine and lung tissue during the second half of the incubation period in the chick embryo, and the changes that hyperoxia induced in this development. To study the effect of hyperoxia, chick embryos were exposed to $60 \% \mathrm{O}_{2}$ for 48 hours at three different time points of their incubation period (days 10,14 and 18). This level of hyperoxia exposure was chosen because the level $\mathrm{PaO}_{2}$ obtained was similar to that of neonatal $\mathrm{P}_{\mathrm{a}} \mathrm{O}_{2}$ levels. In the control group, $\mathrm{AOE}$ activity changes were measured from day 10 until day 21 of the incubation period. In all test groups measurement of $\mathrm{AOE}$ activity changes were started 24 hours after initiation of hyperoxia, and continued until the last incubation day. We found that exposure to hyperoxia resulted in an increased $\mathrm{AOE}$ activity. This response to hyperoxia depends on $A O E$, organ, incubation time, and time points of exposure.

In order to be prepared for the relatively enriched $\mathrm{O}_{2}$ world after birth, a prenatal increase and/or a rapid postnatal response in $A O E$ activity is necessary. The cause for this increase in $\mathrm{AOE}$ activity is not known, but possible mechanisms involved are: (a) level of $\mathrm{PO}_{2}$, (b) rate of oxidative metabolism during fetal development, (c) maturational state of the tissues and (d) concentrations of enzyme substrate (Engelen 1990; Wilson 1992). In the chick embryo, $\mathrm{PO}_{2}$ increases from minimal levels on day 4 to much higher levels on day 10 (Freeman 1970). But since a gradual decline in $\mathrm{PO}_{2}$ and metabolic rate occurs from day 10 or 12 onwards, these factors play a less important role in the increase in AOE activity (Freeman 1970; Prinzinger 1995). However, it might be assumed that when the immature AOE system is exposed to hyperoxia the immature organ system might be activated to increase the AOE level. Other studies have already shown that AOE increase in the final part of normal gestation in other species including guinea pig, rabbit, rat, hamster or human fetus (Frank 1984; Gerdin 1985; Janssen 1993; Saugstad 1990; Transwell 1984). However, in these studies the first measurements of AOE were performed 3 days before birth. In our study, where we measured AOE levels from day 10 until day 21, we found an increase in AOE appearing in the final 20 to $30 \%$ of the total incubation time (days 14-21); however, catalase activity did not increase.

SOD is present in organs that are highly vulnerable to reactive oxygen species (Munim 1992). Interestingly, we found that AOE levels were strikingly higher in the liver than in other organs. This might be explained by the extensive 
metabolizing and detoxifying capacity of this organ, for example, the rate of extramitochondrial release of $\mathrm{H}_{2} \mathrm{O}_{2}$ is approximately two orders of magnitude greater in the liver than in the brain (Wilson et al. 1992). In this study hyperoxia induced a 2 to 10 fold increase in SOD enzyme activity in all organs, with the exception in the brain. This observed increase in $A O E$ was higher when hyperoxia was applied later in fetal development. A possible explanation for the lack of $\mathrm{AOE}$ induction in the brain tissue might be the decrease in cerebral blood flow caused by hyperoxia. A decrease in cerebral blood flow due to cerebral vasoconstriction, caused by hyperoxia, has been described for premature infants exposed to $80 \%$ oxygen during initial stabilization in the delivery room (Leahy 1980; Lunstrфm 1995). However, no data are available to support the hypothesis that cerebral vasoconstriction occurs in the perinatal period. Another explanation for the lack of induction of brain SOD caused by hyperoxia could be the inhibition or scavenging of superoxide, e.g. its reaction with NO (nitric oxide) (Radi 1991). This reaction is more than 3 times faster than the enzymatic dismutation of superoxide catallyzed by $\operatorname{SOD}\left(\mathrm{k}_{\mathrm{SOD}}=2 \times 10^{9} \mathrm{~m}^{-1} \cdot \mathrm{s}^{-1}\right)$ (Radi 1991). Moreover, this reaction product, 'ONOO' (peroxinitrite), has also been described to inactivate SOD-activity (MacMillan-Crow 1996). In contrast, administration of lead acetate (1.25 and 2.5 $\mu \mathrm{mol} / \mathrm{kg}$ egg weight) to 14-day old chick embryos increased AOE activity significantly in all organs, including the brain (Somashekaraiah 1992). This might be explained by the high doses of lead acetate and the depletion of glutathione in this study.

Induction of GPx and catalase activity was observed only in chick embryos exposed to hyperoxia on days 10 and 11 of incubation period (test group 1). Interestingly, in test groups 2 and 3, levels of GPx and catalase enzyme activity decreased compared to control group. Different changes in enzyme activity between the three AOE in the developing chick embryo might be explained by differences in regulation of gene expression during the incubation period (Chen 1993; Clerch 1992). CuZnSOD and catalase are regulated at a pretranslational level and their increase in activity is associated with an increase in mRNA concentrations (Chen 1993; Clerch 1992; Clerch 1995). In contrast, GPx is regulated at a translational or post-translational level and changes in GPx concentrations are caused by an increase in stability of mRNA. However, all studies on gene expression of AOE have been performed during the last $20 \%$ of incubation and postnatally (Chen 1993; Clerch 1992; Clerch 1995). The regulation of differential AOE gene expression during early perinatal development, in which we observed important differences compared to the more developed chick embryo, has never been studied. 
SOD might be particularly important as protection against early acute oxygen toxicity of the premature born and therefore, is induced earlier than GPx or catalase (Crapo 1974; Yam 1987). However, an increase in SOD enzyme activity without induction of GPx or catalase could result in an increase in hydrogen peroxide and hydroxyl radicals, due to the Haber-Weiss reaction (Ditelberg 1996). An imbalance in the ratio SOD to GPx and catalase may, therefore, result in an increase of lipid peroxidation (Haan 1995). Hyperoxia applied to adult and prematurely delivered rats led to induction of SOD enzymes in lung tissue (White 1989; Chen 1994). Our study corroborated this finding. However, levels of GPx and catalase also increased in prematurely delivered rats, a finding that was not observed in chick embryos. In another study, exposure of chick embryos to hyperoxia (60\%) for 72 hours on days 16-18 of the incubation period did not result in increased levels of lipid peroxidation (Stock 1990). This absence of lipid peroxidation might have been the result of an increase in the AOE activity, as observed in our study. This is supported by the presence of lung injury and the absence of an increase in $\mathrm{AOE}$ activity in premature rabbits exposed to hyperoxia 3 days before the end of gestation (Frank 1991).

We demonstrated that hyperoxia in the developing chick embryo induces a temporary increase in $A O E$ activity. This increase depends on $A O E$, organ, incubation time, and time points of exposure to hyperoxia. In further studies it remains to be established if this increase AOE activity is sufficient to circumvent cell damage. Furthermore, studies of the regulation of the differential gene expression would give more insight in the development of the perinatal development of the AOE defense system. Although the results of this animal model are interesting, more studies are warranted to determine whether our observations are relevant for the human premature born infant. 


\section{References}

Bissonnette, JM, Metcalfe J (1987) Gas exchange of the fertile hen's egg: components of resistance. Resp Physiol 34, 209-218.

Bradford MN (1976) A rapid sensitive method for quantization of microgram quantities of protein utilizing the method of dye binding. Anal Biochen 72, 248-254.

Chen Y, Frank L (1993) Differential gene expression of antioxidant enzymes in the perinatal rat lung. Pediatr Res 34, 27-31.

Chen Y, Whitney PL, Frank L (1994) Comparative responses of premature versus full-term newborn rats to prolonged hyperoxia. Pediatr Res $35,233-237$.

Clerch LB, Massaro D (1992) Rat lung antioxidant enzymes: differences in perinatal gene expression and regulation. Am J Physiol 263, L466- L470.

Clerch LB, Massaro D (1995) Oxidation-reduction-sensitive binding of lung protein to rat catalase mRNA. J Biol Chem 267, 2853-2855.

Crapo JD, Tiemey DF (1974) Superoxide dismutase and pulmonary oxygen toxicity. Am I Physiol $226,1401-1407$.

Ditelberg, JS, Sheldon RA, Epstein CJ, Ferriero DM (1996) Brain injury after perinatal hypoxiam ischemia is exacerbated in Copper/Zinc Superoxide Dismutase transgenic mice. Pediatr Res 39, 204-209.

Engelen JJM, Borm PJA, Sprundel M, Leenaertz L (1990) Blood antioxidant parameters at different stages of pneumoconiosis in coal workers. Environ Health Persp 84:165-172.

Frank L, Groseclose EE (1984) Preparation for birth into an $\mathrm{O}_{2}$-rich environment: the antioxidant enzymes in the developing rabbit lung. Pediatr Res 3, 240-244.

Frank L (1985) Effects of oxygen on the newborn. Federation Proceedings 44, 2328-2334.

Frank. L, Sosenko IRS (1987) Prenatal development of lung antioxidant enzymes in four species. J Pediatr 110, 106-110.

Frank L, Sosenko RS (1991) Failure of premature rabbits to increase antioxidant enzymes during hyperoxic exposure: increased susceptibility to pulmonary oxygen toxicity compared with term rabbits. Pediatr Res 29, 292-296.

Freeman $\mathrm{BM}$, Mission $\mathrm{BH}(1970) \mathrm{pH}, \mathrm{PO}_{2}$ and $\mathrm{PCO}_{2}$ of blood from the foetus and neonate of gallus domesticus. Comp Biochem Physiol 33, 763-772.

Gerdin E, Tyden O, Eriksson UJ (1985) The development of antioxidant enzymatic defense in the perinatal rat lung: activities of superoxide dismutase, glutathione peroxidase and catalase. Pediatr Res 19,687-691.

Haan de JB, Cristiano F, lanello RC Kola 1 (1995) Cu/Zn-Superoxide dismutase and glutathione peroxidase during aging. Biochem Mol Biol Int 35, 6:1281-1297.

Hamburger $V_{*}$, Hamilton HL. (1951) A series of normal stages in the development of the chick embryo. J Morphol 88, 49-92.

Janssen YMW, Marsh JP, Absher M, Borm PJA, Mossman BT (1990) Increases in antioxidant enzymes during asbestos inhalation in rats. Free Radical Res Com 11, $53-58$.

Janssen YMW, Borm PJA, Van Houten B, Mossman BT (1993) Cell and tissue responses to oxidative damage. Lab Invest 3, $261-274$.

Leahy FAN, Cates D, MacCallum M, Rigatto $\mathrm{H}(1980)$ Effects of $\mathrm{CO}_{2}$ and $100 \% \mathrm{O}_{2}$ on cerebral blood flow in preterm infants. I Appl Physiol 48, 468-472.

Lunstrom KE, Pryds O, Greisen G (1995) Oxygen at birth and prolonged cerebral vasoconstriction in preterm infants. Arch Dis Child 73, F81-F86. 
MacMillani-Crow LA, Crow JP, Kerby JD, Beckman JS, Thompson JA (1996) Nitration and inactivation of manganese superoxide dismutase in chronic rejection of human renal allografts. Proceedings of the National Academy of Sciences of United States of America 93,11853-11858.

Munim A, Asayama K, Dobashi K, Suzuki K, Kawaoi A, Kato K (1992) Immunohistochemical localization of superoxide dismutase in fetal and neonatal rat tissues. J Histochem Cytochem 40,1705-1713.

Piiper J, Tazawa H, Ar A, Rahn H (1980) Analysis of chorioallantoic gas exchange in the chick embryo. Resp Physiol 39, 273-284.

Prinzinger $R_{*}$ Schmidt $M$, Dietz $V(1995)$ Embryogeny of oxygen consumption in 13 altricial and precocial birds. Resp Physiol 100, 283-287.

Radi R, Beckman JS, Bush KM, Freeman BA (1991) Peroxinitrite induced membrane lipid peroxidation: the cytotoxic potential of superoxide and nitric oxide. Arch Biochemi Biophys 2, $481-487$.

Saugstad OD (1990) Oxygen toxicity in the neonatal period. Review. Acta Paediatr Scand 79, $8811-892$.

Somashekaraiah BV, Padmaja $K_{*}$ Prasad ARK (1992) Lead-induced lipid peroxidation and antioxidant defense components of developing chick embryos. Free Radical Biol Med $13,107 \cdot 114$.

Stock MK, Silvernail KK, Metcalfe J (1990) Prenatal oxidative stress: I.malondialdehyde in hypoxic and hyperoxic chick embryos. Free Radical Biol Med 8, 313-318.

Transwell AK, Freeman BA (1984) Pulmonary antioxidant enzyme maturation in the fetal and neonatal rat. I. Developmental profiles. Pediatr Res 7, 584-587.

Varsila E, Hallman M, Andersson S (1994) Free-radical-induced lipid peroxidation during the early neonatal period. Acta Paediatr 83, 692-695.

White CW, Ghezzi P, McMahon S, Dinarrello CA, Repine JE (1989) Cytokines increase lung antioxidant enzymes during exposure to hyperoxia. J Appl Physiol 66, 1003-1007.

Wilson JX, Lui EMK, Del Maestro RFD (1992) Developmental profiles of antioxidant enzymes and trace metals in chick embryo. Mech Ageing Dev 65, 51-64.

Yam J, Frank L, Roberts JR (1987) Oxygen toxicity: Comparison of lung biochemical responses in neonatal and adult rats. Pediatr Res 12,115-119.

Yu BP" (1994) Cellular defenses against damage from reactive orygen species. Review. Phys Rev 1, 139-162. 


\title{
Chapter IX
}

\section{The effect of repetitive hypoxia under normoxic or hyperoxic conditions on the extent of intestinal damage in the developing chick embryo}

\author{
J. Van Golde, T. Okazaki, D. Tibboel, C.E. Blanco.
}

\section{Abstract}

Episodes of hypoxia and reperfusion can play an important role in the development of intestinal damage during the perinatal development. This study describes histological changes in the intestine of the developing chick embryo after exposure to repetitive hypoxia and recovery under room air or $100 \%$ oxygen. Chick embryos were exposed to $5 \mathrm{~min}$ hypoxia by changing the airflow to $100 \% \mathrm{~N}_{2}$ adjusted to the egg holder, this was repeated six times with a recovery period of 15 minutes under normoxic conditions $\left(21 \% \mathrm{O}_{2}\right)$ (test group 1 (TG1), $\left.\mathrm{n}=149\right)$ or under hyperoxic conditions $\left(100 \% \mathrm{O}_{2}\right.$ ) (test group 2 (TG2), $\left.\mathrm{n}=146\right)$, in chick embryos from day 11 until day 20. Chick embryos recovered under hyperoxic conditions were previously incubated under hyperoxic conditions $\left(100 \% \mathrm{O}_{2}\right.$, during 24 hours). Histological evaluation of the ileum was performed at different time points after the intervention $(2,4,8,16$ and 24 hours). In both groups, chick embryos younger than 19 days, showed no intestinal damage. Intestinal histology showed vasodilation of villus capillaries (10\% in TG1 and 15\% in TG2), necrosis in the top of the villi ( $29 \%$ in TG1 and $30 \%$ in TG2), and necrosis with preservation of crypts and transmucosal necrosis ( $2 \%$ in TG1 and $2 \%$ in TG2), on day 19. Only those chick embryos histologically evaluated 2 hours after the interventions showed a significant increase in intestinal damages compared to the controls. Furthermore, recovery under hyperoxic conditions, after repetitive hypoxia insults, did not cause increased intestinal damage compared to recovery under normoxic conditions. 


\section{Introduction}

Due to development of new techniques in the neonatal intensive care an increased percentage of the premature born infants can be rescued. However, this improvement in neonatal care bring about new complications such as necrotizing enterocolitis (Kliegman 1990). The intestinal tract of immature infants has a reduced capability for regulation of local blood flow (Crissinger 1994, Kliegman 1984). However, the mechanisms involved in the response during hypoxia/reperfusion insults, resulting in the development of intestinal damage in the newborn born infant at different gestational ages, remains to be elucidated. In this study we investigated the effects of repetitive hypoxia on the intestine in the developing chick embryo. It is known from a previous study in the developing chick embryo, that acute hypoxia causes a redistribution of the cardiac output, favouring the heart and the brain at expense of intestine, liver and carcass (Mulder 1998). This response is described as the 'diving reflex theory' by Lloyd (1969), and hypothesized to be an important factor in the development of NEC (Kliegman 1984).

After a period of reduced oxygenation, reperfusion of the tissue causes an increased production of reactive oxygen species (ROS) which is also suggested to be an important factor in the acceleration of intestinal damage in different animal models (Cueva 1988; Granger 1981; Crissinger 1989; Parks 1986; Schoenberg 1984; Touloukian 1972; Weixiong 1994). According to current practice, asphyxiated neonates are resuscitated using 100\% oxygen (Milner 1991). It can be postulated that a period of high oxygen tension in blood and tissues during resuscitation may enhance ROS formation causing tissue damage leading to bronchopulmonary dysplasia, retinopathy of prematurity, necrotizing enterocolitis and patent ductus arteriosus. However, it remains to be investigated whether the use of $100 \%$ oxygen during resuscitation increases the risk for intestinal damage.

In order to evaluate the effect of hypoxia/reperfusion and prematurity, histological changes in the ileum were determined after exposure to repetitive hypoxia in developing chick embryos. One group chick embryos was incubated under room air, the other group was previously incubated under hyperoxic conditions (100\% $\mathrm{O}_{2}$, during 24 hours). To determine an eventual repair of injury histological changes were studied at five different time points post-hypoxic interventions $(2,4$, 8,16 and 24 hours). 


\section{Materials}

\section{Animals}

Fertile White Leghorn eggs were incubated at $38^{\circ} \mathrm{C}$ and $60 \%$ humidity. During incubation, eggs were turned hourly along their long axes to avoid adhesion of the membranes and abnormal development (Pearson 1996; Tazawa 1980).

\section{Protocol}

All interventions were done inside a rebuild clinical incubator, in which the temperature was kept at $38^{\circ} \mathrm{C}$ and the humidity at $60 \%$. Since the gas exchange in the chick embryo takes place by diffusion through the micropores of the eggshell (Bissonnette 1978), this principle allowed us to induce changes in the embryonic blood gasses by changing the gas composition around the eggshell. Histological changes of the ileum in control groups, incubated in room air (CGI) or incubated in $60 \% \mathrm{O}_{2}$ during 48 hours on days $10-12,14-16$ and 18-20, were studied on days 12,16 and 20. Eggs from test groups were placed in a plexiglass holder on previously determined intervention days. Continuous gas flow of an $\mathrm{O}_{2} / \mathrm{N}_{2}$ mixture at $38^{\circ} \mathrm{C}$ and $60 \%$ humidity was admitted to the holder. From a previous study it is known that exposure to $100 \% \mathrm{~N}_{2}$ causes a significant decrease in arterial $\mathrm{Po}_{2}(1.2$ $\pm 0.34 \mathrm{kPa} ; \Delta 5.4 \mathrm{kPa}$ ). Chick embryos in the first test group (TG1) were exposed to six periods of hypoxia ( $100 \% \mathrm{~N}_{2}$, during 5 minutes), with a recovery time of 15 minutes under normoxic conditions $\left(21 \% \mathrm{O}_{2}\right)$ on days 11,15 or 19 . Chick embryos in the second test group (TG2) were incubated until 10,14 or 18 days when the inflowing gas to the incubator was switched to $60 \% \mathrm{O}_{2}$ during 48 hours. Embryos of TG2 were also exposed to repetitive periods of hypoxia on days 11,15 or 19 , but in contrast to TG1, they were recovered under hyperoxic conditions (100\% $\mathrm{O}_{2}$ ). Histological changes of the intestine were studied in five subgroups, 2, 4, 8, 16 and 24 hours after the end of the interventions.

\section{Histological examination}

At different time points after the interventions the chick embryos were removed from their eggs and immediatly decapitated. Next, the intestine was dissected and fixed in $10 \%$ phosphate buffered formaline $(50 \mathrm{ml} 37-40 \%$ formaldehyde, $450 \mathrm{ml}$ aqua bidest, $2 \mathrm{~g} \mathrm{NaP} 2 \mathrm{PO}_{4} 2 \mathrm{H}_{2} \mathrm{O}, 3.25 \mathrm{~g} \mathrm{Na} \mathrm{HPO}_{4}$, $\mathrm{pH} 7.0$ ) for at least one week. They were later dehydrated in progessive concentrations of ethanol, cleared with xylene, and embedded in paraffin. Deparaffinized $5 \mu \mathrm{m}$ thick sections of terminal ileum were stained with hematoxylin-eosine stain. The morphological changes were classified by an investigator blinded from the investigation protocol. For the convenience of presentation, the morphological changes were classified in a 0 to 5 
grading scale: (0) normal mucosa; (1) subepithelial space at villus tip; (2) necrose in topper villi; (3) comprehensive necrosis with preservation of the crypts; (4) transmucosal necrosis; (5) transmural necrosis.

\section{Statistics}

The results of the grading of mucosal injury (non-parametric data) are expressed as median and interquartile range. Significance between the groups were tested with the Mann-Whitney $\mathrm{U}$ test. $\mathrm{P}<0.05$ was considered statistically significant.

\section{Results}

The exposure to repetitive hypoxia and reperfusion was non-invasive and caused no mortality. The control groups (CG1 and CG2) showed no intestinal injury in chick embryos on days 12 and 16 . However, minor changes were observed on day 20 , in both control groups $36 \%$ of embryos had vasodilation of villus capillaries (grade 1) (Table 1 and 2). In both test groups (TG1 and TG2), repetitive hypoxia only on day 19 produced damage of the intestinal villi (Table 1 and 2). When no distinction was made between the time points of histological evaluation (five subgroups), no tissue injury (grade 0) was observed in $60 \%$ of TG1 and in $53 \%$ of TG2. Vasodilation of villus capillaries (grade 1) was observed in $10 \%$ of TG1 and $15 \%$ of TG2. Necrosis of the top of the villi (grade 2) was observed in $29 \%$ of TG1 and $30 \%$ of TG2. Severe necrosis was observed in two chick embryos: one embryo had comprehensive necrosis with preservation of crypts (2\%) (grade 3 ) and one embryo had transmucosal necrosis (2\%) (grade 4). Figure 1 and 2 show that intestinal damage was significantly different from the control groups only 2 hours post hypoxic interventions: in this first subgroup, in TG1, 67\% had necrosis of the top of the villi and $11 \%$ comprehensive necrosis with preservation of crypts (table 1) and in TG2 20\% had vasodilation of the villus capillaries and $60 \%$ necrosis of the top of the villi (table 2). 


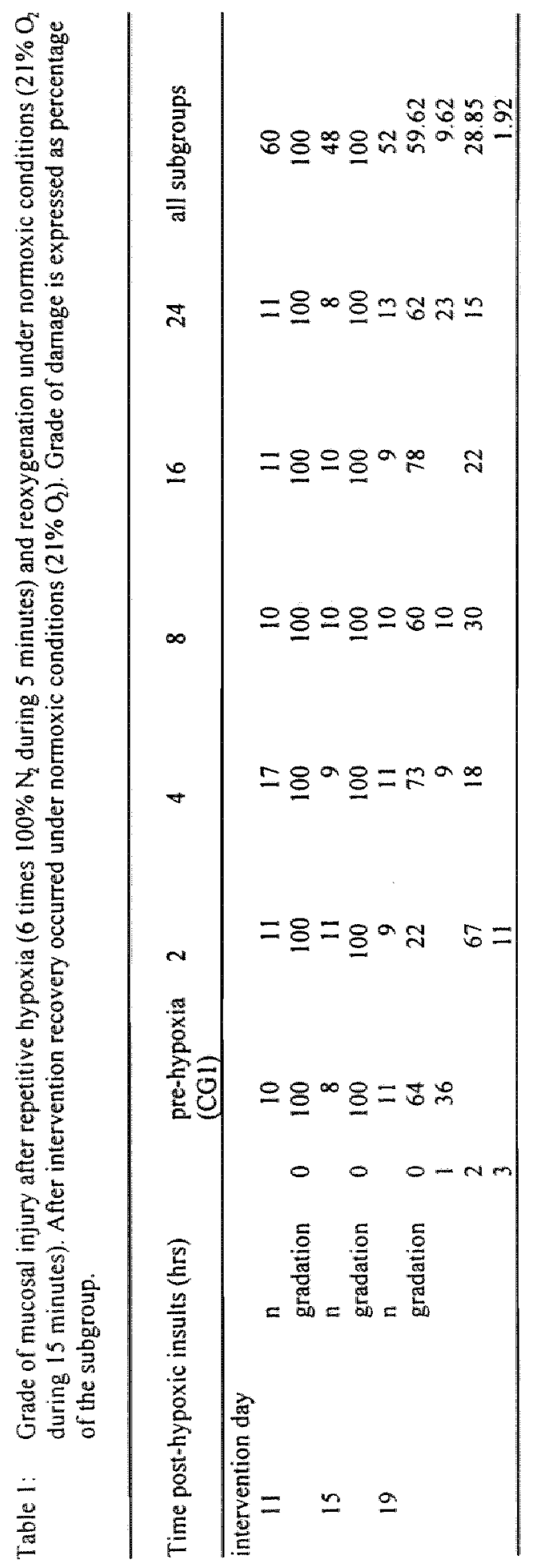




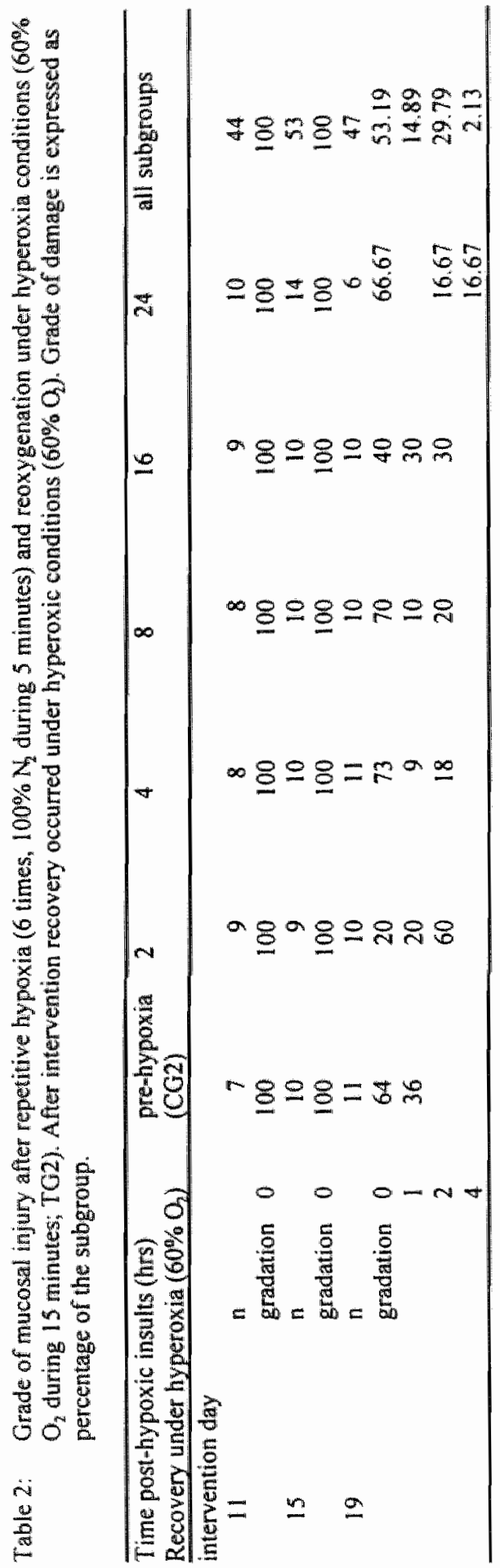




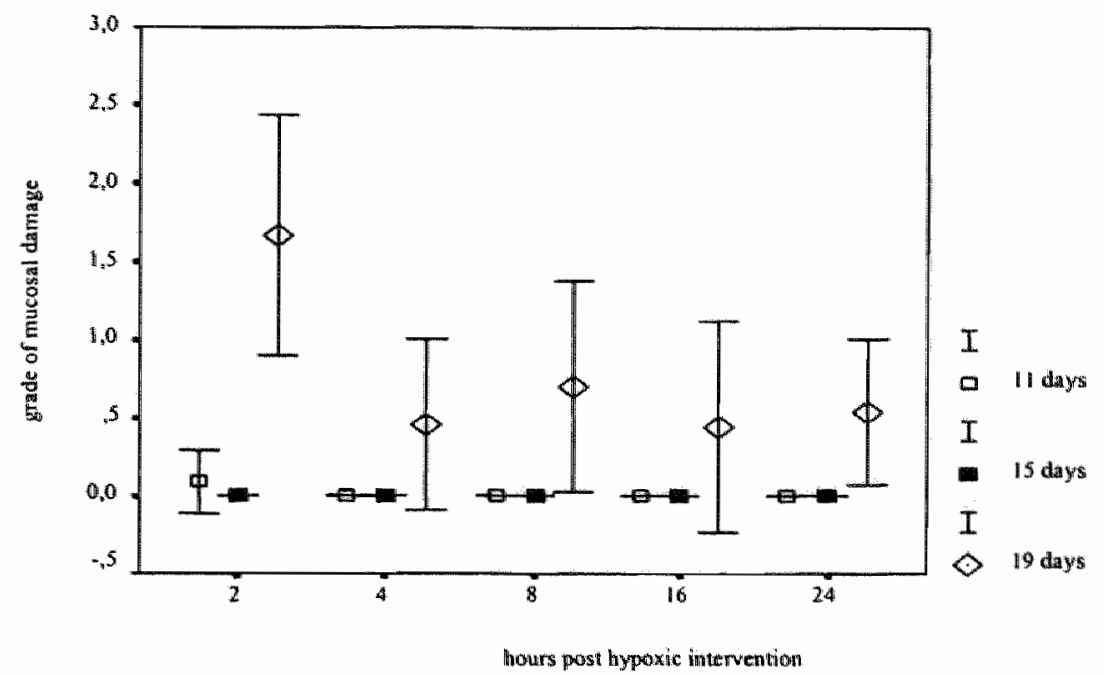

Figure 1: Grade of mucosal damage in TG1, after repetitive hypoxia and recovery under normoxic conditions in three different age groups (days 11,15 and 19) studied at 5 different time points post hypoxic interventions $(2,4,8,16$ and 24 hours). Significant different from the control group, $\mathrm{p}<0.05^{*}$.

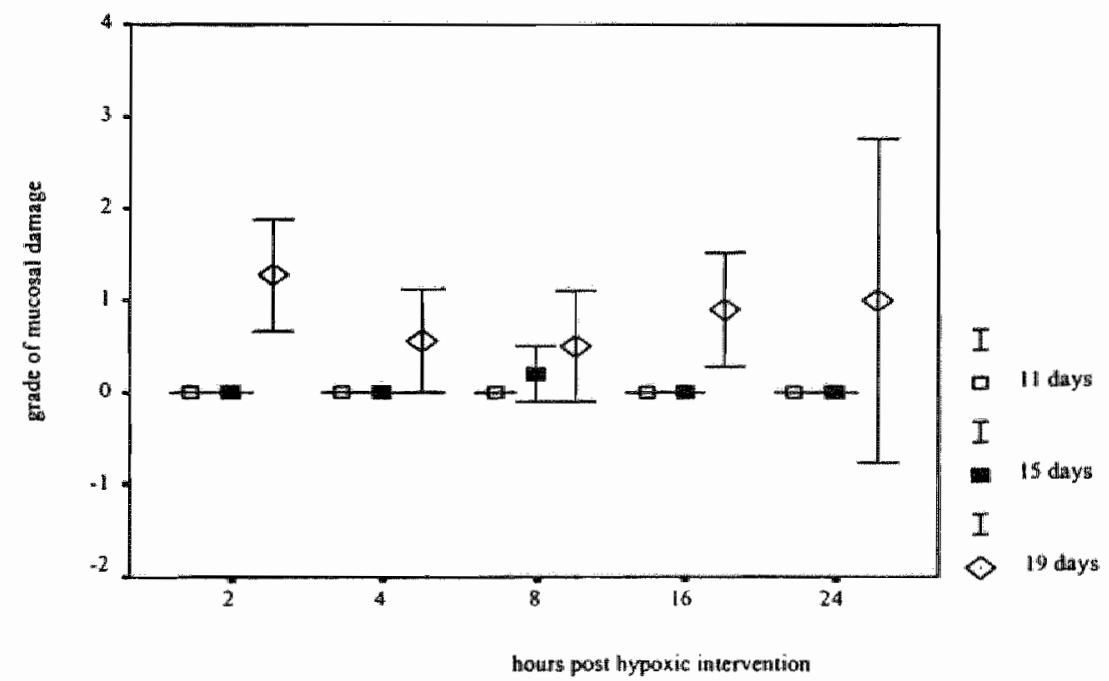

Figure 2: Grade of mucosal damage in $\mathrm{TG} 2$, after repetitive hypoxia and recovery under hyperoxic $\left(100 \% \mathrm{O}_{2}\right)$ conditions in three different age groups (days 11,15 and 19) studied at 5 different time points post hypoxic interventions $(2,4,8,16$ and 24 hours). Significant different from the control group, $\mathrm{p}<0.05$. 


\section{Discussion}

Periods of hypoxia may cause tissue damage due to tissue hypoxia or production of ROS during reperfusion. Our study describes a new model to study the effects of hypoxia and reperfusion in a non-invasive manner. The purpose of our study was (1) to examine the effect of repetitive hypoxia on the development of intestinal damage in the developing chick embryo, (2) to determine whether the induced intestinal damage was different at predetermined time points after hypoxic interventions; and (3) to determine the additional effect of reoxygenation with $100 \% \mathrm{O}_{2}$ after repetitive hypoxia. In both groups, repetitve hypoxia resulted in intestinal damage in the most mature chick embryo. Reoxygenation with $100 \% \mathrm{O}_{2}$ did not augment the intestinal damage.

\section{Intestinal damage caused by hypoxia}

The capacity for regulation of intestinal blood flow matures with advancing development. Oxygen delivery to the mitochondria of parenchyma cells is controlled by three distinctive processes: 1) convection, 2) diffusion, and 3) chemical reactions (Granger 1982). Convection is regulated by modulation of blood flow via appropriate alterations in vascular resistance. Intrinsic vasoregulation (myogenic or metabolic factors) (Granger 1983) and extrinsic vasoregulation (neural and hormonal factors) (Granger 1982, Buckley 1987) control intestinal blood flow. Sympathetic noradrenergic nerves play a major role in neural control of intestinal blood flow. $\alpha$-Adrenergic receptors stimulation decreases intestinal flow, whereas $\beta$-adrenergic and dopaminergic receptors increase flow. Furthermore, locally released vasodilators, such as adenosine or prostaglandins are also involved in flow autoregulation, functional hyperemia, reactive hyperemia and hypoxic vasodilation. Diffusion is determined by $\mathrm{PO}_{2}$ levels in capillaries and cells capillary surface areas and capillary to cell distances. Within cells oxygen acts as electron acceptor and removes reducing equivalents from the terminal oxidase of the respiratory chain (Granger 1982). Although oxygen uptake might be sustained by blood flow adaptation and increased oxygen extraction (Edelstone 1984), the immature intestinal circulation appears less capable of vasodilatation to maintain $\mathrm{O}_{2}$ uptake, suggesting that the young chick embryo might be at metabolic risk during periods of repetitive hypoxia. In contrast to what might be expected from previous described information, our results showed intestinal damage in the most mature chick embryos only. These observations might be explained by observations in a previous study, describing the redistribution of cardiac output $(\mathrm{CO})$ in response to acute hypoxia in the developing chick embryo (Mulder 1998). Hypoxia caused a redistribution of $\mathrm{CO}$ in 
favour of vital organs and this response increased during the development of chick embryos (Mulder 1998). Only chick embryos from days 17-19 showed significant decreases in fraction of $\mathrm{CO}$ distributed to the intestine in response to acute hypoxia (Mulder 1998). From these results it might be hypothesized that only late in incubation, at least in developing chick embryos, intestinal blood flow is reduced to such an extent that tissue oxygenation is severely restricted.

\section{Intestinal damage produced during the reperfusion}

Although increased production of ROS may facilitate intestinal damage (Cueva 1988; Papparella 1997; Park 1990), it is not known if resuscitation with hyperoxia $\left(100 \% \mathrm{O}_{2}\right)$ causes an increased production of ROS which could lead to an increase in intestinal damage. The premature infant has an immature antioxidant enzyme (AOE) status (Frank 1985), and when exposed to ROS the risk for the development of tissue damage could increase. It has been hypothesized that ROS are derived from xanthine oxidase, leukocytes and the prostanoid metabolism (Nowicki 1994). ROS promote the formation of compounds that attract and activate leukocytes. Leukocyte infiltration observed in the mucosal layer during reperfusion, causes microvascular injury (Cueva 1988; Gonzales 1994; Granger 1989). The degree of damage might be determined by the balance between production of ROS and activation of antioxidant enzymes (AOE) or scavengers in the tissue. In a previous study we have shown that reoxygenation after exposure to acute hypoxia caused a blood flow increase above baseline blood flow to the intestine from day 11 (reactive hyperemia) (Mulder 1998). Since we did not observe any intestinal damage in the younger chick embryos, it might be hypothesized that ROS are produced at a low level, because of a limited capacity to produce ROS via the xanthine oxidase in the premature (Crissinger 1989). When chick embryos were reoxygenated with pure oxygen, augmented damaging effects in the intestine were not observed. This is in contrast to the expectation that very high oxygen tension in blood and tissues during resuscitation with $100 \% \mathrm{O}_{2}$ would cause an increased production in ROS, responsible for an increased intestinal damage. Addition of oxygen may cause two important (opposing) mechanism, 1) accelerate the re-establishment of normal oxidative metabolism and cardiovascular function, and 2) increase production of ROS. In a previous study we have shown that exposure to hyperoxia can produce a temporary induction of the AOE system (van Golde 1998). It might be speculated that this AOE increase in the intestine is sufficient to circumvent cell damage at the incubation times studied. Further studies are needed to investigate the balance between ROS production and $A O E$ activity. 


\section{Microscopic evaluation}

Two types of intestinal damage were observed in our study. The first type was characterized by vasodilation, hyperemia, oedema or bleeding in the top of the villi causing a subepithelial space at the villus top, which can be defined as a preface of the development of necrosis of the top of the villi (the second grade of damage). The degree of intestinal damage was similar in chick embryos recovered with air or $100 \% \mathrm{O}_{2}$, indicating that villus injury occurs during a period of low intestinal blood flow. The morphological changes in the topper villi were comparable to those observed after exposure to mild prolonged and severe acute hypoxia in developing chick embryos (Tibboel 1980) and other animal models such as the adult dog, cat and the newborn pig (Chiu 1970; Papparella 1997; Park 1990; Weixiong 1994). Differences in levels of damage in the various layers of the bowel wall might be explained by fractional changes in blood flow to different layers (Crissinger 1988). In a newborn pig model the blood flow to the mucosal layer remained underperfused after ischemia, whereas the muscularis layer showed a complete recovery to baseline during reperfusion (Papparella 1997). Those regions with sustained blood flow showed resistance to histological damage (Papparella 1997). After a period of hypoxia and recovery, repair processes are activated, which may result in healing of damaged tissues (Kliegman 1993). This process might explain why the significant damage was observed only 2 hours post-hypoxic interventions.

\section{Chick embryo as a model for intestinal damage}

Histological and functional development of the ileum in developing chick embryos is very similar to the human fetus during the last trimester (Romanoff 1960). In chick embryos, villi and micro villi develop at $50 \%$ of the total incubation period and the amount of (micro)villi increases towards the end of incubation. The muscularis mucosa is differentiated from day 14. The pathogenesis of NEC is multifactorial, however in this model it was possible to isolate a single variable. Since gas exchange occurs by diffusion through micropores in the egg shell to the vascular bed in the chorioallatic membrane (CAM) (equivalent of the placenta), changes in embryonic blood gas could be achieved in a non-invasive and reproducible way. Separated from the CAM, transport of nutrients from the yolksac to embryo occurs via the vitelline circulation (Metcalfe 1993). 


\section{Conclusions}

The average extent of intestinal damage is similar after reoxygenation with pure oxygen compared to air. Late in the incubation time the villus region was most sensitive to hypoxia/reperfusion insults, probably due to low oxygen supply in these regions. In the younger chick embryos other factors than circulatory instability might play an important role in the development of intestinal damage. Further studies are being performed to gather more information of blood flow changes and inflammatory response during hypoxia/reperfusion insults. 


\section{References}

Beeby PJ, Jeffery H (1992) Risk factors for necrotizing enterocolitis: the influence of gestational age. Arch Dis Child 67, 432-435.

Bissonnette JM, Metcalfe $J(1978)$ Gas exchange of the fertile hen's: components of resistance. Respir Physiol 41, 727-733.

Buckley NM, Brazeau P, Frasier ID, Gootman PM (1987) Circulatory effects of splanchmic nerve stimulation in developing swine. Am J Physiol 252, H118-124.

Chiu C, McArdle AH, Brown R, Scott HJ, Gurd FN (1970) Intestinal mucosal lesions in llow-flow states. Arch Surg 101, 478-483.

Cohn HE, Sacks EJ, Heymann MA, Rudolph AM (1974) Cardiovascular responses to hypoxemia and acidemia in fetal lambs. Am J Obstet Gynecol $120,817-824$.

Crissinger K.D., Grisham J., Granger D. (1989) Developmental biology of oxidant producing enzymes and antioxidants in the piglet intestine. Pediatr Res 25,612 .

Crissinger KD (1994) Regulation of hemodynamics and oxygenation in developing intestine: insight into pathogenesis of necrotizing enterocolitis. Acta Paediatr Suppl 396, 8-10.

Cueva JP, Hsueh W (1988) Role of oxygen derived free rdicals in platelet activating factor induced bowel necrosis, Gut 29, 1207-1212.

Edelstone $\mathrm{DI}_{4}$ Holzman IR (1984) Regulation of perinatal intestinal oxygenation. Seminars in Perinatology 8, 226-233.

Frank L. (1985) Effects of oxygen on the newborn. Federation Proceedings 44, 2328-2334.

Gonzalez AP, Sepulveda S, Massberg S, Baumeister R, Menger MD (1994) In vivo fluorescence microscopy for the assesment of microvascular reperfusion inhury in small bowel transplants in rats. Transplantation $58,403-408$.

Gosche JR, Harris PD, Garrison RN (1993) Age-related differences in intestinal microvascular responses to low-flow states in adult and suckling rats. Am J Physiol 264, G447-453.

Granger DN, Rutili G, McCord JM (1981) Superoxide radicals in feline intestinal ischemia. Gastroenterology 81, 22-29.

Granger HJ, Nyhof RA (1982) Dynamics of intestinal oxygenation: interactions between oxygen supply and uptake. Am J Physiol 243, G91-96.

Granger DN, Benoit JN, Suzuki M, Grisham MB (1989) Leukocyte adherence to venular endothellum during ischemia-reperfusion. Am J Physiol 257, G683-G688.

Granger DN, Perry MA, Kwietys PR (1983) Metabolic, myogenic and hormonal factors in local regulation of alimentary blood flow. In: Koo A, Lam SK, Smaje LH, (eds.) Microcirculation of the alimentary tract. Singapore: World Scientific.

Jensen $A$, Hohmann $M$, Kunzel $W$ (1987) Dynamic changes in organ blood flow and oxygen consumption during acute asphyxia in fetal sheep. J Dewel Physiol 9, 543-559

Karna $P$, Senora $A$, Chou CC (1983) Comparison of the effect of asphyxia, hypoxia and acidosis on intestimal blood flow and $\mathrm{O}_{2}$ uptake in newborn piglets. Pediatr Res, 1986, 929-932.

Kliegman RM, Fanaroff AA (1984) Necrotizing enterocolitis. New Engl J Med 310, 1093-1103.

Kliegman RM, Walker WA, Yolken RH (1993) Necrotizing enterocolitis: research agenda for a disease of unknown etiology and pathogenesis. Pediatr Res 34, 701-708.

Metcalfe 1, Stock MK (1993) Current topic: oxygen exchange in the chorioallantoic membrane, avian homolque of the mammalian placenta. Placenta 14, 605-613.

Milner AD (1991) Resuscitation of the newborn. Arch Dis Child 66, 66-69.

Mulder ALM, wan Golde JC. Prinzen FW, Blanco CE (1998) Cardiac output distribution in response to hypoxia in the chick embryo in the second half of the incubation. J Physiol 508 (part 1), $281-287$. 
Nowicki PT, Nankervis GA (1994) The role of the circulation in the pathogenesis of necrotizing enterocolitis. Clin Perinatol 21, 219-233.

Papparella $A$, DeLuca FG, Oyer CE, Pinar H, Stonestreet BS (1997) Ischemia-reperfusion injury in the intestines of newborn pigs. Pediatr Res $42,180-188$.

Park $\mathrm{PO}_{*}$ Haglund U, Bulkley GB, Falt $\mathbb{K}(1990)$ The sequence of development of intestinal tissue injury after strangulation ischemia and reperfusion. Surgery 107, 574-580.

Parks DA, Granger DN (1986) Contribution of ischemia and reperfusion to mucosal lesion formation. Am J Physiol 250, G749-G753.

Pearson JT, Haque MA, Hou P-CL, Tazawa H (1996) Developmental patterns of $\mathrm{O}_{2}$ consumption, heart rate and $\mathrm{O}_{2}$ pulse in unturned eggs. Respir Physiol 103,83-87.

Peeters LLH, Sheldon RE, Jones Jr, Makowski EL, Meschia G (1979) Blood flow to fetal organs as a function of arterial oxygen content. Am J Obstet Gynecol 135, 637-646.

Saugstad, OD (1990) Oxygen toxicity in the neonatal period. Review. Acta Paediatr Scan 79, 881-892.

Schoenberg MH, Muhl E, Sellin D, Younes M, Schildberg FW, Haglund U (1984) Posthypotensive generation of superoxide free radical possible role in the patho genesis of the intestinal mucosal damage. Acta Chir Scand 150, 301-309.

Tazawa $H$ (1980) Adverse effect ailure to turn avian egg on the embryo oxygen exchange. Resp Physiol 41,137-142.

Tibboel D, van Nie CJ, Molenaar JC (1980) The effects of temporary general hypoxia and local ischemia on the development of the intestine: an experimental study. J Pediatr Surg 15 (1), 57.63.

Touloukian RJ, Posch JN, Spencer R (1972) The pathogenesis of ischemic gatroenterocolitis of the neonate: selective gut mucosall ischemia in asphyxiated neonatal piglets. J Pediatr Surg 7, 194 205.

van Golde J, Borm PJ, Wolfs MC, Rhijnsburger EH, Blanco CE (1998) Induction of antioxidant enzyme activity by hyperoxia $\left(60 \% \mathrm{O}_{2}\right)$ in the developing chick embryo. I Physiol 509 (part 1), 289-296.

Weixiong $\mathrm{H}$, Aneman A, Nilsson U, Lundgren $\mathrm{O}$ (1994) Quantification of tissue damage in the feline small intestine during ischaemia-reperfusion: the importance of free radicals. Acta Physiol Scand $150,241-250$. 


\section{Chapter X}

\section{Summary and conclusions}

This thesis is a compilation of work directed to gather information for further understanding of the cardiovascular development and responses to changes in oxygenation before birth. This knowledge allows to comprehend the strategy of the fetus for survival during reduced oxygenation and the preparation to face the moment of birth, when it becomes an independent individual. In the majority of cases exposure to an air breathing world enriched with oxygen happens when the fetus is totally mature. However, in 5 to $8 \%$ (depending on the area of the world) of the newborn infants, the fetus is obligated to make this step very prematurely, when responses or defense mechanisms are not prepared for this challenge. The chick embryo shows many advantages as a fetal model (Chapter 1), this peculiar model was used in this thesis as an alternative for other animal models in fetal physiology. The work in this thesis was conducted with the following aims: (1) to judge the suitability of the developing chick embryo as a fetal preparation to study fetal physiology; (2) to study the cardiovascular development and responses to changes in fetal oxygenation; (3) to determine the inducibility of the AOE activity and (4) to study the effects of periods of reduced oxygenation and reperfusion under normoxic or hyperoxic condition on the gastrointestinal tract.

\section{Suitability of the model}

It is clear that the chick embryo belongs to a different species, it is not a mammalian but there are several similarities, which are described in this thesis. The study of questions related to fetal physiology in the chick embryo, reduces the number of animals used to half since there is no mother animal as it is the case in the mammalian fetus. This animal model offered the possibility to induce independent and reproducible changes in blood gases. This offered the advantage of avoiding new variables, as matemal factors, elicited by the experimental situation such as hypoxia or hyperoxia. More advantageous is that the chick embryo can be exposed to acute or chronic hypoxia without interfering with the nutrient supply to the embryo since gas exchange and nutrition are separately provided. This experimental situation is more difficult to achieve in a mammalian fetus since the placenta provides both functions. The total incubation time of the chick embryo is 21 days, this is a relative short gestation which allowed to have in 
a short period of time observation of the changes in the cardiovascular responses. The relative non-invasive techniques necessary to achieve blood gas changes such as, acute hypoxia or hyperoxia, are described in Chapter 2. Technological development such as, $0.5 \mathrm{~mm}$ transonic flow probe (0.5VB39. Transonic Systems Inc., Ithaca $\mathrm{NY}$ ) and $15 \mu \mathrm{m}$ fluorescent microspheres technique, made it possible to perform measurements of chorioallantoic artery blood flow (CABF), heart rate and cardiac output (CO) distribution. These parameters helped us to characterize the cardiovascular development and the fetal responses to changes in fetal oxygenation.

\section{Cardiovascular development and responses to blood gas changes}

Chapter 3 and 4 describes the normal development of the CABF (comparable to the umbilical blood flow in mammals), heart rate and the $\mathrm{CO}$ distribution in the developing chick embryo during the last $50 \%$ of the total incubation period. The CABF increased 10 -fold, from $0.35 \mathrm{ml} / \mathrm{min}$ on day 9 to $3.13 \mathrm{ml} / \mathrm{min}$ on day 16 . Heart rate also increased during this incubation period. This increase correlated to the rapid development of the chick embryo, a large increase in body mass and oxygen consumption. The $\mathrm{CO}$ in the chick embryo was similarly distributed to the mammalian fetus. The fraction of the CO distributed to the CAM is $52 \%$ on days $10-13$ and $41 \%$ on days $17-19$. Also the fraction of the $\mathrm{CO}$ to the yolk sac decreased, as the incubation time advanced, whereas the fraction of the $\mathrm{CO}$ to the heart, brain, liver, intestine and carcass increased. This shift of the fraction of the CO from extra-embryonic tissue to embryonic tissue (CAM or placenta) is also observed in the mammalian fetus.

Acute hypoxia, a decrease in arterial $\mathrm{Po}_{2}$ from $25-30 \mathrm{mmHg}$ to $8-10 \mathrm{mmHg}$, elicits cardiovascular adaptations which are "meant" to be protective, but can also cause damage. Acute hypoxia was chosen as intervention because it is a possible situation, which the fetus could encounter during gestation or during delivery. The chick embryo will not be exposed to labor and delivery, but it is exposed to periods of hypoxia in the last days of incubation and it is obligated to start pulmonary ventilation before external hatching. The mammalian fetus presents bradycardia, systemic hypertension and redistribution of cardiac output when exposed to acute hypoxia. However, the development of the response at increasing incubation time (gestational age) is not well characterized. In the chick embryo the initial response to hypoxia $\left(5 \min 100 \% \mathrm{~N}_{2}\right)$ showed a significant decrease in 
CABF (30\% at stage 34 and $60 \%$ at stage 42 ) and a significant decrease in heart rate (4\% on day 9 and $40 \%$ on day 16 ). This response was observed within 100 seconds (Chapter 5). The CO during the hypoxic period was redistributed in favour of the brain and the heart at expense of the intestine, liver, yolk sac and carcass (Chapter 6). This response maintains the oxygenation to the brain and the heart during a period of advanced differentiation when there is more susceptibility for tissue damage. The percentage changes in $\mathrm{CABF}$ and heart rate as well as the fraction of the $\mathrm{CO}$ to the vital organs increased with advancing incubation time. This is interpreted as "maturation of the reflex".

In future studies the contribution of neural or endocrinological or peripheral (vasomotor) mechanisms involved in the mediation of the response to hypoxia will be characterized. Although it is not possible to abolish the chemoreflex by cutting the carotid nerves in the chick embryo, adrenergic and cholinergic receptors can be blocked pharmacologically. Furthermore, it is possible to measure the plasma levels of different vasoactive mediators released during different fetal oxygenation levels. The strength of the response is not only determined by (para)sympathetic activation and the level of released vasoactive mediators, but also by the receptor density or sensitivity or ion channel density in vascular smooth muscle cells. Since the (para)-sympathetic is not completely functional before day 16 of the incubating chick embryo, other mechanisms could also be responsible for the observed bradycardia, decreased CABF and CO redistribution. As described in chapter 1, adrenergic receptors and catecholamines or other endocrine factors probably play an important role in the regulation of cardiovascular responses before optimal (para)sympathetic innervation. The adrenal medulla can be activated directly by hypoxia, causing an increased release of (nor)adrenaline and dopamine. The level of released catecholamines might explain the increase in the strength of response to hypoxia. To test if the peripheral vasoconstriction reflex is mediated by $\alpha$ adrenergic receptors, an $\alpha$-adrenergic blockade (phentolamine) can be performed. The remaining increased peripheral resistance after blockade of the $\alpha$-adrenergic receptors might be explained by the release of $\alpha$-adrenergic independent endocrine factors such as, arginine vasopressin, renin- angiotensin II, neuropeptide $Y$ and endothelin-1. This information could lead to the following questions: Is hypoxia/reperfusion more damaging early in incubation, when the protective mechanism are not mature yet? Which organs are most vulnerable at a determined developmental stage? 
The capacity for vasoconstriction is an important developmental step since it is a crucial component for the maintenance of the oxygenation of the most vulnerable organs. It is already discussed how chemoreflex and endocrine mechanisms in fetal cardiovascular responses to hypoxila can produce vasoconstriction. Hyperoxia, present after birth, produces also vasoconstriction in different organ systems. Vasoconstriction in response to hyperoxia might serve two goals (1) to limit the oxygen delivery to the tissue and (2) to protect the tissue from an increased oxidative stress due to increased release of ROS. However, it is not known how early in development this vasoconstriction response is present. Changes in the fraction of the cardiac output distributed to the different organs after exposure to $100 \% \mathrm{O}_{2}$ were studied during the last half of the incubation period (Chapter 7). Hyperoxia caused a decrease in fraction of $\mathrm{CO}$ to the brain, heart, intestine, liver and carcass, only in chick embryos of 18-19 days old. This observation indicates that local mechanisms responsible for vasoconstriction due to hyperoxia develops late, after $85 \%$ of incubation time in the developing chick embryo. It could be speculated that high arterial oxygen stimulates chemically the endothelium to release vasoconstrictive substances such as endothelin-1, angiotensin $I$, thromboxane $A_{2}$ and prostaglandin $F_{2 \alpha^{*}}$. These mediators cause increase influx of $\mathrm{Ca}^{2+}$ and contraction of the smooth muscle. Thus, the capacity of vasoconstriction depends on the capacity to produces these vasoconstrictive mediators, the ion channel density and the smooth muscle density. The produced ROS might enlarge this vasoconstriction response, by inhibiting vasodilator mediators such as prostacyclin or nitric oxide. However, the exact mediation of this response has to be explored in future studies.

\section{Oxidative stress and antioxidant enzyme system}

Not only the reduced oxygenation of the fetus might cause fetal stress and potentially pathological effects, but also the sudden exposure to a relative hyperoxic environment compared to the intra-uterine oxygenation level at the time of premature birth might cause an increase in oxidative stress. The theory maintains that under hyperoxic conditions there occurs an increased release of highly reactive $\mathrm{O}_{2}$ metabolites that include, superoxide radical, hydrogen peroxide, hydroxyl radical and singlet oxygen. These reactive $\mathrm{O}_{2}$ metabolites might overwhelm the immature AOE system and interact with and damage important components of the cell (lipids, proteins or DNA). In the developing chick embryo the AOE system matures late in incubation, superoxide dismutase (SOD) and 
glutathione peroxidase (GPX) enzyme activity increased in all selected organs (brain, heart, liver, intestine and lungs) during the last $20-30 \%$ of the normal incubation period. The catalase enzyme activity showed no significant changes during normal development. The increase in AOE activity during the final part of the incubation might be interpreted as a preparation for postnatal life (Chapter 8), The developing chick embryo is premature exposed to relative hyperoxic conditions (60\% $\mathrm{O}_{2}$ during 48 hours) at different incubational ages (days 10-11, 14-15 and 18-19). The SOD activity increased a two to ten fold after 24-48 hours of hyperoxia in all organs, except in the brain. This temporary increase was stronger in the more developed chick embryo. The GPx and catalase enzyme activity was only induced in chick embryos exposed to $60 \% \mathrm{O}_{2}$ during 48 hours on day 10. Despite the observed induced AOE activity it is not known whether these increased enzyme levels are sufficient to detoxify ROS. Furthermore, the fact that mainly SOD enzyme activity is increased leads to an increased production of hydrogen peroxide and hydroxyl radicals. It might be hypothesized that this induced imbalance in the ratio SOD to GPx and catalase results in an increased oxidative stress. In future studies the regulation of the different $A O E$ gene expression in relation to detoxification of ROS in the developing chick embryo will give information about the time in development and which organ is predisposed to develop tissue damage.

\section{Effects of hypoxia or hyperoxia on the gastrointestinal tract}

Necrotizing enterocolitis (NEC) has a multifactorial basis, a variety of factors have been identified which are important in the pathological process such as bacterial colonization, inflammatory mediator(s), feedings and circulatory instability. In our model the pathogenetic effects of hypoxia or hyperoxia on developing intestinal tract are studied (Chapter 9). Chick embryos were exposed to repetitive hypoxia (100\% $\mathbb{N}_{2}, 6$ times during 5 minutes), from day 11 untill day 20 , recovered under normoxic conditions $\left(21 \% \mathrm{O}_{2}\right)$ (test group 1 (TG1) or under hyperoxic conditions $\left(100 \% \mathrm{O}_{2}\right)$ (test group 2). Chick embryos recovered under hyperoxic conditions were previously incubated under hyperoxic conditions $\left(100 \% \mathrm{O}_{2}\right)$. Histological evaluation of the ileum was performed at different time points after the intervention ( $2,4,8,16$ and 24 hours). In both groups, chick embryos younger than 19 days did not show intestinal damage. Intestinal histology on day 19 , showed vasodilation of villus capillaries (10\% in TG1 and 15\% in TG2), necrosis in topper villi (29\% in TG1 and $30 \%$ in TG2), and necrosis with preservation of crypts and 
transmucosal necrosis ( $2 \%$ in TG1 and $2 \%$ in TG2). The fact that only late gestation embryos presented damage could be explained by a simultaneous "maturation" of vasoconstriction response to acute hypoxia in the peripheral organs with increasing incubation time as described in chapter 6. Recovery under hyperoxic conditions did not cause an increased intestinal damage. 


\section{Samenvatting en conclusies}

Dit proefschrift is samengesteld uit een aantal onderzoeken die de prenatale cardiovasculaire ontwikkeling en reacties op verandering in foetale oxygenatie bestuderen. Kennis van de foetale ontwikkeling van het cardiovasculaire systeem vergroot het inzicht in de adaptatieprocessen van de foetus voor overleving tijdens verminderde oxygenatie en bij zijn voorbereidingen op het extra-uterine leven. Meestal is de ontwikkeling van de foetus voltooid bij de geboorte, wanneer hij voor zijn gasuitwisseling afhankelijk is van de ademhaling. Echter, in 5 tot $8 \%$ van de gevallen wordt de foetus prematuur geboren en moet zich aanpassen wanneer diverse beschermende mechanismen nog niet volledig functioneel zijn. Om deze mechanismen te bestuderen biedt het kippenembryo veel voordelen. Daarom is dit model gebruikt als een altematief diermodel voor foetaal fysiologisch onderzoek. De vraagstellingen in dit proefschrift zijn: (1) beoordeling van het zich ontwikkelende kippenembryo als alternatief dier-experimenteel model in onderzoek van de foetale fysiologie; (2) bestudering van cardiovasculaire ontwikkeling en reacties op veranderingen in foetale oxygenatie (3) bestudering van de induceerbaarheid van het antioxidant enzym systeem tijdens de foetale ontwikkeling; en (4) onderzoek naar de effecten van repetitieve periodes van verminderde oxygenatie gevolgd door normoxische of hyperoxische condities op de tractus digestivus.

\section{Bruikbaarheid van het model}

Ofschoon het kippenembryo geen zoogdier is, vertoont het toch een aantal fysiologische overeenkomsten die in dit proefschrift beschreven zijn. Door het gebruik van het kippenembryo voor foetaal fysiologisch onderzoek, kan het gebruik van proefdieren met $50 \%$ gereduceerd worden. Omdat het embryo zich onafhankelijk van het moederdier ontwikkelt, zijn diverse maternale factoren uitgesloten. Het kippenembryo biedt bovendien het voordeel dat veranderingen in toevoer van nutrienten en/of het blootstellen aan acute of chronische hypoxie separaat van elkaar kunnen worden uitgevoerd. Deze experimentele condities zijn moeilijker te bewerkstelligen bij zoogdieren. Door de korte incubatietijd van het kippenembryo (21 dagen) is het mogelijk om in korte periode cardiovasculaire ontwikkeling en reacties te bestuderen. De relatieve non-invasieve technieken noodzakelijk om bloedgas veranderingen te induceren, zoals hypoxie of hyperoxie, zijn beschreven in Hoofdstuk 2. Technologische vooruitgang zoals fabricatie van $0.5 \mathrm{~mm}$ transonic flow probes en $15 \mu \mathrm{m}$ fluorescerende microsfeers maken het mogelijk chorioallantois arteriële bloedflow (CABF), hartslag en cardiac output 
(CO) distributie. Met behulp van deze parameters kunnen we de cardiovasculaire ontwikkeling en reacties op veranderingen in foetale oxygenatie bestuderen.

\section{Cardiovasculaire ontwikkeling en reacties op bloedgas veranderingen}

In hoofdstuk 3 en 4 worden de normale ontwikkeling van $\mathrm{CABF}$, hartslag en de CO distributie gedurende de laatste $50 \%$ van de incubatietijd van het zich ontwikkelende kippenembryo beschreven. De CABF neemt met een factor 10 toe van $0.35 \mathrm{ml} / \mathrm{min}$ op dag 9 tot $3.13 \mathrm{ml} / \mathrm{min}$ op dag 16 . De hartslag neemt ook toe. Deze toename correleert aan de snelle ontwikkeling van het kippenembryo, de toename in lichaamsgewicht en de zuurstof consumptie. De distributie van de CO in het kippenembryo is vergelijkbaar met die in het foetale zoogdier. Het CAM ontvangt 52\% van de CO op dag 10-13 en $41 \%$ an het einde van de incubatie periode. De fractie van de CO naar de dooierzak neemt gedurende de ontwikkeling af, terwijl de fracties naar hart, hersenen, lever, darmen en skelet toenemen. Deze herverdeling van de $\mathrm{CO}$ van het extra-embryonale weefsel (CAM of placenta) naar het embryo is vergelijkbaar met wat er gebeurt bij het foetale zoogdier.

Een acute afname van de arteriële $\mathrm{Po}_{2}$ van $25-30 \mathrm{mmHg}$ tot $8-10 \mathrm{mmHg}$, veroorzaakt cardiovasculaire aanpassingen ter bescherming tegen deze hypoxie. Voor acute hypoxie als perinataal insult werd gekozen, omdat dit de situatie nabootst die de foetus kan ondergaan tijdens de zwangerschap of de bevalling. Het kippenembryo ondergaat welliswaar niet de ontsluitings en uitdrijvings fase, maar wordt blootsgestelde aan een fysiologische hypoxie gedurende de laatste dagen van de incubatie. Daarom start het kippenembryo rondom de $19^{e}$ dag met longventilatie ('internal pipping') voordat hij uit zijn ei komt ('hatching"). De reactie op acute hypoxie bij het foetale zoogdier wordt gekenmerkt door bradycardie, systemische hypertensie en redistributie van de $\mathrm{CO}$. Echter de maturatie van deze reacties op hypoxie gedurende de ontwikkeling is nog niet bekend. Wij vonden dat initiële reactie op hypoxie $\left(5 \mathrm{~min} 100 \% \mathrm{~N}_{2}\right)$ een significante daling van de CABF toonde van $30 \%$ op dag 9 en van $60 \%$ op dag 16 en tevens een significante daling van de hartslag van $4 \%$ op dag 9 en van $40 \%$ op dag 16. Deze reactie tradt binnen 100 seconden (Hoofdstuk 5). De CO gedurende de hypoxische periode werd geredistribueerd ten voordele van de hersenen en het hart en tenkoste van darmen, lever, dooierzak en skelet (Hoofdstuk 6). Deze reactie onderhoudt de oxygenatie van de hersenen en het hart gedurende de periode van gevorderde differentiatie wanneer er sprake is van mogelijke weefsel beschadiging als gevolg van hypoxie. De procentuele veranderingen in $\mathrm{CABF}$, hartslag en fractie van de CO naar de vitale organen is groter bij langere een incubatietijd. Dit kan geïnterpreteerd worden als "rijping van de reflex". 
Toekomstige studies zullen worden gericht op het karakteriseren van neuronale, endocriene of perifeer vasomotorische mechanismen die betrokken zijn bij de mediatie van de reactie op hypoxie. Ofschoon het in het kippenembryo niet mogelijk is de chemoreflex uit te sluiten door carotis denervatie kunnen we wel gebruik maken van farmacologische adrenerge of cholinerge receptor blokkades. Ook is thet mogelijk om bij verschillende niveaus van oxygenatie de afgifte van vasoactieve mediatoren in het bloedplasma te meten. De reactie op hypoxie wordt niet alleen bepaald door (para)sympathische activatie en het niveau van circulerende vasoactieve mediatoren, maar ook door dichtheid en sensitiviteit van receptoren en/of ionenkanalen. Omdat de (para)sympathicus niet volledig functioneel is voor dag 16 zijn er in deze periode mogelijk andere mechanismen betrokken bij de reactie op hypoxie. Zoals beschreven in Hoofdstuk 1, spelen de adrenerge receptoren en catecholamines een belangrijke rol bij de regulatie van cardiovasculaire reacties op hypoxie. Hypoxie kan het bijniermerg direct aanzetten tot afgifte van (nor)adrenaline en dopamine. De sterkte van een cardiovasculaire reactie wordt bepaald door de mate van afgifte van deze catecholamines. Met behulp van de $\alpha$-adrenerge receptor agonist fentolamine kan de betrokkenheid van $\alpha$-adrenerge receptoren bij de perifere vasoconstrictie worden bestudeerd. De eventueel resterende perifere weerstand na blokkade van $\alpha$-adrenerge receptoren zou bepaald kunnen worden door $\alpha$-adrenerge onafhankelijke factoren zoals: arginine, vasopressine, renine-angiotensine II, neuropetide $Y$ en endotheline-1. Meer kennis van deze mechanismen kan de volgende vragen oproepen: Leidt hypoxie/reoxygenatie tot meer schade vroeg in de ontwikkeling, wanneer beschermende mechanismen nog niet matuur zijn? Welke organen zijn het meest kwetsbaar tijdens bepaalde stadia in de ontwikkeling?

Niet alleen tijdens hypoxische condities is het noodzakelijk de oxygenatie van de diverse weefsels te bewaken, maar ook op het moment van de geboorte wanneer de foetus blootgesteld wordt aan een relatief hyperoxische omgeving. Het pasgeboren kind vertoont vasoconstrictie in diverse orgaan systemen. Vasoconstrictie als reactie op hyperoxie heeft de volgende functies: (1) regulatie van het zuurstof aanbod en (2) bescherming van het weefsel tegen oxidatieve stress ten gevolge van toegenomen afgifte van reactieve zuurstof radicalen. Het is onbekend vanaf welk tijdstip vasoconstrictie als reactie op hyperoxie aanwezig is. In hoofdstuk 7 wordt beschreven vanaf welk tijdstip vasoconstrictie optreedt in het zich ontwikkelende kippenembryo. De CO redistributie ten gevolge van blootstelling aan $100 \% \mathrm{O}_{2}$ is bestudeerd gedurende de laatste 50\% van de incubatie tijd (dag 10-19). Een afname van de fractie van de CO naar de hersenen, hart, tractus digestivus, lever en carcass wordt alleen in kippenembryos waargenomen op dag 18 en 19 . Hieruit 
kan geconcludeerd worden dat locale mechanismen die vasoconstrictie veroorzaken pas laat in de ontwikkeling functioneel zijn (na $85 \%$ van de totale incubatie tijd). Verder onderzoek op dit gebied is noodzakelijk teneinde een beter inzicht te krijgen in de mediatoren van deze constrictoire reacties op hyperoxie. Mogelijk stimuleert een hoge arteriële zuurstofspnaning het vasculaire endotheel, waardoor er een verhoogde afgifte van vasoconstrictieve mediatoren plaatsvindt, zoals endotheline-I, angiotensine-II, thromboxane $A_{2}$ en prostaglandine $F_{2 a *}$ Deze mediatoren veroorzaken een contractie van het gladde spierweefsel door toename van de $\mathrm{Ca}^{2+}$ influx. De capaciteit van vasoconstrictie is dus afhankelijk van afgifte van mediatoren, dichtheid van ionenkanalen en hoeveelheid glad spierweefsel. Bovendien zouden de geproduceerde reactieve zuurstofradicalen de vasoconstrictieve kunnen versterken door blokkade van de vasodilatoire mediatoren, zoals prostacycline of nitriet oxide.

\section{Oxidatieve stress en het antioxidant enzym systeem}

Niet alleen periodes van gereduceerde foetale oxygenatie, maar ook plotselinge blootstelling van een prematuur geborene aan een relatief hyperoxische omgeving veroorzaakt een situatie van foetale stress en potentiële pathologische effecten. Hyperoxie leidt tot een toegenomen afgifte van reactieve zuurstof radicalen zoals, superoxide radicaal, waterstofperoxide en het hydroxylradicaal. Het immature antioxidant enzym (AOE) is mogelijk niet toereikend om deze reactieve zuurstof radicalen te detoxificeren, waardoor zij verschillende celcomponenten kunnen beschadigen (lipiden, eiwitten of nucleïnezuren). Gedurende de foetale ontwikkeling bereidt het $\mathrm{AOE}$ systeem zich voor op een eventuele blootstelling aan verhoogde oxidatieve stress. In hoofdstuk 8 is beschreven hoe het $\mathrm{AOE}$ systeem zich ontwikkelt gedurende de laatste $50 \%$ van de totale incubatietijd van het zich ontwikkelende kippenembryo. De superoxide dismutase (SOD) en glutathione peroxidase (GPx) enzym activiteit in de hersenen, hart, lever, darm en longen neemt toe gedurende de laatste $20-30 \%$ van de totale incubatietijd. Echter, de catalase enzym activiteit verandert niet tijdens de ontwikkeling. Het kippenembryo werd vervolgens blootgesteld aan $60 \% \mathrm{O}_{2}$ gedurende 48 uur op drie verschillende tijdstippen in de incubatieperiode (dag 10-11, 14-15 en 18-19). De SOD enzym activiteit nam toe met een factor 2-10 in alle organen, met uitzondering van de hersenen. De GPx en catalase enzym activiteiten waren alleen verhoogd in die embryos die op dag 10-11 aan hyperoxie was blootgesteld. In dit model hebben we weliswaar de induceerbaarheid van het AOE systeem aangetoond, maar het niet bekend of dit voldoende hoog was om alle reactieve zuurstof radicalen te detoxificeren. Het feit dat voornamelijk SOD enzyme activiteit verhoogd wordt kan leiden tot een toegenome productie van 
waterstofperoxide en hydroxylradicalen. Deze disbalans tussen SOD enerzijds en GPx en catalase enzym activiteit anderzijds kan mogelijk resulteren in verhoogde oxidatieve stress. In toekomstige studies zal de expressie van de verschillende componenten van het $\mathrm{AOE}$ systeem worden onderzocht in relatie tot detoxificatie van reactieve zuurstof radicalen in het kippenembryo. Hierdoor zal ons inzicht worden vergroot ten aanzien van de ontwikkeling van het $A O E$ systeem en de gevoeligheid van diverse organen voor oxidatieve stress.

\section{Effecten van hypoxie of hyperoxie op de tractus digestivus}

Verschillende oorzakelijke factoren worden gerelateerd aan het optreden van necrotizerende enterocolitis, zoals bacteriële colonisatie, inflammatoire mediatoren, enterale voeding en circulatoire instabiliteit. In ons model zijn kippenembryos op verschillende tijdstippen in de incubatie (dag 11, 15 of 19) blootgesteld aan repetitive hypoxie ( 6 maal $100 \% \mathrm{~N}_{2}$, gedurende 15 minuten). Recovery in test groep 1 (TG1) vond plaats onder normoxische condities en in test groep 2 (TG2) onder hyperoxische condities. De kippenembryos in TG2 zijn reeds gedurende 24 uur aan hyperoxie blootgesteld voorafgaand aan de hypoxie interventies. Op verschillende tijdstippen na de insulten $(2,4,8,16$ en 24 uur) is er histologisch onderzoek verricht van het ileum. Beschadiging van de villi is alleen in de meest mature kippenembryos geconstateerd. Deze beschadiging wordt gekarakteriseerd door vasodilatatie van capillairen in de villi (10\% in TG1 en $15 \%$ in TG2), necrose van de villustoppen (29\% in TG1 en $30 \%$ in TG2), en een uitgebreidere necrose met behoud van de crypten en transmurale necrose ( $2 \%$ in TG1 en $2 \%$ in TG2). De mate van beschadiging is in beide test groepen gelijk. Herstel onder hyperoxische condities na een periode van hypoxie leidt dus niet tot ernstigere beschadiging van de darm. De fractie van de CO die tijdens een periode van hypoxie naar de tractus digestivus gaat is lager naar mate de incubatietijd langer is. Het is mogelijk dat door een "maturatie" van deze vasconstrictoire reactie de tractus digestivus gepredisponeerd wordt voor het ontwikkelen van weefselbeschadiging. 


\section{Curriculum Vitae}

Jolanda M.C.G. van Golde werd geboren op 3 april 1967 te Maastricht. In 1987 behaalde zij het VWO diploma aan het Stedelijk College in Maastricht. In dat zelfde jaar begon zij met de studie Gezondheidswetenschappen aan de Universiteit Maastricht. Het doctoraal examen, met als afstudeerrichting Beleid \& Beheer en Biologische Gezondheidkunde, werd behaald in september 1993.

Vanaf januari 1994 was zij bij de afdeling Kindergeneeskunde aangesteld als onderzoeker in opleiding. Zij werkte onder begeleiding van Prof. dr. C.E. Blanco aan het project: "Het kippenembryo als een model in de foetale fysiologie". De resultaten van dit onderzoek zijn weergegeven in dit proefschrift.

Vanaf januari 1998 tot oktober 1998 was zij werkzaam als onderzoeker bij de afdeling Obstetrie en Gynaecologie, Academisch Ziekenhuis Maastricht. Sinds oktober 1998 is zij werkzaam bij TNO Voeding te Zeist, divisie Toxicologie. 


\section{List of Publications}

\section{Scientific Abstracts}

J. van Golde, T. Mulder, C.E. Blanco. Chorioallantoic artery blood flow and heart rate in the chick embryo from stage 34 to 43 . Pediatric Research 39: 68A, 1996

J. van Golde, T. Mulder, C.E. Blanco. Cardiovascular effects of acute hypoxia in the chick embryo from stage 34 to 43. Pediatric Research 39: 69A, 1996

J. van Golde, T. Mulder, C.E. Blanco. Cardiovascular changes in response to acute hypoxia in the chick embryo from stage 34 to 43 . Journal of Physiology, 494:30P, 1996

J. van Golde, P. Borm, M. Wolfs, E. Rhijnsburger, C.E. Blanco. Induction of antioxidant enzyme activity (AOE) by hyperoxia $\left(60 \% \mathrm{O}_{2}\right)$ in the developing chick embryo. Joumal of Physiology, 494:30P, 1996

J. van Golde, R. Beuk, M. Oude Egbrink, D. Slaaf, E. Heineman, C.E. Blanco. Intravital video microscopy of individual pial vessels of the chick embryo. Proceedings of the Fetal and Neonatal Physiology Society, 23rd annual meeting: 33, 1996

R. Beuk, E. Heineman, M. Oude Egbrink, J. Van Golde, D. Slaaf, C.E. Blanco. A new, in vivo model to investigate the pathophysiology of the compromised gut in prematures. ESPGAN Nutricia Research forum for young investigators

J. van Golde, P. Borm, M. Wolfs, E. Rhijnsburger, C. Blanco. Stimultion of embryonic and organ growth in the developing chick embryo by hyperoxia. Pediatric Research 51: 1439A, 1997

T. Mulder, J. Van Golde, F. Prinzen, H. van Straaten, C.E. Blanco. Changes in cardiac output distribution in response to hyperoxia in the developing chick embryo. Pediatric Research 51: 1087 A, 1997

J. van Golde, D. Tibboel, C.E. Blanco. Histological changes in the intestine of the developing chick embryo after exposure to repetitive hypoxia or asphyia under normoxic and hyperoxic conditions. Pediatric Research 51: 1438A, 1997 
Jolanda C. van Golde, Twan L. Mulder, Carlos E. Blanco. Parasympathetic contribution to the cardiovascular response to acute hypoxia in the chick embryo. Pediatric Research 43, 4, 56A (314), 1998

Jolanda C. van Golde, Twan L. Mulder, Carlos E. Blanco. Reoxygenation with oxygen $\left(100 \% \mathrm{O}_{2}\right)$ on the cardiac output distribution (COD) after acute hypoxia. Pediatric Research 43, 4, 56A (314), 1998.

\section{Articles}

J. van Golde, T. Mulder, H. van Straaten, C.E. Blanco. The chorioallantoic artery blood flow of the chick embryo from stage 34 to 43 . Pediatric Research 40 (6): 867-871, 1996

J. van Golde, T. Mulder, C.E. Blanco. Changes in mean chorioallantoic artery blood flow and heart rate produced by hypoxia in the developing chick embryo. Pediatric Research 42 (2): 293-298, 1997

T. Mulder, J. van Golde, F. Prinzen, H. van Straaten, C.E. Blanco. Cardiac output distribution in the chick embryo from stage 33 to 45 . Cardiovascular Research 34: 525-528, 1997

T. Mulder, J. van Golde, F. Prinzen, H. van Straaten, C.E. Blanco. Cardiac output distribution in response to hypoxia in the chick embryo in the second half of the incubation. Journal of Physiology, 508.1, 281-287, 1998

J. van Golde, P. Borm, M. Wolfs, E. Rhijnsburger, C. Blanco. Induction of antioxidant enzyme activity by hyperoxia $\left(60 \% \mathrm{O}_{2}\right)$ in the developing chick embryo. Journal of Physiology, 509.1, 289-296, 1998.

J. van Golde, P. Borm, M. Wolfs, E. Rhijnsburger, C. Blanco. Hyperoxia accelerates embryonic and organ weight when applied early and late late in the developing chick embryo. Respiration Physiology, 113, 75-82

J. van Golde, T. Mulder, F. Prinzen, H. van Straaten, C.E. Blanco. Cardiac output distribution in response to hyperoxia in the chick embryo in the second half of the incubation. Joumal of Physiology, in press

J. Van Golde, T. Okazaki, D. Tibboel, C.E. Blanco. The effect of repetitive hypoxia under normoxic or hyperoxic conditions on the extent of intestinal damage in the developing chick embryo 


\section{Dankwoord}

Dit proefschrift is tot stand gekomen dankzij de enthousiaste samenwerking en adviezen van veel mensen. Zonder deze vruchtbare samenwerking was dit ei nooit gelegd. Ik wil daarom iedereen die een bijdrage aan het "kippenteam" heeft geleverd bedanken. Een aantal mensen wil ik graag met name noemen.

Allereerst mijn promotor, Prof. dr. C.E. Blanco: Beste Carlos jij was de initiator van dit onderzoek. Je enthousiasme en kritiek tijdens de verschillende fasen van het onderzoek hebben me geleerd in een kort tijdbestek 'de kiip' als valide onderzoeksmodel uit te bouwen. Bedankt voor alles.

Dr. W Maetzdorf, beste Wiel jij was degene die vanaf het eerste uur betrokken was bij het onderzoek, al verloren we elkaar uit het oog toen het schapenmodel ingeruild werd voor het kippenmodel. In de afrondingsfase heb jij je kritisch oordeel gegeven om zo tot een mooi afgerond boek te komen, bedankt.

Al mijn collega's van de vakgroep Kindergeneeskunde wil ik bedanken voor de prettige werksfeer, steun en de interesse in het onderzoek.

De vakgroep anatomie/embryologie fungeerde voor mij als een soort thuisbasis. In jullie lab werd er ruimte gecreëerd voor onze opstelling, meegedacht over de praktische uitvoerbaarheid en meerdere onderzoeksideeën zijn er uitgebroeid. De koffie zal nooit meer zo smaken als vroeger, bedankt voor jullie hulp en gezelligheid.

Ook mijn dank aan de medewerkers van de instrumentele dienst, Jan Geilen, Leon Essers, Jeroen Hameleers voor ontwikkelen, installeren of repareren van de benodigde elektronica en computerprogrammatuur.

Zonder de perfecte levering van het bevruchte kippenei door kuikenboerderij en pluimveebedrijf "Het Anker" was dit onderzoek niet mogelijk geweest.

Het "kippenteam" groeide en de eieren consumptie steeg logaritmisch. Twan Mulder, Ferdi Le Noble, Ellen Rouwette bedankt voor de gezellige en vruchtbare werksfeer en succes met de speurtocht naar 'het gouden ei'.

In een groot deel van onze studies zochten we het in de 'fluorescerende sferen', dr. F. Prinzen had alle kennis en technieken in huis om de CO distributie in het kippenembryo te meten. Frits bedankt. Regelmatig werd voor de sfeers ook de hulp van Anita Rousseau ingeschakeld.

Voor het project onderdeel 'NEC' werd beroep gedaan op de expertise van Prof. dr. D. Tibboel, talloze kippendarmpjes werden in Rotterdam beoordeeld. Dick bedankt voor de prettige samenwerking en de verhelderende discussies. 
Een grote bijdrage aan dit project werd ook geleverd door Marion Wolfs als stage-student en Ester Scheve als student-assistent. Met jullie hulp was het mogelijk talloze experimenten te laten slagen.

PERIM maatjes en kamergenoten Brigitte, Han, Ralph, Marc, Carla, Monique, Timo, Olivier, Hugo, My Dung, Taly, Fabian en Ingrid naast de wetenschappelijk inspanningen was het op z'n tijd lekker relaxen met een borrel, ik ben benieuwd hoe bourgondisch het kan worden in Zeist.

Mijn paranimfen Brigitte Slangen en Ron van Golde, die de frustraties van een onderzoeker weten op te vangen of beter gezegd weten om te zetten in positieve energie. Energie voor een avondje sporten, swingen, een lekker etentje..... Eigenlijk zijn er in dat opzicht heel wat vrienden (paranimfen) overdonderd, want wie werd er niet verveeld met de belevenissen van de onderzoeker of 'de positieve energie'.

Tot slot mijn ouders, bedankt voor alle mogelijkheden die jullie mij geboden hebben. Bouwen begint bij een goed fundament. 